Portland State University

PDXScholar

Spring 3-28-2014

\title{
Agricultural Management Decisions Impact Isoprene Emission and Physiology of Arundo donax, an Emerging Bioenergy Crop
}

Jason Charles Maxfield

Portland State University

Follow this and additional works at: https://pdxscholar.library.pdx.edu/open_access_etds

Part of the Agronomy and Crop Sciences Commons, and the Plant Biology Commons Let us know how access to this document benefits you.

\section{Recommended Citation}

Maxfield, Jason Charles, "Agricultural Management Decisions Impact Isoprene Emission and Physiology of Arundo donax, an Emerging Bioenergy Crop" (2014). Dissertations and Theses. Paper 1642.

https://doi.org/10.15760/etd.1641

This Thesis is brought to you for free and open access. It has been accepted for inclusion in Dissertations and Theses by an authorized administrator of PDXScholar. Please contact us if we can make this document more accessible: pdxscholar@pdx.edu. 
Agricultural Management Decisions Impact Isoprene Emission and Physiology of Arundo donax, an Emerging Bioenergy Crop

by

Jason Charles Maxfield

A thesis submitted in partial fulfillment of the requirements for the degree of

Master of Science

in

Biology

Thesis Committee:

Todd N. Rosenstiel, Chair

Sarah M. Eppley

Daniel J. Ballhorn

Portland State University

2014 


\section{Abstract:}

Arundo donax (Giant Reed) is quickly being developed as a rapidlygrowing, robust, and highly productive bioenergy crop, with large scale cultivation of this species planned for the Columbia River basin of the Pacific Northwest (USA). Despite it's potential as a next generation biomass crop, relatively few studies have examined the physiological performance of $A$. donax under agricultural conditions. Unlike traditional crops, $A$. donax is known to be a high-emitter of the volatile compound isoprene, which may significantly impact regional air quality, but it has not been widely cultivated in North America and little is known about how this species will perform in the Pacific Northwest.

Over two field seasons, we measured isoprene fluxes from A. donax plants in both greenhouse conditions and in an agricultural field setting under a variety of conditions and fertilizer treatments. We also measured several other attributes of $A$. donax productivity and leaf physiology including chlorophyll content, photosynthesis rate, stomatal conductance, specific leaf mass, water use efficiency and gas exchange. We found that $A$. donax physiologically performs well under cultivation in the Columbia River basin, but that it also emits isoprene at significantly higher rates than previous reports indicate. We 
also found that both isoprene emission and leaf physiology were highly affected by agricultural management decisions, including nitrogen and irrigation management. Our findings indicate that crop management strategies can be developed that simultaneously seek to minimize isoprene emission while maximizing biomass production in this newly emerging bioenergy crop. 


\section{Acknowledgements:}

This research would not exist without the enthusiastic support, encouragement and assistance of many people. First and foremost, I would like to thank Dr. Todd Rosenstiel for teaching me to be a scientist. I have learned so much from my work with Dr. Rosenstiel and I am extremely grateful for the education and opportunities he has given me.

I would not have completed this thesis without the friendship and guidance of Andrea Melnychenko. She brought me into the Eppley/Rosenstiel lab as a volunteer and she mentored me in many of the techniques used to collect this data. Thank you so much Andrea.

Several key volunteers assisted with the collection of the data presented here. First among them is Scott Kiel who spent many days with me in a hot field in Hermiston running back and forth with syringes full of isoprene. I literally could not have done this research without him. Megan Foley also contributed immensely to the 2013 HAREC field campaign. Thanks Scott and Megan. I would also like to thank other past and present students from the Eppley/Rosenstiel lab group: Erin Shortlidge, Mehment Balkan, Hannah Prather, Matthew Chmielewski, Mandy Slate, Laura Holloway, Sally Rogers, Megan Dillon, Charlene Mercer and Dawn Matarese. You guys inspire and distract me with your love of plants, fungus, lichens and beer. 
I also wish to acknowledge the members of my committee, Dr. Sarah Eppley and Dr. Daniel Ballhorn, for their time and assistance in developing the ideas presented in this thesis. Thank you also to the Portland State University Biology Department and the faculty of the University.

This research would not have occurred without the generous cooperation of Dr. DonHorneck and Nick Bechtoldt of Oregon State University, Hermiston Agricultural Research Extension Campus. Dr. David Olszyk also assisted this research by providing access to chamber facilities at the Environmental Protection Agency's Terrestrial Ecology Research Facility in Corvallis, OR. This work was financially supported by the Portland State University Department of Biology and by Portland General Electric. Thank you to Dr. Wayne Lei, of PGE for recognizing the value of this research.

This thesis is dedicated to my family: my wife Julie and our daughter Scarlet. You guys are my motivation and my refuge. Thank you for your patience, love and encouragement. You both put up with my exhaustion, irritability and lack of housework as I completed this thesis. Thank you. 
Table of Contents:

i Abstract

iii Acknowledgements

vii List of Figures

1 Chapter 1: Introduction

$1 \quad$ Background

$4 \quad$ VOCs and chemical ecology

5 Environmental impacts of VOCs

10 Isoprene

15 Arundo donax

17 Goals of this thesis

19 Chapter 2: Materials and Methods

19 Hermiston field campaign, 2012

23 Hermiston field campaign, 2013

24 Gas exchange measurements

24 Differences between 2012 and 2013 Hermiston field campaigns

27 EPA Chamber Experiments, 2013

29 Isoprene emission across canopy height survey

30 Isoprene emission response to light level survey

31 Statistical analysis of data

\section{$33 \quad$ Chapter 3: Results}

33 3.A: Effect of fertilizer, water management and temperature on leaf chlorophyll content in $A$. donax

39 3.B: Effect of fertilizer and water management on leaf photosynthesis in $A$. donax

45 3.C: Effect of fertilizer, water management and temperature on leaf stomatal conductance in $A$. donax 
53 3.D: Effect of fertilizer, water management and temperature on leaf water use efficiency in $A$. donax

59 3.E: Effect of fertilizer, water management and temperature on specific leaf mass in in $A$. donax

64 3.F: Effect of fertilizer, water management, temperature, canopy height and light level on isoprene emission in $A$. donax

75 3.G: Effect of nitrogen amendment and temperature on gas exchange in $A$. donax

\section{Chapter 4: Discussion}

78 4.A: Biofuels, air quality and Arundo donax

81 4.B: Arundo donax physiology

90 4.C: Isoprene emission in Arundo donax

100 4.D: Gas exchange measurements

101 4.E: Conclusions and future directions

\section{References}

\section{Appendix-Supplemental data}

113 Table 1. Fertilizers added to each individual plant by treatment group

113 Table 2. Ibs acre ${ }^{-1}$ fertilizer usage for each treatment

114 Table 3. Mean values and standard deviations for physiological attributes of Arundo donax 


\section{List of Figures:}

$1 \quad$ Figure 1. Land use change scenario from Wise, et al., 2009

6 Figure 2. Catalytic cycle between $\mathrm{O}_{x}, \mathrm{NO}_{x}$ and VOCs from Porter, 2009

7 Figure 3. Relationship between $\mathrm{NO}_{\mathrm{x}}, \mathrm{VOC}_{\mathrm{s}}$ and $\mathrm{O}_{3}$ from Sillman and $\mathrm{He}, 2002$

25 Figure 4. Air temperature at HAREC before and during data collection

26-27 Figures 5A, 5B and 5C. Soil water content at 4", 8" and 12" depths before and during data collection

34 Figure 6. Leaf chlorophyll content in Arundo donax by nitrogen treatment and year

35 Figure 7. Leaf chlorophyll content in Arundo donax by addition of elemental fertilizers

36 Figure 8. Effect of nitrogen amendment on leaf chlorophyll content in Arundo donax by year

37 Figure 9. Leaf chlorophyll content in Arundo donax by year

38 Figure 10. Effect of long term temperature acclimation on leaf chlorophyll content in Arundo donax

39 Figure 11. Leaf photosynthesis rate of Arundo donax by nitrogen treatment and year

40 Figure 12. Leaf photosynthesis rate of Arundo donax by addition of elemental fertilizers

41 Figure 13. Effect of nitrogen amendment on leaf photosynthesis in Arundo donax by year

$43 \quad$ Figure 14. Leaf photosynthesis rate of Arundo donax by year

44 Figure 15. Effect of long term temperature acclimation on leaf photosynthesis rate in Arundo donax

45 Figure 16. Leaf stomatal conductance of Arundo donax by nitrogen treatment and year

47 Figure 17. Leaf stomatal conductance of Arundo donax by nitrogen treatment, 2012 only 
48 Figure 18. Leaf stomatal conductance rate of Arundo donax by addition of elemental fertilizers

49 Figures 19A and 19B. Effect of nitrogen amendment on leaf stomatal conductance in Arundo donax by individual years

51 Figure 20. Leaf stomatal conductance rate of Arundo donax by year

52 Figure 21. Effect of long term temperature acclimation on leaf stomatal conductance rate in Arundo donax

$54 \quad$ Figure 22. Leaf water use efficiency of Arundo donax by nitrogen treatment and year

55 Figure 23. Leaf water use efficiency of Arundo donax by addition of elemental fertilizers

56 Figures 24A and 24B. Effect of nitrogen amendment on leaf water use efficiency in Arundo donax by individual years

57 Figure 25. Leaf water use efficiency of Arundo donax by year

$58 \quad$ Figure 26. Effect of long term temperature acclimation on leaf water use efficiency in Arundo donax

60 Figure 27. Specific leaf mass of Arundo donax by nitrogen treatment and year

61 Figure 28. Specific leaf mass of Arundo donax by addition of elemental fertilizers

62 Figure 29. Effect of nitrogen amendment on specific leaf mass in Arundo donax by year

63 Figure 30. Specific leaf mass of Arundo donax by year

62 Figure 31. Isoprene emission rate of Arundo donax by nitrogen treatment and year

66 Figure 32. Isoprene emission rate of Arundo donax by nitrogen treatment, 2012 only

67 Figure 33. Isoprene emission rate of Arundo donax by addition of elemental fertilizers

68 Figures 34A and 34B. Effect of nitrogen amendment on isoprene emission rate in Arundo donax by individual years 
69 Figure 35. Isoprene emission rate of Arundo donax by year

70 Figure 36. Effect of long term temperature acclimation on isoprene emission rate in Arundo donax

71 Figure 37. Isoprene emission by leaf height in Arundo donax, control treatment

72 Figure 38. Isoprene emission by leaf height in Arundo donax, high $\mathrm{N}$ treatment

73 Figure 39. Isoprene emission by leaf height in Arundo donax, combined treatments

74 Figure 40. Isoprene emission response to photosynthetically active radiation levels in Arundo donax

75 Figure 41. Effect of fertilizer amendment on gas exchange in Arundo donax

76 Figure 42. Effect of fertilizer amendment on gas exchange in Arundo donax, narrow range

77 Figure 43. Comparison of gas exchange rates in greenhouse grown Arundo donax and Miscanthus x giganteus 


\section{Chapter 1: Introduction}

Background: For the last ten millennia the spread of human agriculture has reshaped the surface of our planet. Today approximately $40 \%$ of all land on Earth is used for the production of food (FAOSTAT). Now, driven by sustainability concerns and rapid advances in biotechnology, we are at the beginning of a much faster and equally profound change: the conversion of both agricultural and wild lands to energy production. Successfully replacing or augmenting a petroleum-based global economy with renewable, plant-based energy will result in significant land use change (LUC) with some peer-reviewed studies suggesting that as much as $50 \%$ of all land on earth could be used for biofuel production by the end of the $21^{\text {st }}$ century (Wise, et al., 2009).

Figure 1. Land use change scenario from Wise, et al., 2009. Possible "worst case scenario" land use change from biofuel production (Copyright: Wise, et al., AAAS 2009)

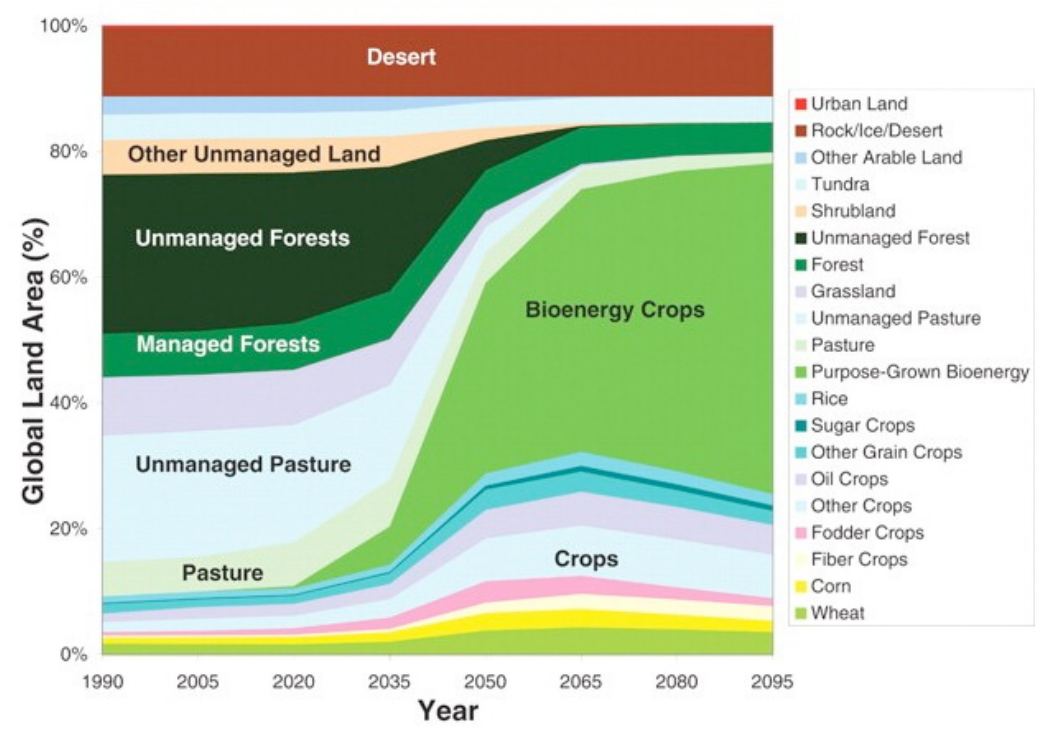


Recent bioenergy research has focused on improving a few crops such as Miscanthus, poplars, Arundo donax, sugar cane and corn, as well as developing models to predict how various bioenergy sources will impact or mitigate global climate change (Searchinger, 2008). These models have increased in complexity as they attempt to account for the footprints of bioenergy 'from seed to wheel' in order to answer the question-what is the true cost of bioenergy production?

Sophisticated models now account for the water, fertilizers and pesticides used on biofuel crops, the fuels used for planting, harvesting, transportation and refining, and LUC impacts, such as adjustments in the amount of carbon the land sequesters. Additionally, recent models have begun to include impacts from indirect land use change (ILUC), such as deforestation that may occur thousands of miles away from biofuel production in response to the market effects of replacing food crops with energy crops (Searchinger, et al., 2008).

Despite the complexity of these models a large blind spot remains in most analyses of the impacts of bioenergy development; little attempt is made to include the biogenic volatile organic compounds (VOCs) released by energy crops as they grow. It is widely understood that plants fix carbon from the air and convert the reduced carbon into myriad metabolites, including volatile gasses such as methane, isoprene and other terpenoids, which are released into the atmosphere. However, because the carbon is removed from the atmosphere and then returned to it, most 
impact analyses consider the process neutral because there is no net change in carbon concentration in the atmosphere.

This line of thinking, however, is dangerously shortsighted. The carbon that plants remove from the atmosphere is in the form of $\mathrm{CO}_{2}$, a relatively inert compound with comparatively mild greenhouse effects. The carbon emitted by plants, in forms such as methane, isoprene, and terpenoids, is often more chemically reactive than $\mathrm{CO}_{2}$ and may have a greater impact on atmospheric temperature both through greenhouse effects and the formation of aerosols, which alter atmospheric albedo (Kulama, et al., 2004).

Compared to traditional food crops and wild plant communities, many plants proposed for bioenergy use emit much more and significantly different types of biogenic volatile organic compounds (Hewitt, et al., 1997; Sharkey, et al., 2008). Consequently, widespread biofuel production will change the composition and intensity of atmospheric VOCs. This will impact atmospheric chemistry, biogeochemical cycles and, potentially, human health (Ashworth et al., 2011). Responsible adoption of bioenergy will, therefore, require a concerted effort to measure and model the impacts of VOCs in order to predict the actual effects of shifting global energy production to plant-based fuels and avoid unintended problems from this transition. 
VOCs and chemical ecology: As a function of normal metabolism, plants, like nearly all organisms, emit volatile chemicals such as methane, carbon dioxide and water vapor. Many of these compounds are considered to be byproducts of normal metabolic activity and serve no immediate function, other than being end products of necessary biochemistry. On the other hand, the production of some volatile compounds is enzymatically controlled and clearly provides adaptive benefits to the organism.

A huge diversity of VOCs are emitted by plants, with individual species often producing hundreds of unique compounds. These compounds may serve a wide variety of adaptive purposes, both to the individual plant releasing them and to the wider ecological community. The emission of some VOCs may protect the source plant by preventing damage to cellular membranes (Siwko, et al., 2007; Velikova et al., 2011; Velikova et al. 2012) and protect leaf tissue from the oxidative stresses associated with photosynthesis (Loreto and Velikova, 2001; Velikova, et al., 2004, Penuelas, et al., 2005; Velikova et al., 2014). Other VOCs play roles in chemical ecology by regulating interactions with soil microbe communities (Badri, et al., 2009), deterring insect herbivores or attracting herbivore predators (Loivamäki, et al., 2008; Laothawornkitkul, et al., 2008), or by acting as pheromone signals to neighboring plants, both conspecific and interspecific (Baldwin, et al., 2002).

The full suite of VOCs emitted by plants is not completely characterized. Due to analytic limitations, past research has necessarily focused on a few major VOCs such 
as terpenoids and isoprene. These investigative restrictions, however, are disappearing rapidly. Analytic advances such as proton transfer reaction mass spectrometry (PTRMS) and multi-dimensional GC-MS now make it possible to simultaneously observe hundreds of volatile compounds rather than just a few (Pankow, et al., 2012) A complete, accurate and quantitative picture of the VOCs released by plants is still a ways off, but recent advances in analytic capacity have greatly increased the resolution.

Environmental impacts of VOCs: At normal atmospheric redox potentials, isoprene and other VOCs act as reducing agents due to their chemical bond structures. In the atmosphere, a catalytic cycle driven by photochemistry exchanges oxygen atoms between $\mathrm{O}_{2}, \mathrm{O}_{3}, \mathrm{NO}$ and $\mathrm{NO}_{2}$ (collectively $\mathrm{O}_{\mathrm{x}}$ and $\mathrm{NO}_{\mathrm{x}}$ ). Under steady state conditions this catalytic cycle exists in equilibrium with a certain amount of ozone being both created and destroyed continuously. The addition of VOCs, however, can disrupt this equilibrium by competing with ozone for NO, resulting in a new equilibrium state with a higher abundance of ozone in the lower atmosphere, or troposhere. The consequences of tropospheric ozone are significant: it is toxic to humans (Papiez, et al., 2009), and it also damages plants, including many important agricultural crops. 
Figure 2. Catalytic cycle between $\mathrm{O}_{\mathrm{x}}, \mathrm{NO}_{\mathrm{x}}$ and VOCs from Porter, 2009

VOCs perturb the normal catalytic cycle between NOx and ozone by competing with ozone for NO, resulting in increased ozone levels. (Porter, 2013)

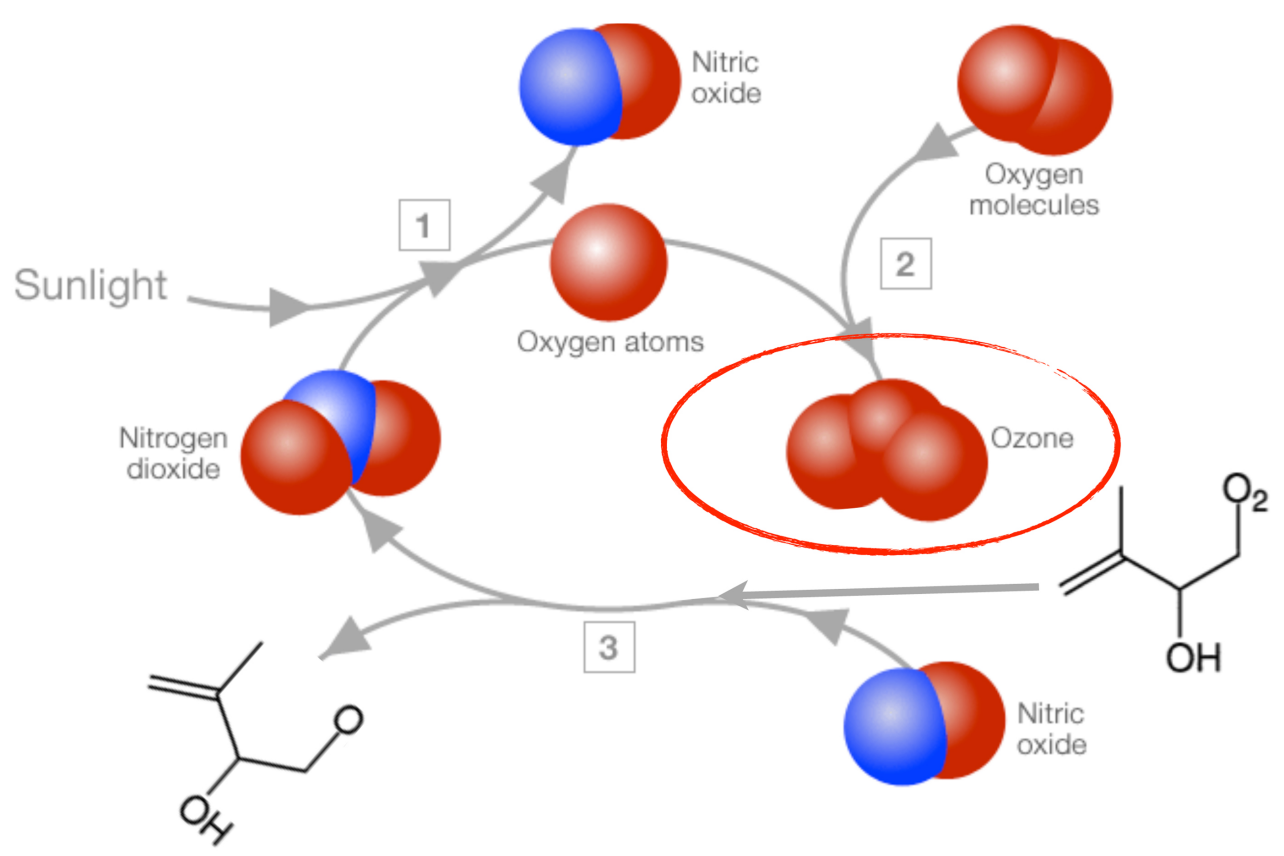

The chemistry that connects VOC emissions and tropospheric ozone production, however, is extremely complex and highly dependent on the background levels of oxides of Nitrogen and Sulfur $\left(\mathrm{NO}_{\mathrm{x}}\right.$ and $\mathrm{SO}_{\mathrm{x}}$ ) (Sharkey, et al., 2008; Papiez, et al., 2009). In certain conditions a modest increase in local isoprene emission could significantly increase ozone levels, while in other locations the same addition of isoprene could have very little effect or even reduce ozone levels (Porter, et al., 2012). 
Figure 3. Relationship between $\mathrm{NO}_{\mathrm{x}}, \mathrm{VOC}_{\mathrm{s}}$ and $\mathrm{O}_{3}$ from Sillman and $\mathrm{He}, 2002$ Isopleth figure demonstrating relationship between $\mathrm{VOC}$ levels, $\mathrm{NO}_{\mathrm{x}}$ emission rates and ozone formation. Locations with background $\mathrm{NO}_{\mathrm{x}}$ and $\mathrm{VOC}$ levels that fall above the blue dashed line are considered VOC sensitive and a modest increase in VOCS could significantly increase $\mathrm{O}_{3}$ levels. Areas below the blue line are considered $\mathrm{NO}_{\mathrm{x}}$ sensitive.

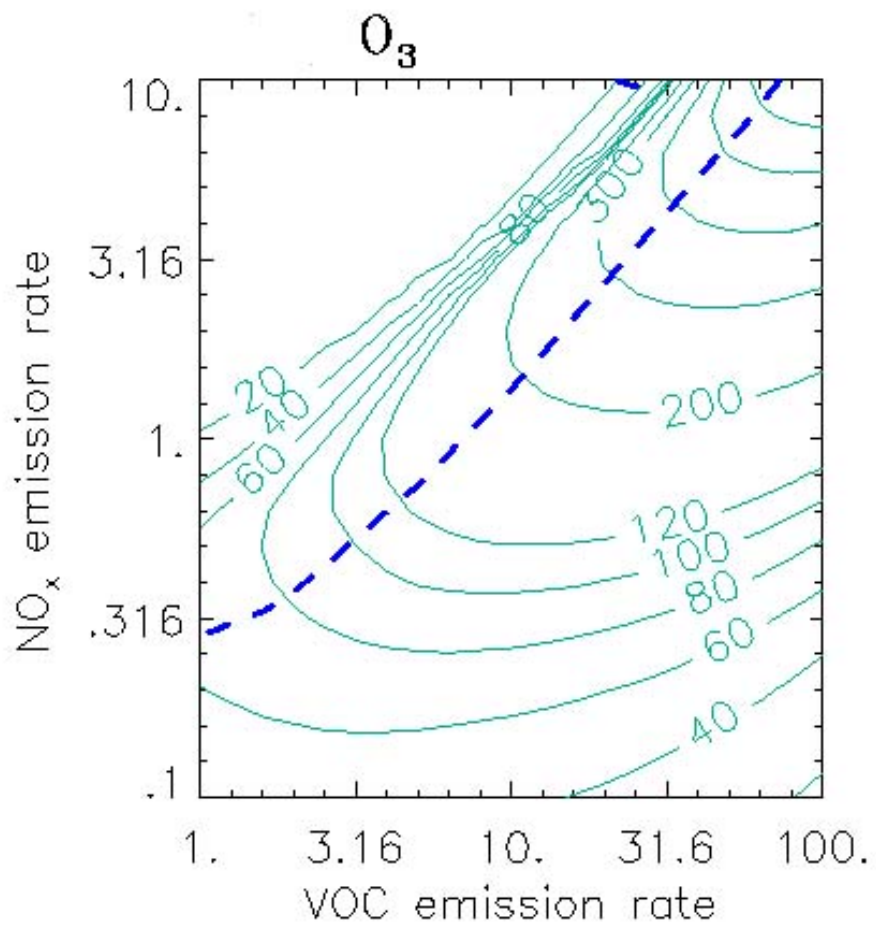


Recent research demonstrates that biogenic VOC induced ozone formation can be a major contributor to air pollution in urban areas (Hickman, et al., 2010). Additionally, many common and economically important agricultural crops are sensitive to ozone induced oxidative damage (Mauzerall and Wang, 2001), thus growing high isoprene-emitting bioenergy crops near other agriculture may negatively impact other agriculture (Hewitt, et al., 2009). This is an important concern because growing significant amounts of biofuels will require the active participation of many farmers, who would be particularly impacted by crop damage and also because any damage to global food production will reduce the potential benefits of biofuels.

Many crop species proposed for bioenergy production, although not Arundo donax, also produce significant amounts of larger terpenoids (Hewett, et al., 1997), including monoterpenes and sesquiterpenes. Some familiar terpenoids include menthol, (an oxegenated monoterpene used as the foundation of Vicks VapoRub aroma), pinene (the dominant compound in the scent of pine trees) and limonene (commonly used in citrus scented cleaning and cosmetic products). Like isoprene, terpenoids can react with atmospheric oxidants and, depending on atmospheric concentrations of $\mathrm{NO}_{\mathrm{x}}$ and $\mathrm{SO}_{\mathrm{x}}$, also may increase or decrease surface ozone concentration (Sharkey, et al., 2008).

In addition to affecting ozone levels, biogenic VOCs, particularly sesquiterpenes, can affect global temperature by spurring the formation of aerosol particles (Kulama, 
et al., 2004). These fine particles (classified by the Environmental Protection Agency as particulate matter smaller than 2.5 microns) impact atmospheric temperature by scattering incoming solar radiation, thereby reducing the amount of radiation reaching the Earth's surface. Organic aerosols also contribute to regional haze and a host of human respiratory problems. The amount of organic aerosol in the atmosphere is currently not well understood, but it is suspected that the oxidation of biogenic VOCs is a fundamental, yet substantially underestimated component of organic aerosol fraction (Kulama, et al., 2004). Identifying the sources, fates, and effects of these aerosol particles is a major challenge for the field of atmospheric chemistry, and another significant unknown for modeling the impact of biofuels. Because biofuels are often proposed as a replacement for fossil fuels in order to mitigate global warming, it is critical that accurate accounting of their effects on atmospheric temperature precedes their widespread adoption.

Predicting the effects of biogenic VOCs on atmospheric chemistry depends on accurately characterizing the chemical composition of the atmosphere in the regions where these crops are grown. Doing so may allow the selection of crops that will not contribute deleterious VOCs to the local environment (Porter, et al., 2012). Additionally, regions that plant biofuel crops could seek to avoid increasing surface ozone by managing sources of anthropogenic $\mathrm{NO}_{\mathrm{x}}$ and $\mathrm{SO}_{\mathrm{x}}$. 
Isoprene: Isoprene, (2-methyl-1,3-butadiene, $\left.\mathrm{C}_{5} \mathrm{H}_{8}\right)$, is both the simplest terpenoid and the most abundant volatile compound produced by plants. Annual global emission from vegetation is estimated to be approximately than $500-700 \mathrm{Tg}$ (Guenther, et al., 2006; Ashworth, et al., 2010). The emission of isoprene represents a loss of fixed carbon and thus imposes an important, and potentially significant, metabolic cost to plants (Behnke et al., 2012; Ryan et al., 2014). While all living organisms make some amount of isoprene as a non-enzymatically produced byproduct of normal metabolic activity, in high isoprene emitting plants, its emission is controlled through light-dependent regulation of the isoprene synthase enzyme (IspS), which uses dimethylalyl diphospate (DMADP) as a substrate for isoprene biosynthesis (Wagner et al., 1999).

Many abiotic factors have been found to impact isoprene emission. High light (PAR) and temperature levels are positively correlated with leaf isoprene emission, and while plants that emit isoprene generally do so throughout the growing season, high temperature events or light flecks can lead to large temporary increases in overall isoprene flux (Sharkey et al., 2008). Isoprene emission has also been found to negatively correlate with atmospheric $\mathrm{CO}_{2}$ levels (Rosenstiel, et al., 2003) possibly because of competition with other metabolic pathways for DMADP substrate (Rosenstiel, et al., 2004). However recent reports suggest that this effect may not consistently hold for all isoprene emitting plant species (Sun et al., 2012; Sun et al., 2013). Isoprene emission also seems to play a role in chemical ecology by mitigating 
the interactions between plants and other organisms. Poplars that were genetically modified to reduce isoprene emission showed a decrease in presence of fungal infections, but were more attractive to herbivores (Behnke, et al., 2012)

Despite decades of work on this topic, the physiological roles of isoprene emission are still a matter of some debate. Theories that have received experimental support suggest that isoprene emission may have evolved to help plants withstand high temperature events; experiments conducted on genetically modified poplars with reduced isoprene emission demonstrate that, in this species, reducing isoprene emission leads to greater leaf damage from high temperature events (Behnke, et al., 2007; Behnke et al., 2013). The inverse has also been demonstrated in Arabadopsis plants, which do not typically emit significant amounts of isoprene. When Arabidopsis plants were modified to express an active isoprene synthase enzyme and thus emit isoprene, a reduction in reactive nitrogen and oxygen species was observed in plants exposed to heat stress, indicating that the addition of isoprene emission capacity provided some degree of thermal protection (Velikova et al., 2012). However, similar experiments conducted on transgenic tobacco plants (also natural non-isoprene emitters that were modified to emit isoprene) showed very little effect on thermotolerance. However, these plants were much more resistant to ozone induced damage (Vikers, et al., 2009) suggesting that the physiological role of isoprene emission may be more related to its putative function as an antioxidant (Holopainen, 2013). 
Oxidative damage to leaf tissue can occur because of atmospheric oxidants such as ozone, but can also result from in vivo oxidation events caused by photosynthetic generation of reactive oxygen species. This occurs primarily during brief, high light events, known as sunflecks, when electron transport chain capacity is insufficient to accommodate the solar energy captured by chlorophyll. Research has shown that poplars modified for reduced isoprene emission suffer greater tissue damage when exposed to sunfleck events (Behnke, et al., 2010; Behnke et al., 2013).

Research has also demonstrated increased ozone tolerance in isoprene emitting species (Calfapietra et al., 2008; Calfapietra et al., 2009; Fares et al., 2006). And there is experimental support for the idea that isoprene may directly function as an antioxidant in plants, quenching free radicals generated by photosynthesis (Affek and Yakir, 2002; Loreto and Velikova, 2001). If isoprene emission is indeed linked to antioxidant quenching in vivo, then leaves should also emit the oxidation products of isoprene: methyl vinyl ketone (MVK) and methacrolein (MACR). Recent reports have found both compounds in leaf emissions (Jardine, et al., 2012; Jardine, et al., 2013). Both MVK and MACR are classified as known carcinogens because of their direct oxidative effects on human respiratory tissues. These chemicals are often found in samples of plant leaf emissions, but analytic limitations make it difficult to determine what fraction of isoprene oxidation occurs within the plant tissue rather than in the atmosphere shortly after emission. The site of oxidation, however, does not mitigate their carcinogenicity. 
Ascribing a direct in vivo antioxidant role to isoprene is complicated, however, by conflicting experimental results. Behnke et al. (2009) found that poplars modified for reduced isoprene emission actually suffered less tissue damage when exposed to ozone. This result suggests that the connection between isoprene emission and oxidative damage are likely more complicated than a direct antioxidant effect. The poplars in this study, which were modified exclusively for reduced isoprene emission also showed an increased concentration of other antioxidant compounds, including ascorbate and xanthophylls (Behnke, et al., 2009). These compounds have stronger antioxidant potential than isoprene and are generated through the same metabolic terpenoid pathways that produce isoprene. Consequently, their production competes for the same substrate as isoprene, DMADP (Rasulav et al., 2013), and thus their concentration may be affected by the reduction in isoprene synthase enzymes. Thus reducing isoprene emission may lead to an unintended increase in the production of antioxidant compounds, which complicates direct ascription of any observed effects to the reduction in isoprene emission, a key experimental shortcoming, which is rarely acknowledged. Additionally, the reduction of isoprene emission in poplars has been shown to affect the redox status, and thus the enzymatic activity, of many proteins within the chloroplast (Velikova et al., 2014) which supports theories that isoprene emission may represent a strategy for regulating chloroplast metabolism (Logan et al., 2000; Rosenstiel et al., 2004; Harrison, et al., 2013). These observed pleotropic effects from modification of 
isoprene emission suggest that the use of GM plants for investigating the physiological roles of isoprene emission may be of limited value.

An alternative approach to exploring the role of isoprene emission in plants has lead to investigation of the evolutionary history of isoprene emission in plants, with the goal of understanding under what environmental conditions isoprene emission has evolved and been selected for (Sharkey, 2013). This approach may allow to a deeper investigation of the ecophysiological role of isoprene emission by plants and consequently lead to a better understanding of the adaptive benefits of isoprene emission by plants. Isoprene emission is highly variable across plant phylogenies; current research estimates that the potential for enzymatic isoprene emission has evolved independently and also been lost numerous times throughout the diversification of plants (Monson et al., 2013). Approximately one third of plants emit isoprene enzymatically, and while many species emit almost no isoprene, others emit significant amounts (Hewitt, et al., 1997). Isoprene emission seems to be concentrated among fast growing plants and due to the protective roles mentioned above; it is more commonly observed in perennial plants that must be able to survive abnormally hot years. Traditional agricultural crops, with mostly annual growth habits and high transpiration rates, rarely emit isoprene (Sharkey et al., 2008), but isoprene emission is fairly common among proposed biofuel plants such as Arundo donax, Eucaplyptus and Poplars, Rubberwood and Acacia (Hewitt, et al., 1997). 
Arundo donax: The perennial reed Arundo donax is a large and productive member of the Poaceae family native to the Mediterranean region, the Middle East and Southeast Asia. A. donax has been used by humans for millennia as a source of papyrus in ancient Egypt, a building material for Mediterranean cultures and as the source of reeds for woodwind instruments such as clarinets and saxophones.

Recently A. donax has been proposed for use as a biofuel in North America.

Specifically, $A$. donax has been chosen as the candidate fuel crop to replace coal at Portland General Electric's (PGE, Portland, Oregon) Boardman Coal Plant (Boardman, Oregon) (Lewis, et al., 2012).

A. donax was selected by PGE because it is one of the most productive plants known, with the potential to produce significantly more biomass than other energy crops such as corn, miscanthus and switchgrass and because its dry material has higher energy density than other terrified biofuel crops (Lee, 2013). Other advantages to the use of $A$. donax as a biofuel crop include its comparatively low requirements for water and fertilizer (Lee, 2013), its sequestration of large amounts of silica in leaf tissue, which prevents much herbivory (McNaughton and Tarrants, 1983), and its perennial growth habit which reduces labor inputs and soil erosion (Lee, 2013). Research is being conducted to determine how this plant will perform as a biofuel crop in the Columbia River basin agricultural region in eastern Oregon and how its growth will impact the regional environment.

There are also reasons to be cautious about the widespread cultivation of $A$. 
donax. In some parts of the United States, including parts of California and Texas where $A$. donax was deliberately planted in wetlands to control erosion, it is considered to be an invasive species, due to many of the same attributes, such as fast growth and resistance to herbivory, that make it an attractive candidate for biofuel use. However, A. donax was first introduced to North America more than 200 years ago (Mariani et al., 2010) as a building material source and since then has also been widely grown as an ornamental plant. During that time, $A$. donax is thought to have never produced a viable seed (Johnson et al., 2006) or sexually reproduced on this continent (Ahmad et al., 2008). Invasive events have generally occurred only where $A$. donax was planted near open water systems that could transport rhizomes. This growth characteristic reduces $A$. donax's ability to invade over long distances and makes containment strategies more manageable. In order to address the concerns of invasive potential in $A$. donax, the state of Oregon recently adopted agricultural practice standards for its cultivation, which include a ban on planting within "Special flood hazard areas" (100-year flood plains) as well as regular monitoring of areas under cultivation (OR State Regulations, 2013).

A. donax is known to emit significant amounts of isoprene, but not other VOCs (Hewitt et al., 1990; Malneychenko, 2013). This large isoprene flux could potentially contribute to a decrease in regional air quality. If this were to occur it would reduce the potential benefits of using $A$. donax as a biofuel, as one of the primary motivations for its use at the Boardman coal plant is to reduce the 
atmospheric impacts of burning coal. Large isoprene fluxes from $A$. donax cultivation have the potential to significantly increase regional ozone levels, which would have deleterious impacts on human health (Papiez, et al., 2009) Additionally, many common and economically important food crops are sensitive to ozone induced oxidative damage, including melons and onions, which are widely cultivated in the Columbia River basin. Recent research and modeling work suggests that the Boardman region may be particularly insensitive to isoprene and other VOCs due to low background $\mathrm{NO}_{\mathrm{x}}$ and $\mathrm{SO}_{\mathrm{x}}$ levels (Porter, et al., 2012), however, this analysis is based on land use based assumptions of $\mathrm{NO}_{x}$ and $\mathrm{SO}_{x}$ inventories for Eastern Oregon, which may be inaccurate due to underestimation of the impact of agricultural equipment. Further, data presented in this thesis indicates that isoprene emission from $A$. donax grown in the Columbia River basin may, depending on management practices, far exceed values in published literature (Hewitt, et al., 1990; Malnychenko, 2013).

Goals of this Thesis: Little published research exists on the physiology of $A$. donax. Historically, A. donax has not been an economically significant plant and consequently it has not attracted much funding or academic attention. Additionally, A. donax has not previously been deliberately grown as an agricultural crop, with the minor exception of some small-scale cultivation for the production of woodwind instrument reeds (Perdue, 1958). For this reason, not much is know about how this 
plant will respond to agricultural management and what the ideal conditions will be for balancing biomass production with minimum environmental damage.

The goal of the research presented here is to begin to address this lack of knowledge by providing baseline data on the physiology of $A$. donax performance when grown as a bioenergy crop in the Columbia River basin. Specifically, we present what we believe to be the first gas exchange measurements of in-ground $A$. donax, which differ significantly from published data collected from $A$. donax grown in a greenhouse environment. We also present data on how decisions about fertilizer and water management of $A$. donax affect its production of isoprene and consequently its impact on air quality. The purpose of this research is to begin the exploration of the physiology of field grown A. donax and to contribute knowledge that will inform protocols for responsible and successful cultivation of this plant as a biofuel crop. 


\section{Chapter 2: Materials and methods}

Hermiston Field Campaign, 2012: All A. donax field data was collected from plants grown in Hermiston, Oregon at Oregon State University's Hermiston Agricultural Research Extension Campus (HAREC) located in the Columbia River basin agricultural region. These plants were grown as part of a series of trials, conducted by Dr. Don Horneck (Oregon State University) and his lab group, to determine optimal conditions for maximizing production of biomass from this crop in the Columbia River basin. Dr. Horneck's group conducted in-ground trials of this plant under a range of fertilizer treatments. All A. donax was planted as rhizomes in spring 2012 and canes were harvested in fall of that year. The rhizomes were allowed to resprout in 2013 in order to continue the trial.

In September 2012 we collected isoprene emission data from a nitrogen amendment trial of $A$. donax. Four treatment groups, with five plants each, were randomly chosen from a large $A$. donax field plot, and were amended with the equivalent of $120,320,520$ and $720 \mathrm{lbs}_{\text {acre }}^{-1}$ of urea $\left[\mathrm{CO}\left(\mathrm{NH}_{2}\right)_{2}\right]$. These plants were spaced across a field, located at least 3 meters from each other in order to avoid overlap of fertilizer treatments. The baseline nitrogen amendment, $120 \mathrm{lbs}$ acre ${ }^{-1}$ was chosen in order to bring the soil $\mathrm{N}$ concentration to standard levels for agricultural crops in the Columbia River basin (Horneck, personal communication). This baseline $\mathrm{N}$ was introduced as a liquid fertilizer through overhead pivot irrigation across the 
entire field on the following dates: $30 \mathrm{lbs}_{\text {acre }}{ }^{-1}$ on April 18 and June 22 and $60 \mathrm{lbs}$ acre $^{-1}$ on July 26. All additional nitrogen fertilizers were applied on May 11 as a mixture of $50 \% \mathrm{w} / \mathrm{w} \mathrm{NH}_{4} \mathrm{SO}_{4}, 25 \% \mathrm{ESN}$ and a $25 \% 180$ day Duration CR (both ESN and Duration $\mathrm{CR}$ are slow-release, polymer encapsulated $\mathrm{CH}_{4} \mathrm{~N}_{2} \mathrm{O}$ ), placed at the base of each plant in order to simulate agricultural application rates of an additional 200,400 and $600 \mathrm{lbs} \mathrm{N}$ acre ${ }^{-1}$. (see Appendix : Tables 1 and 2, for complete fertilizer forms and application rates for all treatment groups) Individual plants were marked with colorcoded flags for identification The field was cleared by burning on April 2, mowing at 24 inch height (above young $A$. donax canes) on May 15 and the application of a preemergence herbicide (Harness Xtra: Acetochlor 46.3\% and Atrazine 18.3\%, manufactured by Monsanto Corporation, St. Louis MO) on May 24, but during the remainder of the growing season, and the several months before our sampling period, no attempt was made to prevent volunteer weed growth between the sparsely planted $A$. donax trial plants. A dense community of weeds was present during our sampling period, although due to water stress, discussed below, the weeds were almost completely desiccated.

The field was watered regularly by overhead pivot irrigation, however watering was insufficient in 2012 and sensors placed at soil depths of 4, and 8 inches showed that soil moisture was only slightly above the wilt-point level estimated to be required to maintain turgor in $A$. donax, while a sensor at 12 " depth showed readings below the wilt point during and for approximately 1 week before our trial (Figure 4). 
This soil moisture data is consistent with observations that nearly all above ground biomass was brown and desiccated, with the exception of $A$. donax plants, which appeared green and healthy. We assume this is due to the size and depth of the $A$. donax root system (personal observation).

The central aim of our research in 2012 was to determine how isoprene emission from $A$. donax responds to $\mathrm{N}$ amendment. Leaf level isoprene flux was sampled via syringe from a septum port attached to the exhaust gas flow path on a Licor 6400 XT portable photosynthesis system and measured with GC-RGD-D2). The instrument was calibrated with a known isoprene standard at the beginning of the trial (see calibration, appendix X). This setup allowed us to control light level (maintained at $2000 \mu \mathrm{E}, \pm 3 \mu \mathrm{E}$ ), relative humidity (60-65\%), carbon dioxide level $(400 \mathrm{ppm}, \pm 2 \mathrm{ppm}$ ) and leaf temperature (maintained at $25 \mathrm{C}, \pm 3 \mathrm{C}$, this parameter varied more than intended due to equipment error, however there was no overall significant differences among treatment groups) in order to collect precise dynamic isoprene flux measurements. Flow rates for the Licor 6400 were set at $400 \mathrm{ml} \mathrm{min}^{-1}$ to provide adequate gas mixing.

We chose undamaged fully mature leaves (avoiding the newest 7 leaves on each plant) for sampling. All leaves were located between $2-3 \mathrm{~m}$ in height along the cane and we avoided sampling leaves that were growing in shaded locations, in order to ensure long-term adaptation to a similar light environment. All Licor 6400 XT measurements were made on the widest part of the leaf, approximately $1 / 3$ of the 
distance from cane to leaf tip. All samples were collected between 10am and 4pm when spot measurements indicated that photosynthesis was fully active. We sampled two syringes of exhaust gas from three leaves on three separate canes per plant over four consecutive days between September 12-15, 2012. Sampling order was randomized throughout the trial in order to ensure that each treatment was sampled throughout each day. There were no significant time-of-day differences between samples from each treatment group. The isoprene abundance in the two syringes was averaged and this average value was considered to be a single measurement, resulting in 15 independent samples per treatment.

The Licor $6400 \mathrm{XT}$ also recorded net carbon assimilation rate (gross photosynthesis minus respiration), stomatal conductance and transpiration rate, from which we were able to calculate water use efficiency (WUE). Additionally, we measured chlorophyll content in each sampled leaf (an average of 7 measurements along the sampled section of the leaf surface) with a Licor SPAD 502 chlorophyll meter and also used a tape measure to record the length and width of each sampled leaf. After sampling, we used a punch to remove 2 leaf discs (19mm diameter) from each sampled leaf, from the same region we had placed in the Licor 6400 XT cuvette, and dried them in an oven in order to calculate specific leaf mass (SLM). All dry leaf samples were weighed with an analytic micro balance (AB 104-S/FACT, manufactured by Mettler Toledo corporation, Tualatin, Oregon). 
Hermiston Field Campaign, 2013: In 2013, Dr. Horneck's lab group conducted similar biomass yield trials, but added additional treatment groups, including tests of interaction between various elemental fertilizers. The preparation of the field and application of fertilizers was done in the same manner as the 2012 trials, however new plants were chosen in order to avoid confounding effects caused by multiple years of variable fertilizer application. We returned to HAREC in late July-early August 2013 in order to resample isoprene fluxes from $A$. donax grown with various nitrogen application rates as well as to expand our survey to include treatments that combined nitrogen application with the addition of phosphorus, potassium, sulfur and chloride for a total of 8 treatment groups (Tables 1, 2, appendix).

We repeated sampling of isoprene emission, following all the same protocols outlined for our 2012 field campaign-all Licor 6400 XT settings were the same (except leaf temperature was maintained within \pm 1 degree $C$ ), the same GC-RGD described above was used and it was calibrated in Hermiston immediately before data collection.

Between the two sampling years, 2012 and 2013, there was a large difference in soil moisture due to variability in the HAREC irrigation system, which is discussed above. In addition to the soil moisture difference, between the two years there were also significant differences in temperature, humidity and time of year. Specific details on these differences are discussed below. 
Gas Exchange Measurements: In addition to surveying isoprene emission, in 2013 we also used the Licor $6400 \mathrm{XT}$ to perform gas exchange measurements and generate $A / C_{i}$ curves for $A$. donax grown with various nutrient treatments. All gas exchange measurements were conducted according to the protocol outlined by Long and Bernacchi (Long and Bernacchi, 2003) except that leaf level conditions (temperature, light level, and RH) and Licor 6400 XT flow rates were kept the same as our 2012 isoprene emission survey in order to permit comparison of our data sets and ambient carbon dioxide levels were increased to $1400 \mu \mathrm{mol} \mathrm{CO}_{2} \mathrm{~mol}^{-1}$ rather than stopping at $1000 \mu \mathrm{mol} \mathrm{mol}{ }^{-1}$ because no plateau in assimilation rate was observed at $C_{a}$ of $1000 \mu \mathrm{mol} \mathrm{mol} \mathrm{m}^{-1}$

Differences between 2012 and 2013 Hermiston Field Campaigns: We sought to maintain as similar as possible conditions between the two HAREC field campaigns, however due to the vagaries of both human commitments and natural phenomena, a certain amount of variation was present. There were two important phonological differences between the field campaigns: first, the 2013 plants were second year growth from the same rhizomes, and second, in 2013 we measured the plants approximately five weeks earlier in the year, in late July/early August rather than mid September. Between these two years (and the month preceding data collection) the temperature was also significantly warmer in 2013. 
Figure 4. Air temperature at HAREC before and during data collection-graph indicates the daily high, low and average air temperatures recorded for Hermiston OR for the period before and during data collection in 2012 and 2013.

\section{HAREC air temperature $\left({ }^{\circ} \mathrm{C}\right)$}

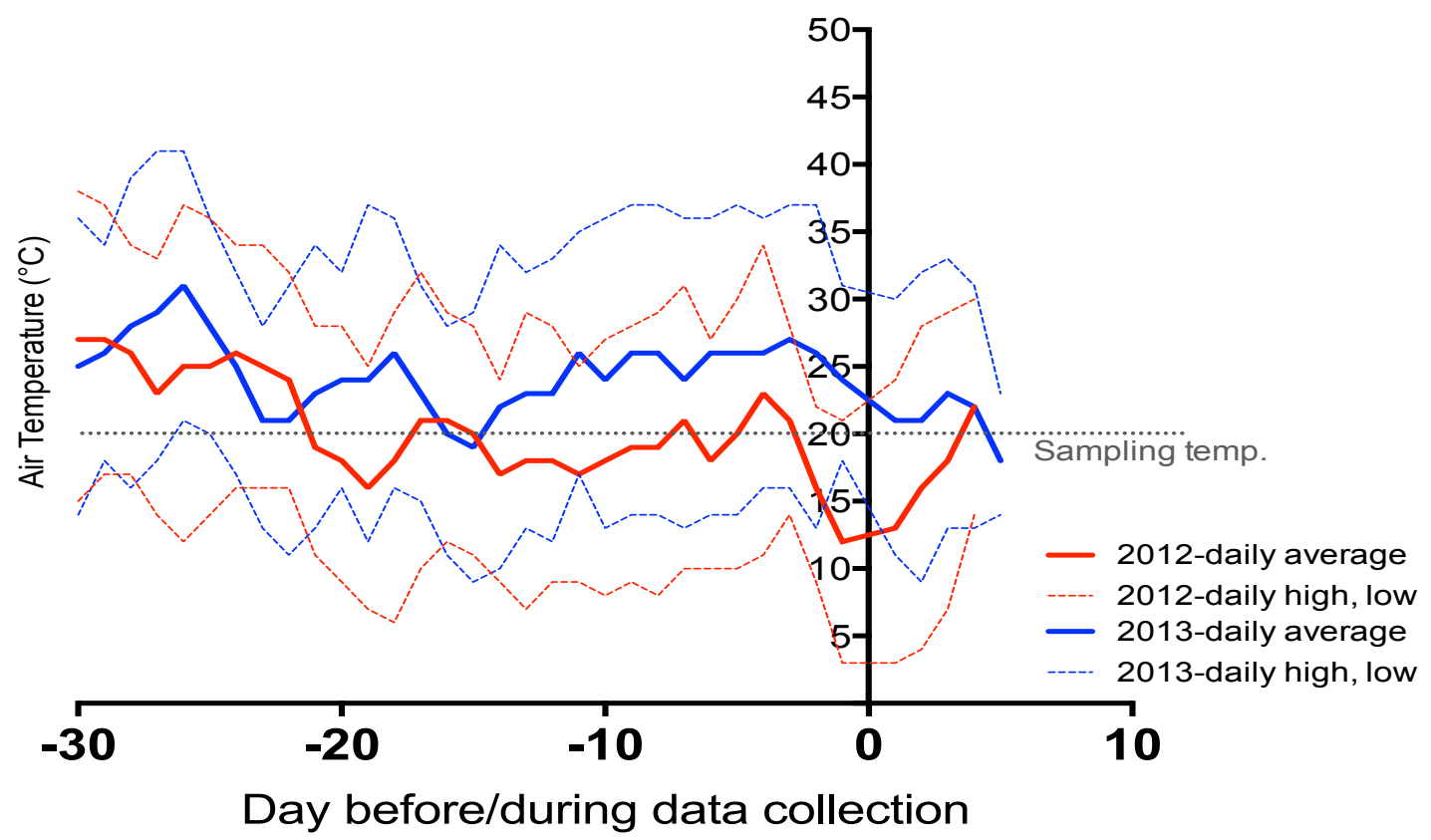

In addition to these differences, the HAREC irrigation system was operated less

frequently in 2012, resulting in significantly drier soil compared to 2013 (Figure 5).

They show smoothed daily averages of readings collected every 30 minutes. Overlaid on the figures is a green line which represents the soil saturation point, calculated based on soil type. Also shown is an orange line, which indicates an estimated wilt point, below which crops cannot maintain turgor. This wilt point is not specific to $A$. donax, but is used generally for a broad range of crops grown in the Columbia River basin. 
Figures 5A, 5B and 5C. Soil water content at 4", 8" and 12" depths before and during data collection-Figures display average soil moisture reported as inches of water $\bullet$ inches of soil $^{-1}$. Dashed green line indicates soil saturation point and dashed orange line indicates estimated wilt point. Data is from soil moisture sensors operated by IRZ consulting, which operates the HAREC irrigation system.

Figure 5A: Soil water content at 4" before and during data collection

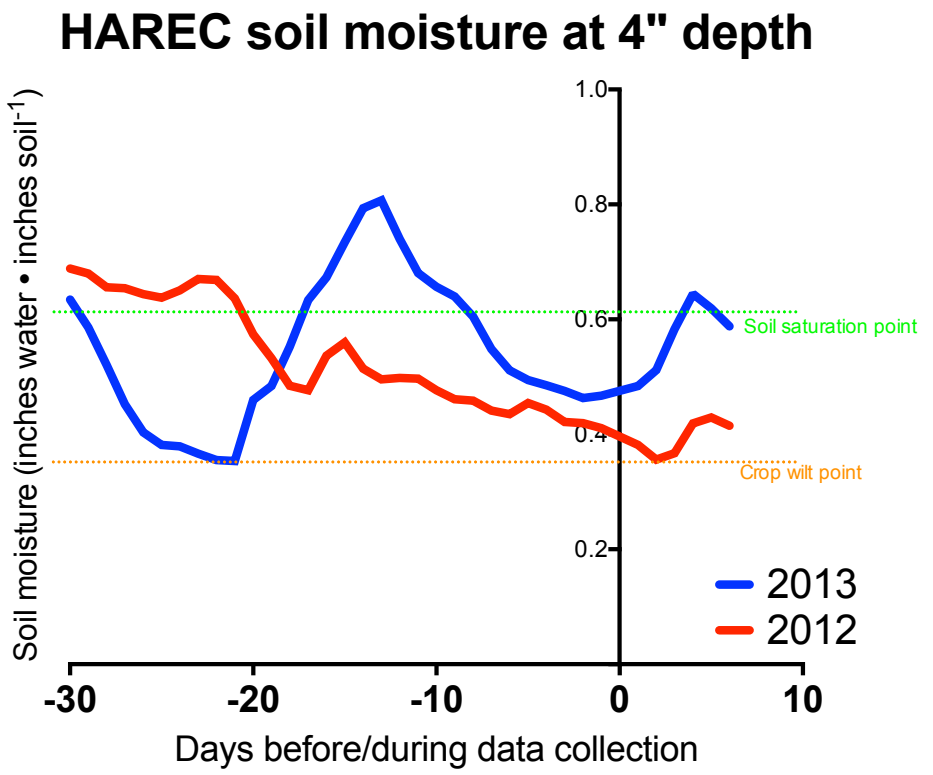

Figure 5B: Soil water content at 8" before and during data collection

HAREC soil moisture at 8" depth

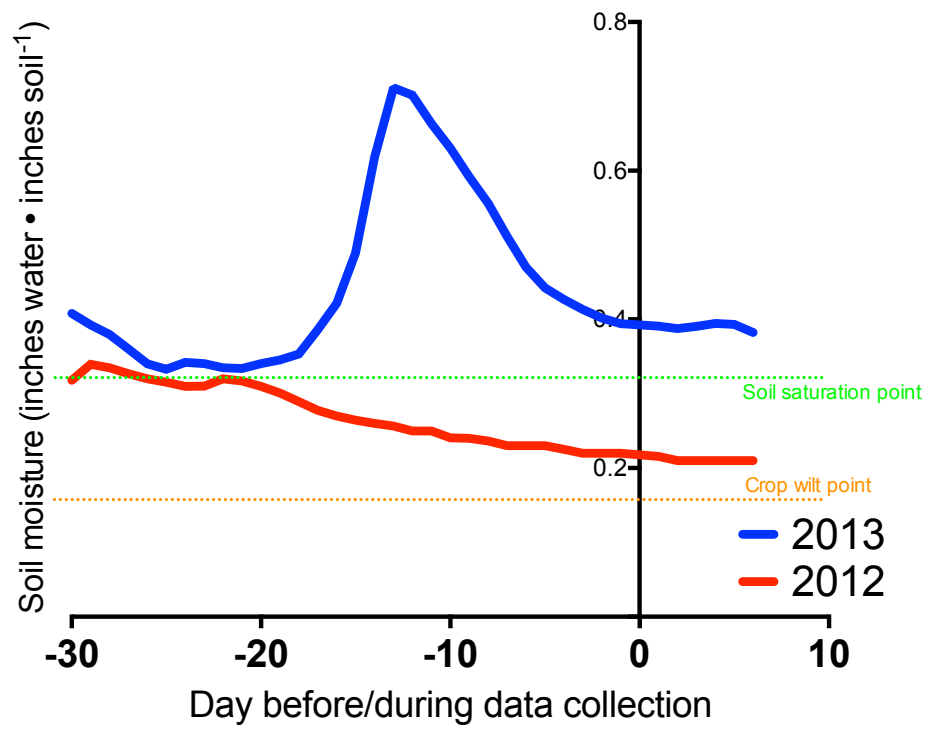


Figure 5C: Soil water content at 12 " before and during data collection

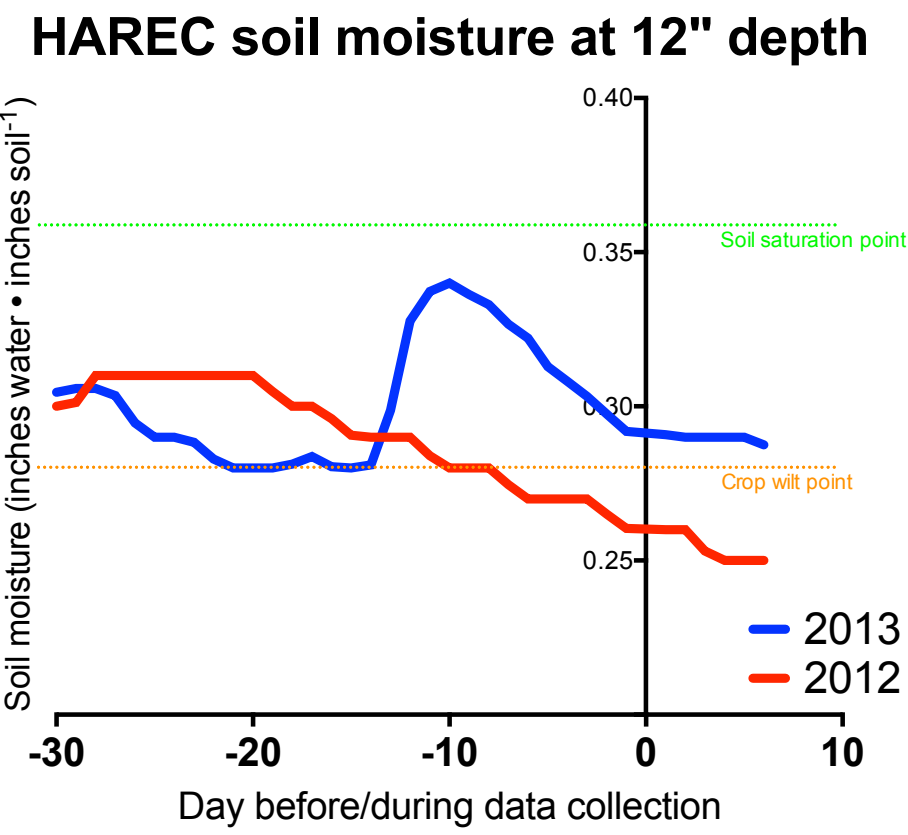

EPA Chamber Experiments, 2013: The United States Environmental Protection Agency (EPA), National Health and Environmental Effects Research Laboratory, part of the Western Ecology Division located in Corvallis, Oregon is currently studying the human health impacts of pollen produced by second generation biofuel crops (second generation indicates crops that are selected for total biomass production, all of which is converted into fuel products, rather than first generation crops grown exclusively for oil and sugar/ethanol production). As part of this study EPA researchers are growing Arundo donax and Miscanthus $x$ giganteus in six large, semiopen clear plastic chambers. These chambers, which are cylindrical and approximately 3.0 meters in diameter and 2.4 meters high, are sunlit and exposed to ambient air through fine mesh screens designed to prevent pollen excursion. As part 
of the Terrestrial Ecology Research Facility, these chambers have been in operation for nearly 30 years and have been described in detail in in several publications (Hogsett et al., 1985; Waltrud et al., 2011; Waschmann et al., 2010).

Biofuel crops in the current study are being grown in large pots, approximately 1.2 square meters in surface area and .6 meters deep (with a volume of approximately 190 gallons), which are filled with a sandy loam soil. Each chamber contained 3 large pots, and a single species was planted in each pot. The soil was fertilized shortly after planting with both liquid and granular fertilizers containing equal proportions of N, P and K. Soil moisture was monitored weekly and all pots were watered from an overhead sprinkler system in order to maintain approximately $25 \%$ soil moisture by volume. Weeds were manually removed regularly. Evaporative water-cooling was used to mitigate heat buildup in three of these chambers due to greenhouse effects, while the other three chambers were allowed to become hotter than ambient conditions. This resulted in an increase in daytime maximum temperatures of approximately 2 degrees Celsius for the four weeks preceding our data collection (Olszyk, in preperation).

We were provided access to this facility in order to measure the effects of temperature on isoprene production in $A$. donax and gas exchange in $A$. donax and Miscanthus $x$ giganteus (Miscanthus is known to be a non-isoprene-emitting species, which we confirmed with spot measurements). We collected isoprene emission data, along with measuring stomatal conductance, photosynthesis and leaf chlorophyll 
level in A. donax on September 16, 2013, following the same protocols as the 2012 Hermiston field campaign. Gas exchange measurements were conducted on September 13 and 20, 2013. All data was collected with a Licor 6400 , according to the same protocols and with the same leaf conditions outlined in the Hermiston field campaign methods above. We collected isoprene emission data from $A$. donax by measuring three leaves, each on separate canes in each of the six chambers. Gas exchange data was collected, in the same manner described above for the 2013 HAREC field campaign, from one leaf in each of the three high temperature chambers for both A. donax and Miscanthus x giganteus.

Isoprene emission across canopy height survey: The relationship between isoprene emission and canopy height was investigated on the same plants used for the HAREC 2013 field campaign, described above. Four plants from both the control and high $\mathrm{N}$ treatment groups were sampled. Three leaves on each plant were selected, one each from the lower, middle and upper thirds of the plant (excluding the still-expanding highest leaves). Leaf height was measured from the ground up along the length of the cane and recorded as the point where the leaf terminated at the cane. The sampled leaves ranged from $.85 \mathrm{~m}$ to $2.48 \mathrm{~m}$ in cane height. In all 12 separate leaves (3 each from four canes) were sampled from each treatment.

A leaf punch was used to extract a circular sample of known size from each leaf. The sampled leaf disc was placed in a transparent $44 \mathrm{ml}$ glass vial containing 
$10 \mathrm{ml}$ of tap water and closed with a gas-tight septa cap. Leaf samples were incubated under ambient conditions for $60 \mathrm{~min}$. Light levels were recorded every 10 minutes and averaged $1809 \mu \mathrm{E}$ during the incubation period. At the end of the incubation period, vials were transferred to dark containers to stop photosynthesis and an analytic syringe was used to transfer headspace samples to the RG-D2 GC system, described above, in order to determine isoprene levels.

Isoprene emission response to light level survey: The response of isoprene emission to light levels in A. donax was measured on plants grown under greenhouse culture at Portland State University Research Greenhouse. A. donax was planted from shoot culture (obtained from Boo Shoot Gardens, Mt. Vernon WA), in 1-gallon buckets filled with a mix of $50 \%$ sand and $50 \%$ potting soil (Ocean Forest blend from FoxFarm soil and fertilizer company, Humbolt CA). The plants were kept at at $22^{\circ} \mathrm{C}$ during the day, and $15{ }^{\circ} \mathrm{C}$ at night. HID lights provided an average of $250 \mu \mathrm{mol}$ photons $\mathrm{m}^{-2} \mathrm{sec}^{-1}$ of photosynthetically active radiation (PAR) from 6 am to 10 pm daily to augment incoming sunlight. No additional fertilizer amendment was applied and the plants were watered twice per week to soil saturation. Data was recorded approximately 6 months after $A$. donax was replanted from shoot culture at which time the plants were approximately $1 \mathrm{~m}$ tall.

Two plants were sampled and one leaf on each plant was used. Mature, healthy leaves were selected from the mid-canopy of each plant. Sampling for 
isoprene was done from outflow gas on the Licor 6400 in the manner described above. All leaf conditions were the same as described in the HAREC field survey, except that light level was varied from 0 to $2000 \mu \mathrm{E}$, in $250 \mu \mathrm{E}$ increments. As light levels were adjusted, leaves were allowed to reach steady state photosynthesis at the new light level and then given an additional 10-minute acclimation period before isoprene was sampled. Two syringes were drawn from each leaf at each light level and the isoprene content of the two was averaged to provide a single data point.

Statistical Analysis of Data: All data presented in this thesis was analyzed with JMP statistical analysis software (SAS Institute Inc., Cary, North Carolina) and all figures were created with GraphPad Prism software (GraphPad Software, La Jolla, California). Analysis of variance tests (ANOVAs) were performed in JMP on all measured attributes according to fertilizer or temperature treatment groups. Additionally, for the HAREC field trials, data was batched by year and ANOVAs were performed to test for the impact of abiotic variability between sampling periods. If ANOVA tests indicated significant differences, defined as $\alpha \leq .05$, Tukey's HSD tests were performed with JMP on all pairs to determine where differences were statistically significant. For comparisons of the effects of temperature treatments and other instances where only two treatment groups were considered, such as when data was batched into +/- nitrogen groups, a Student's t-test was performed in JMP to determine whether any differences in the results were statistically significant. $P$ 
values were reported for all significant findings as well as all results that approached significance $(\alpha \leq .1)$ and $p$ values $>.1$ were simply reported as non-significant.

In a few cases, between the two HAREC sampling years, there was large variability in mean values of particular attributes. In these instances, when data from both years was included in a single statistical model the large variability between the sample years suppressed the significance of differences between individual treatment groups; in other words differences between fertilizer treatment groups appeared insignificant because the overall differences between the two sampling years contributed a large amount of variance to the overall model. In these cases, the data set was broken out by individual year in order to more accurately determine the effects of fertilizer treatment on the attributes in question. ANOVA and Tukey's HSD tests were performed on these data subsets in the same manner described above.

As discussed above, the individual isoprene flux measurements reported here are the mean of two samples taken in rapid succession from the same leaf. In one instance, during the 2013 HAREC field trial, an anomalously high isoprene flux value was recorded for one syringe in a sample. We performed a Q-test, which indicated that this value was a statistical outlier and thus we excluded it from our analysis. For this sample we reported the value of the other syringe, which was in line with other values measured during the survey and was not a statistical outlier. Thus the exclusion of this data point did not result in an overall decrease in sample size. 


\section{Chapter 3: Results}

\section{A Effect of fertilizer, water management and temperature on leaf chlorophyll content in $A$. donax}

HAREC field trials: Chlorophyll content in Arundo donax changed significantly in response to the addition of nitrogen but not when provided other elemental fertilizers. In the 2012 field trials, the addition of nitrogen resulted in an increase in leaf chlorophyll content; all increased $\mathrm{N}$ treatment groups were significantly different than the control group and both the mid- $\mathrm{N}$ group and high- $\mathrm{N}$ group were significantly different than the low-N group (post hoc Tukey's HSD). In the 2013 data, the same general positive relationship between nitrogen and chlorophyll content was observed; however, the effect was less pronounced and the differences between the control group and the low- $\mathrm{N}$ group was not significant; however, the high- $\mathrm{N}$ group was significantly different from both of these treatment groups. 
Figure 6. Leaf chlorophyll content in Arundo donax by nitrogen treatment and year-The mean leaf chlorophyll content, \pm one s.e., for Arundo donax grown with different amounts of nitrogen fertilizer in two different years. Red bars indicate 2012 data and blue bars indicate 2013 data. If treatments do not share any of the same letters they are significantly different from each other at $\mathrm{P}<.05$ (Tukey's HSD).

Chlorophyll content of Arundo donax by nitrogen treatment and year

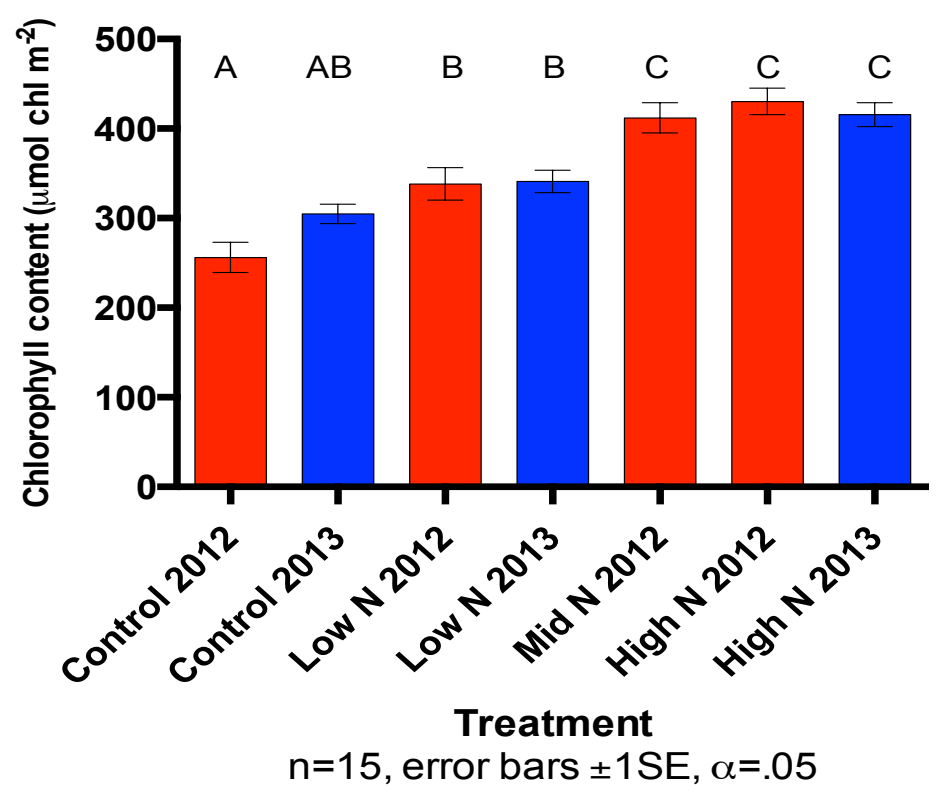


All plants in treatment groups containing other elemental fertilizers had higher

chlorophyll content than the $\mathrm{N}$ control group, except for the urea treatment group,

which contained slightly less chlorophyll, but none of the individual groups was

statistically distinguishable from the $\mathrm{N}$ control group (post hoc, Tukey's HSD).

Figure 7. Leaf chlorophyll content in Arundo donax by addition of elemental fertilizers -The mean leaf chlorophyll content, \pm one s.e., for Arundo donax grown with various elemental fertilizers in 2013. No groups were significantly different from the control group (post hoc, Tukey's HSD).

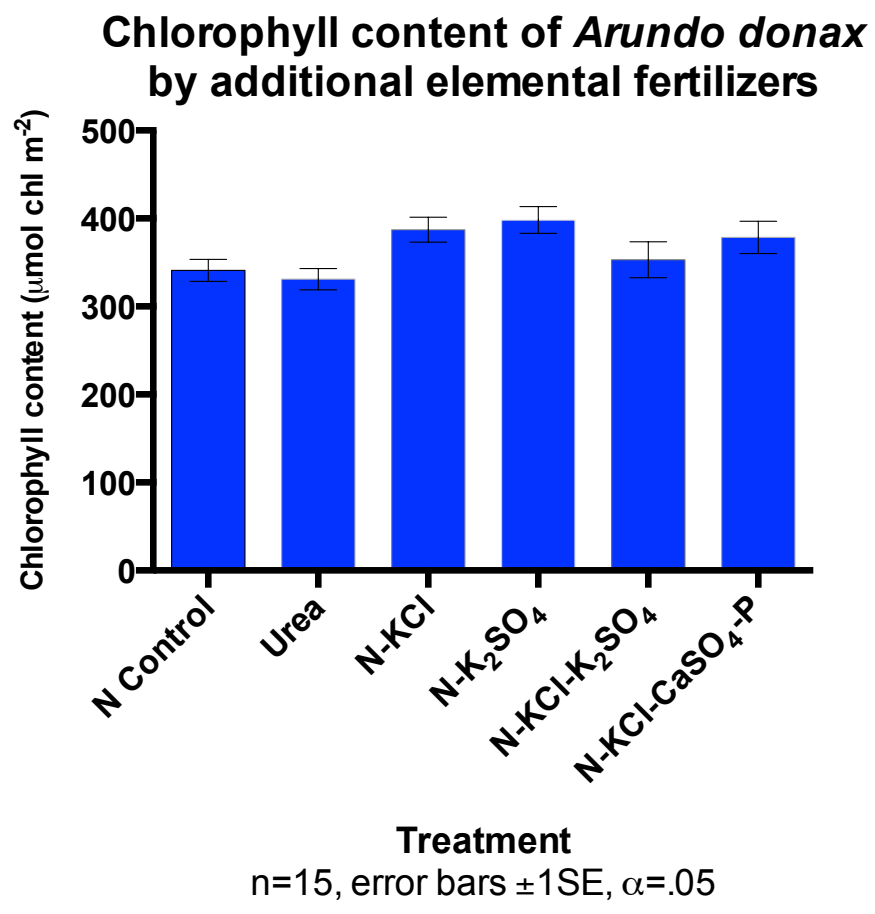


Nitrogen application: As expected based on the previous data, a significant increase in leaf chlorophyll level was also observed when the data was analyzed for the effect of nitrogen application, rather than individual treatment groups. This analysis is confined to the control, low $\mathrm{N}$ and high $\mathrm{N}$ treatment groups, as these were the only groups sampled in both 2012 and 2013.

Figure 8. Effect of nitrogen amendment on leaf chlorophyll content in Arundo donax by year - The mean leaf chlorophyll content, \pm one s.e., for Arundo donax as grouped by +/- nitrogen. Red bars indicate 2012 data and blue bars indicate 2013 data. If treatments do not share any of the same letters they are significantly different from each other at $\mathrm{P}<.05$ (Tukey's HSD).

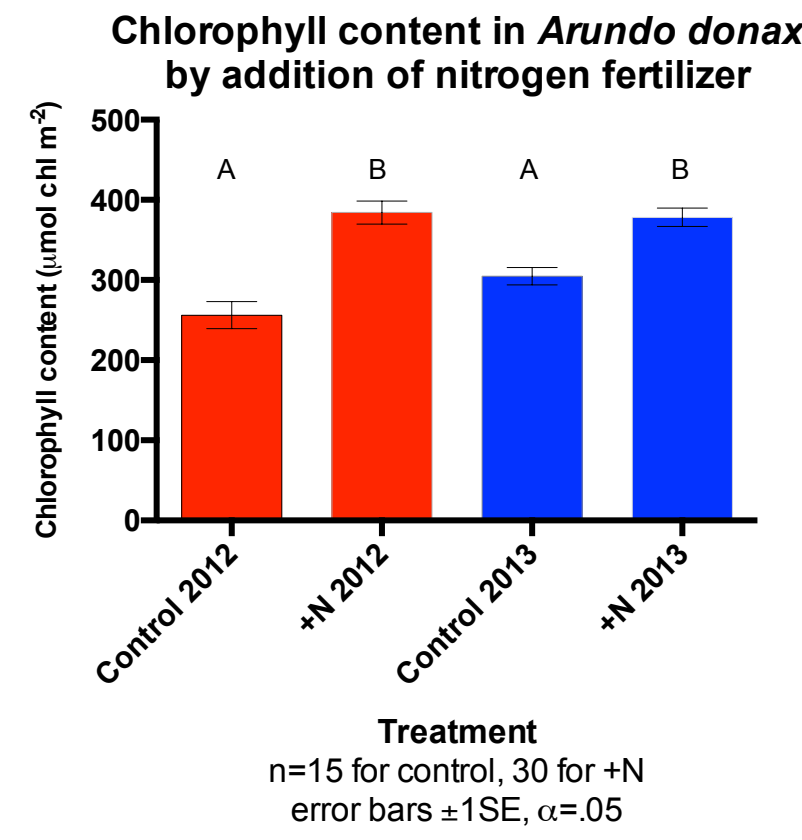

In 2012, a 50\% increase in chlorophyll level was seen among the plants given additional nitrogen compared to the control group. This difference was statistically significant $(P<.0001$, post hoc Tukey's HSD). 
A similar positive relationship between chlorophyll content and nitrogen application was observed in 2013 under moist soil conditions, although the increase in chlorophyll levels was smaller. The addition of nitrogen to individual plants resulted in a $24 \%$ increase in leaf chlorophyll content, a difference that was also statistically significant $(\mathrm{P}<.01$, post hoc Tukey's HSD).

Sampling year differences: The differences in soil moisture and air temperature between 2012 and 2013 did not significantly alter leaf chlorophyll content.

Figure 9. Leaf chlorophyll content in Arundo donax by year-The mean leaf chlorophyll content, \pm one s.e., for Arundo donax from the treatment groups that were grown in both sample years. Years were not significantly different from each other (students t Test).

Chlorophyll content in Arundo donax by sampling year

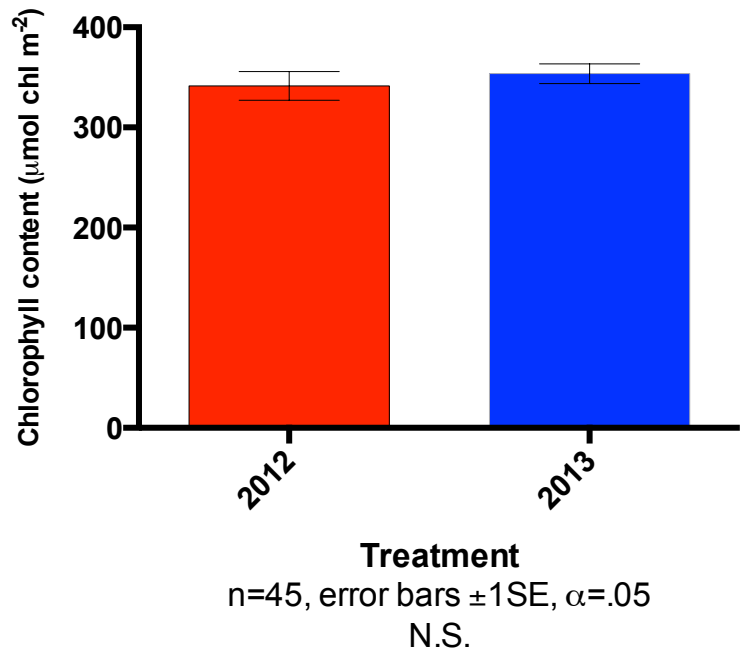

Compared to plants sampled in 2012 (dry, cool conditions) plants sampled in 2013 (wet, hot conditions) had approximately 3\% higher leaf chlorophyll content, a 
difference that was not statistically distinguishable from possible random sampling error (N.S., students t Test).

Air temperature: Changes in ambient air temperature had no significant effect on leaf chlorophyll content. Plants in the high-temperature treatment group had approximately $6 \%$ higher chlorophyll content compared to the low-temperature group, but this difference was not significant (students t Test).

Figure 10. Effect of long term temperature acclimation on leaf chlorophyll content in Arundo donax -The mean leaf chlorophyll content, \pm one s.e., for Arundo donax grown with an average temperature difference of $2^{\circ} \mathrm{C}$ in greenhouse conditions. Treatments were not significantly different from each other (students $t$ Test).

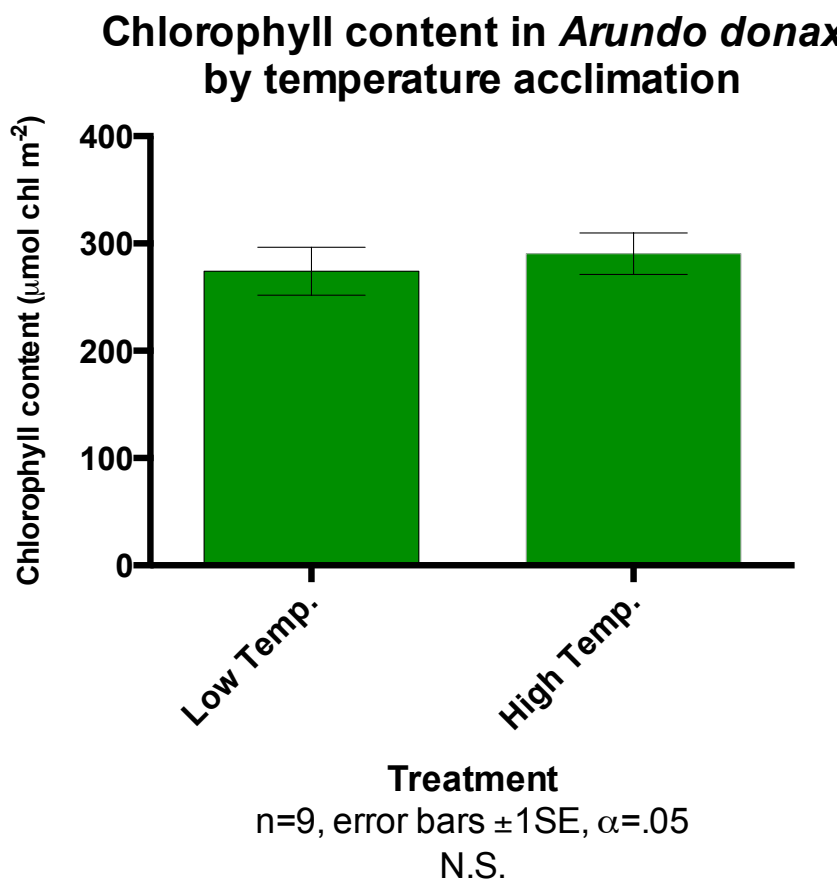


3.B: Effect of fertilizer and water management on leaf photosynthesis in A. donax

HAREC field trials: Fertilizer treatment did not profoundly affect photosynthesis rates in A. donax. In both the 2012 and 2013 field campaigns, carbon assimilation rates between individual fertilizer treatment groups did not differ from each other significantly. This was true when comparing any pair of groups within the same year, and for comparisons of nearly every pair between the two years.

Figure 11. Leaf photosynthesis rate of Arundo donax by nitrogen treatment and year-The mean photosynthesis rate, \pm one s.e., for Arundo donax grown with different amounts of nitrogen fertilizer in two different years. Red bars indicate 2012 data and blue bars indicate 2013 data. If treatments do not share any of the same letters they are significantly different from each other at $\mathrm{P}<.05$ (Tukey's HSD).

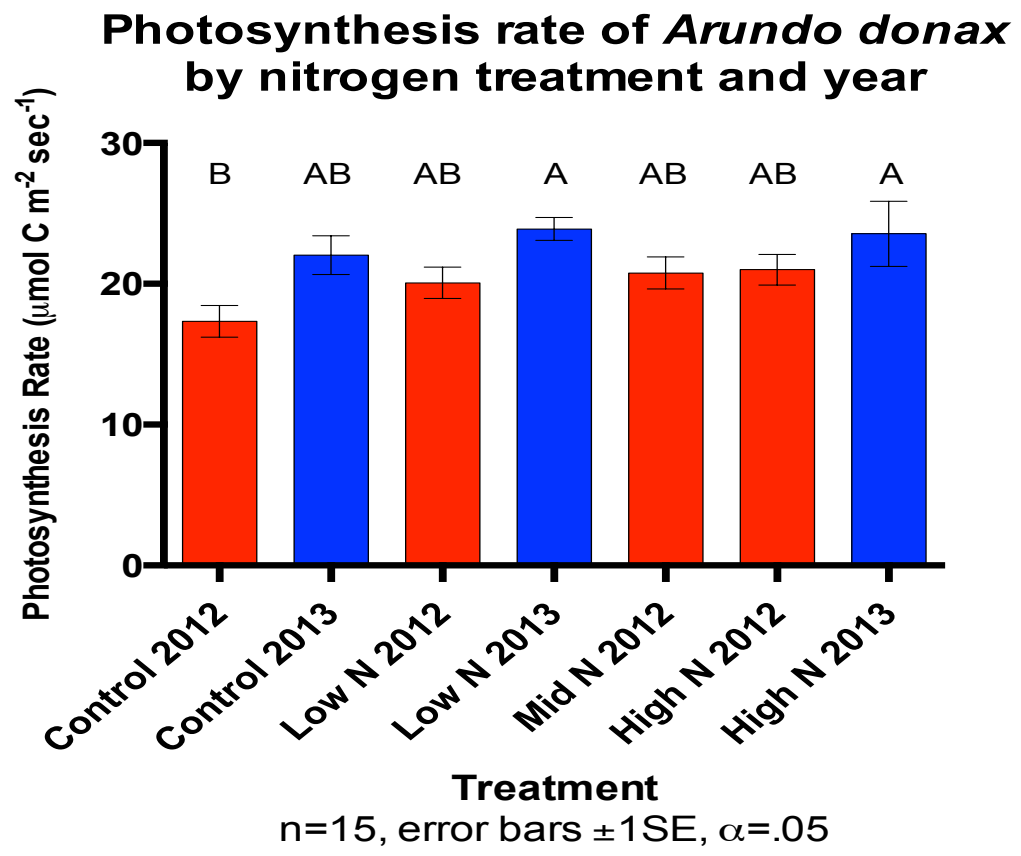


The application of additional elemental fertilizers $(\mathrm{N}, \mathrm{P}, \mathrm{K}, \mathrm{S}, \mathrm{Cl}, \mathrm{Ca})$ did not result in any change in carbon assimilation rates that was inconsistent with random variation

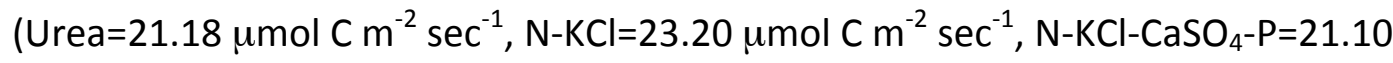

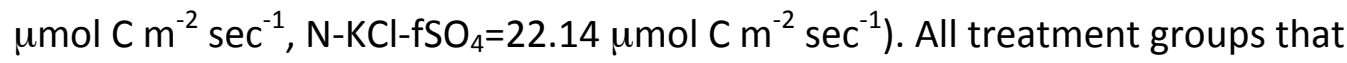
received additional elements also received $200 \mathrm{lbs}$ of nitrogen. Consequently, for all analyses of additional elemental fertilizer effects, the Low $\mathrm{N}$ treatment group is being used as a control in order to determine which effects can be causally attributed to the addition of elements other than nitrogen.

Figure 12. Leaf photosynthesis rate of Arundo donax by addition of elemental fertilizers - The mean photosynthesis rate, \pm one s.e., for Arundo donax grown with various elemental fertilizers in 2013. No groups were significantly different from the control group (Tukey's HSD).

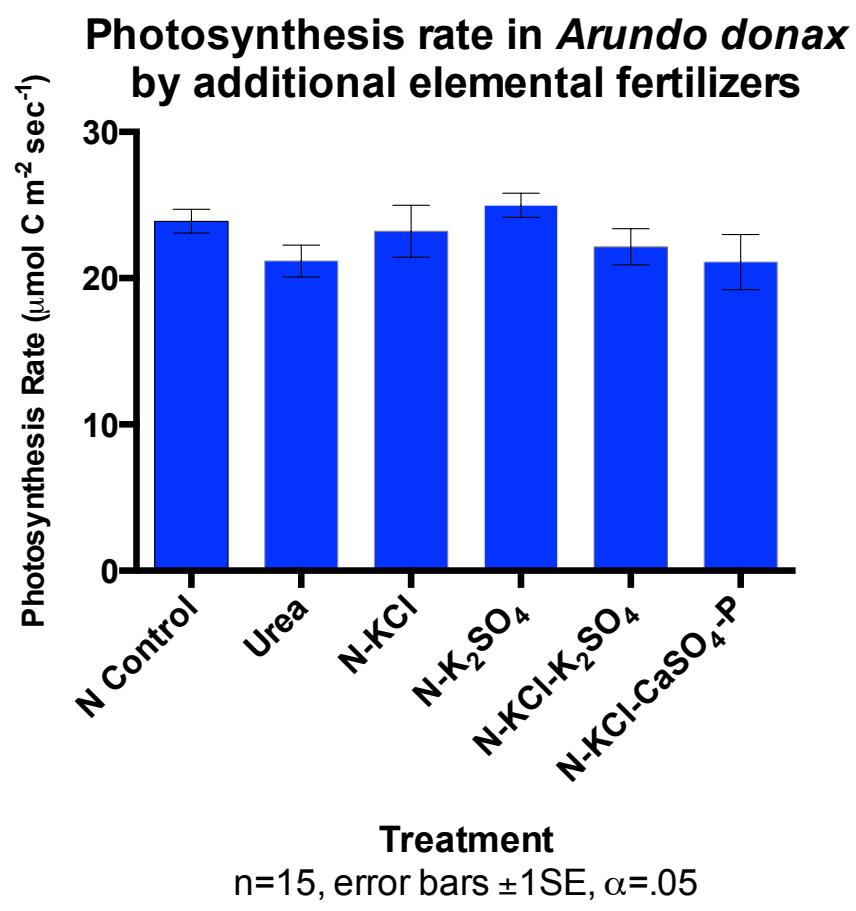


A number of trends were suggested by the treatment data and significant differences in photosynthesis rate were found when data was analyzed for the overall effects of nitrogen amendment and soil water conditions.

Nitrogen fertilizer application: We found a positive relationship between photosynthesis and the application of nitrogen fertilizer in A. donax in both our 2012 and 2013 data collection period when looking at only the treatment groups that were sampled both years (control, low-N and high-N) however, within the same year's sampling, the effect of nitrogen application was not statistically significant (post hoc, Tukey's HSD).

Figure 13. Effect of nitrogen amendment on leaf photosynthesis in Arundo donax by year-The mean photosynthesis rate, \pm one s.e., for Arundo donax as grouped by +/- nitrogen. Red bars indicate 2012 data and blue bars indicate 2013 data. If treatments do not share any of the same letters they are significantly different from each other at $\mathrm{P}<.05$ (Tukey's HSD).

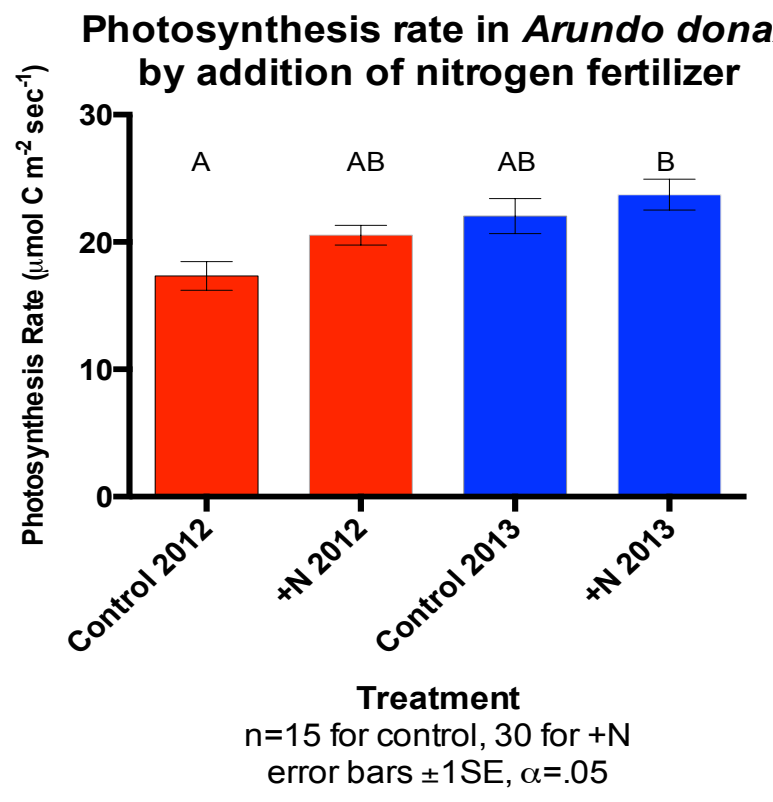


In 2012, under dry field conditions, mean net carbon assimilation rates were approximately $19 \%$ higher in the plants receiving additional nitrogen amendment compared to the control plants, which received $\mathrm{N}$ amendment at standard rates for agriculture in the Columbia River basin $\left(17.33 \mu \mathrm{mol} \mathrm{C} \mathrm{m} \mathrm{sec}^{-1}\right.$ in the control plants, vs. $20.54 \mu \mathrm{mol} \mathrm{C} \mathrm{m} \mathrm{sec}^{-1}$ in the plants receiving additional N; N.S. P=.08, post hoc Tukey's HSD).

A similar increase in net carbon assimilation with the application of $\mathrm{N}$ fertilizers was recorded in 2013; however, the overall increase was smaller. Compared to the control plants, the plants receiving increased $\mathrm{N}$ amendment assimilated nearly 9\% more carbon over the same leaf surface area (control=22.04 $\mu \mathrm{mol} \mathrm{C} \mathrm{m} \mathrm{sec}^{-1},+\mathrm{N}=23.72 \mu \mathrm{mol} \mathrm{C} \mathrm{m} \mathrm{sec}^{-1}$ for all plants receiving additional N; N.S., post hoc Tukey's HSD). 
Sampling year differences: Photosynthesis rates in $A$. donax were also found to be significantly different between 2012 and 2013 sampling periods. In comparing 2012 data (dry soil, cooler air conditions) to 2013 data (wet soil, hotter air conditions) we found a large change in photosynthetic carbon assimilation by $A$. donax.

Figure 14. Leaf photosynthesis rate of Arundo donax by year-The mean photosynthesis rate, \pm one s.e., for Arundo donax from the treatment groups that were grown in both sample years. Years were significantly different from each other $(\mathrm{P}<.001$, students $\mathrm{t}$ Test).

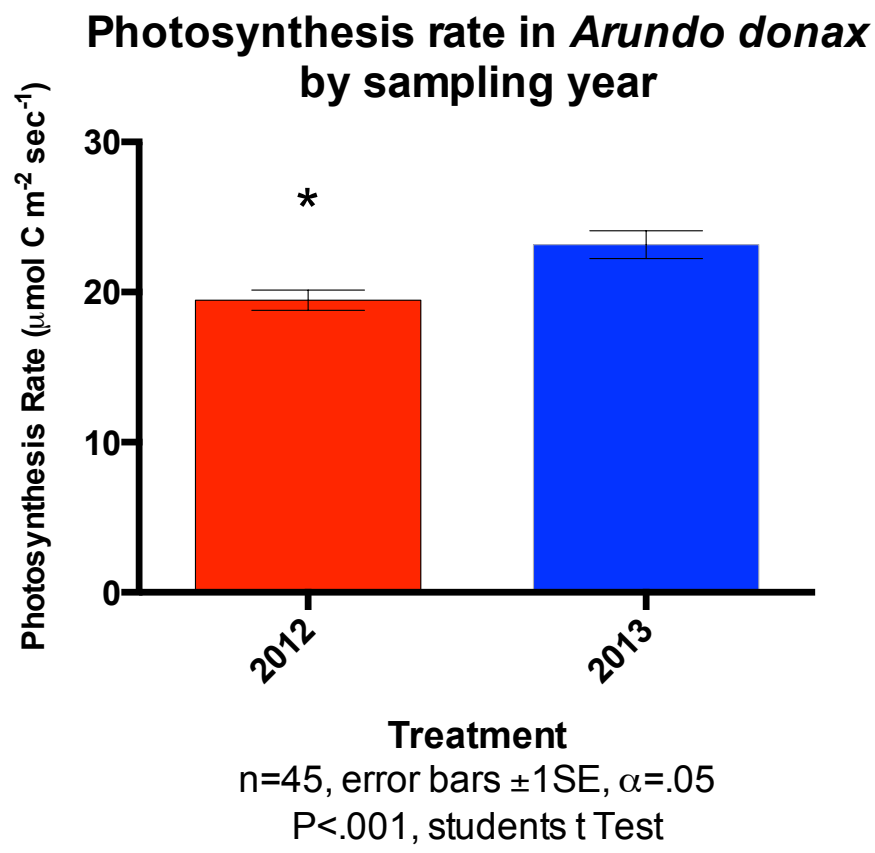

When the three treatment groups that were sampled each year (Control, Low $\mathrm{N}$ and High $N$ ) are combined, net carbon assimilation was approximately $27 \%$ higher in the wet and hot conditions of 2013 compared to the dry, cooler conditions of 2012 ( $P<.001$, post hoc, students t Test). 
Air Temperature: $A$. donax plants grown in greenhouse conditions at different ambient air temperatures did not differ significantly in photosynthesis rates (students t Test).

Figure 15. Effect of long term temperature acclimation on leaf photosynthesis rate in Arundo donax - The mean photosynthesis rate, \pm one s.e., for Arundo donax grown with an average temperature difference of $2^{\circ} \mathrm{C}$ in greenhouse conditions. Treatments were not significantly different from each other (students $t$ Test).

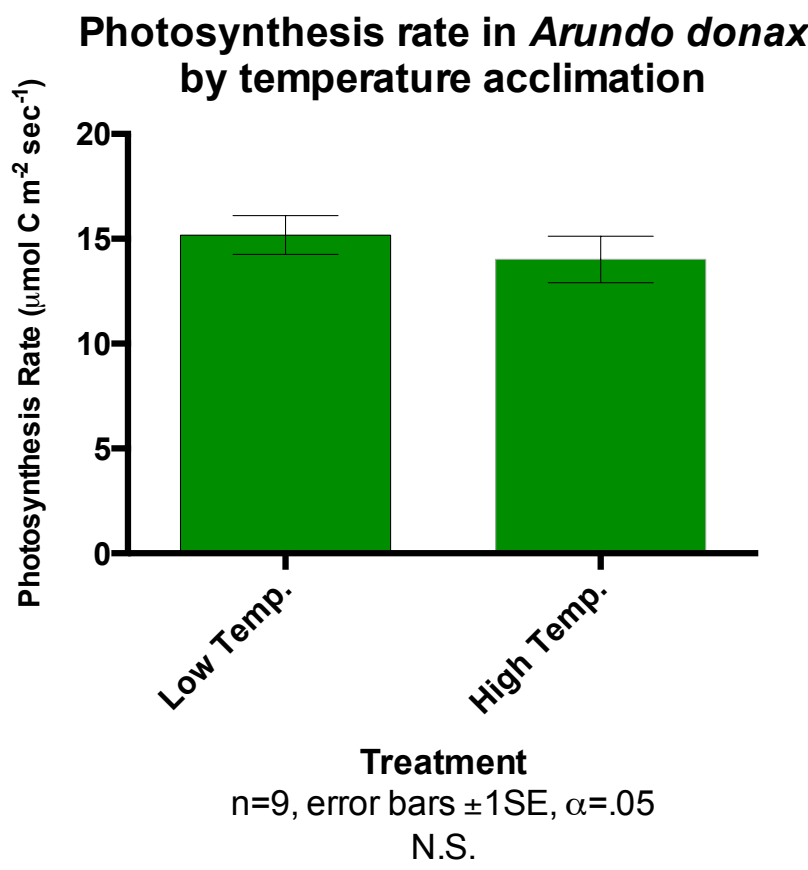

Photosynthesis rates in $A$. donax grown in growth chambers were $15.18 \mu \mathrm{mol} \mathrm{C} \mathrm{m}^{-2}$ $\mathrm{sec}^{-1}$ for the low temperature treatment group and $14.0 \mu \mathrm{mol} \mathrm{C} \mathrm{m} \mathrm{sec}^{-1}$ for the high temperature treatment plants. This difference was not statistically significant (post hoc, students t Test). 
3.C: Effect of fertilizer, water management and temperature on leaf stomatal conductance in A. donax

HAREC field trails: In both 2012 and 2013 leaf stomatal conductance in A. donax varied negatively with application of elemental fertilizers. There was high variance in the observed conductance values, however, and none of the individual treatments in either year was significantly different from the control groups in the same year.

Figure 16. Leaf stomatal conductance of Arundo donax by nitrogen treatment and year-The mean stomatal conductance rates, \pm one s.e., for Arundo donax grown with different amounts of nitrogen fertilizer in two different years. Red bars indicate 2012 data and blue bars indicate 2013 data. If treatments do not share any of the same letters they are significantly different from each other at $\mathrm{P}<.05$ (Tukey's HSD).

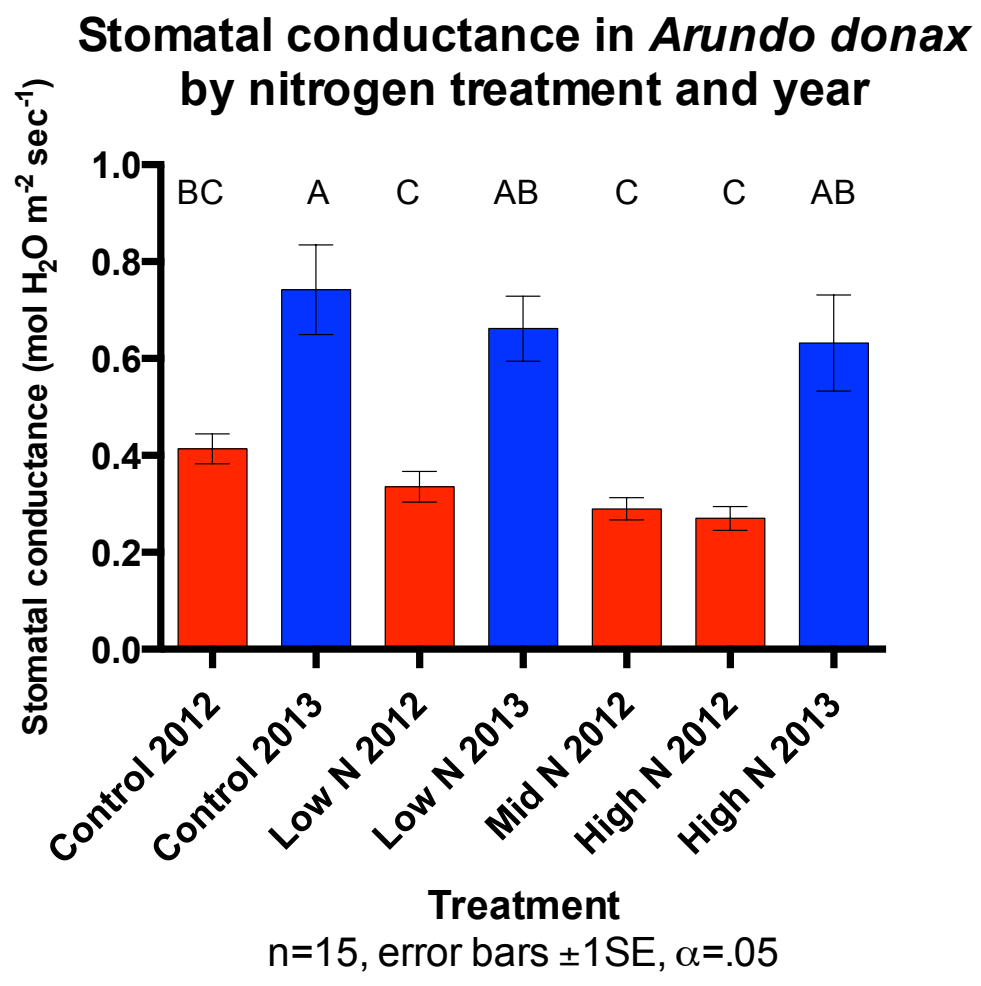


Similarly to 2012, in our 2013 data, a negative relationship between nitrogen application and leaf stomatal conductance was observed in $A$. donax; an increase in $\mathrm{N}$ levels correlated with a decrease in stomatal conductance. Mean leaf stomatal conductance was approximately $17.5 \%$ lower in the high-N plants compared to the control group (.74 mol H $\mathrm{O} \mathrm{m}^{-2} \mathrm{sec}^{-1}$ in control plants and $.64 \mathrm{~mol} \mathrm{H}_{2} \mathrm{O} \mathrm{m}^{-2} \mathrm{sec}^{-1}$ in the high N group). This difference, however, was also not significant (N.S., post hoc, Tukey's HSD) due to high within-treatment variance.

The large difference in conductance rates between 2012 and 2013 sampling years suppresses the statistical differences between the individual treatment groups within 2012. When the 2012 data is analyzed independently, significant differences exist between the control group and the Mid $\mathrm{N}$ group as well as between the control group and the High N group (post hoc, Tukey's HSD). In 2012, mean conductance rates were more than $50 \%$ higher in the control plants compared to those receiving the highest levels of nitrogen amendment (control plants $=0.41 \mathrm{~mol} \mathrm{H}_{2} \mathrm{O} \mathrm{m}^{-2} \mathrm{sec}^{-1} \mathrm{vs}$. $0.27 \mathrm{~mol} \mathrm{H}_{2} \mathrm{O} \mathrm{m}^{-2} \mathrm{sec}^{-1}$ in high-N plants). 
Figure 17. Leaf stomatal conductance of Arundo donax by nitrogen treatment, 2012 only-The mean stomatal conductance rates, \pm one s.e., for Arundo donax grown with different amounts of nitrogen fertilizer in 2012. If treatments do not share any of the same letters they are significantly different from each other at $\mathrm{P}<.05$ (Tukey's HSD).

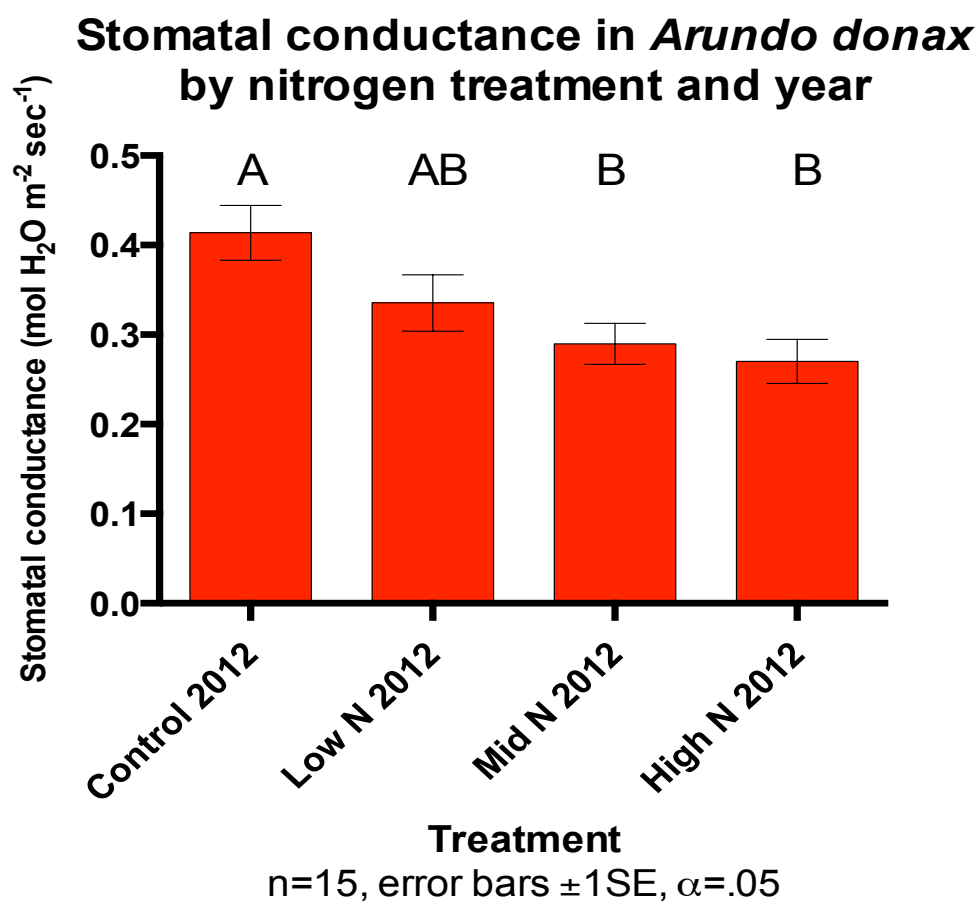


All treatment groups that included N plus other elements showed lower stomatal conductance compared to the control group, with the exception of the $\mathrm{N}-\mathrm{KSO}_{4}$ treatment group, which had approximately $2 \%$ higher stomatal conductance $(.76 \mathrm{~mol}$ $\mathrm{H}_{2} \mathrm{O} \mathrm{m} \mathrm{sec}^{-1}$ ) than the control plants. However, none of the differences were significant (post hoc, Tukey's HSD).

Figure 18. Leaf stomatal conductance rate of Arundo donax by addition of elemental fertilizers -The mean leaf stomatal conductance rate, \pm one s.e., for Arundo donax grown with various elemental fertilizers in 2013. No groups were significantly different from the control group (Tukey's HSD).

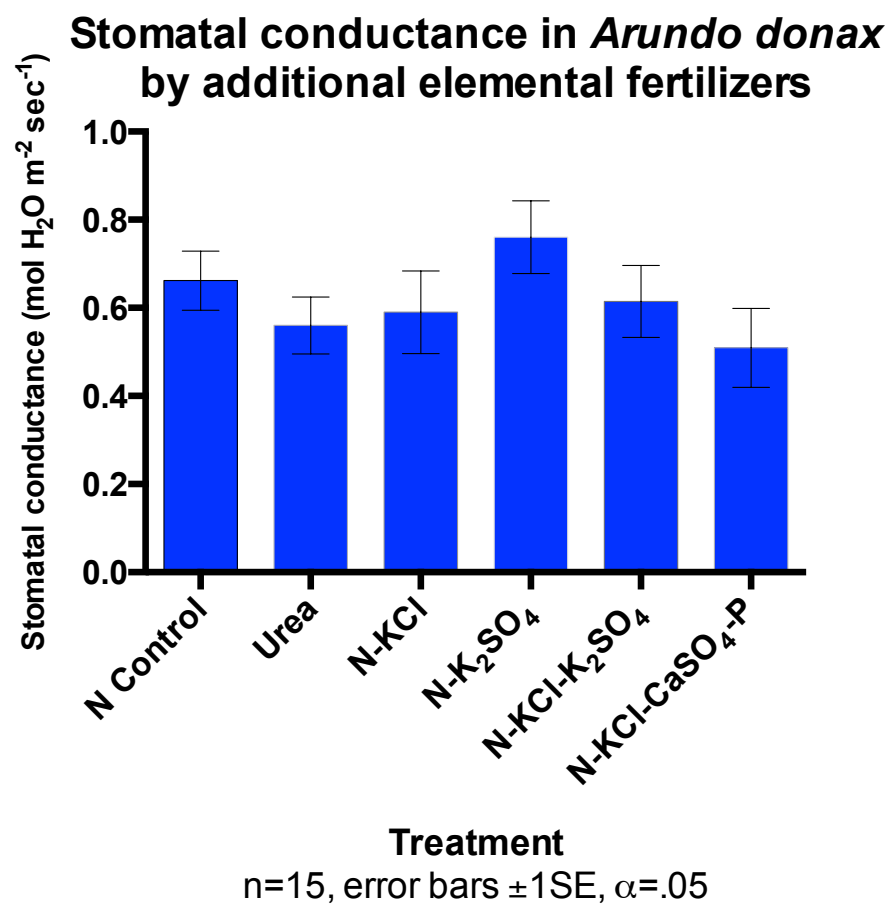


Nitrogen application: When the data was batched to isolate the effects of adding nitrogen (by including only the control, low- $\mathrm{N}$ and high-N treatment groups) a stronger effect on stomatal conductance in $A$. donax was observed.

Figures 19A and 19B. Effect of nitrogen amendment on leaf stomatal conductance in Arundo donax by individual years -The mean photosynthesis rate, \pm one s.e., for Arundo donax as grouped by +/- nitrogen. Figure 19A (red bars) indicates 2012 data and figure 19B (blue bars) indicates 2013 data. Effect of nitrogen was significant in 2012 ( $P<.01$, students $t$ Test) but was not significant in 2013 (students t Test).
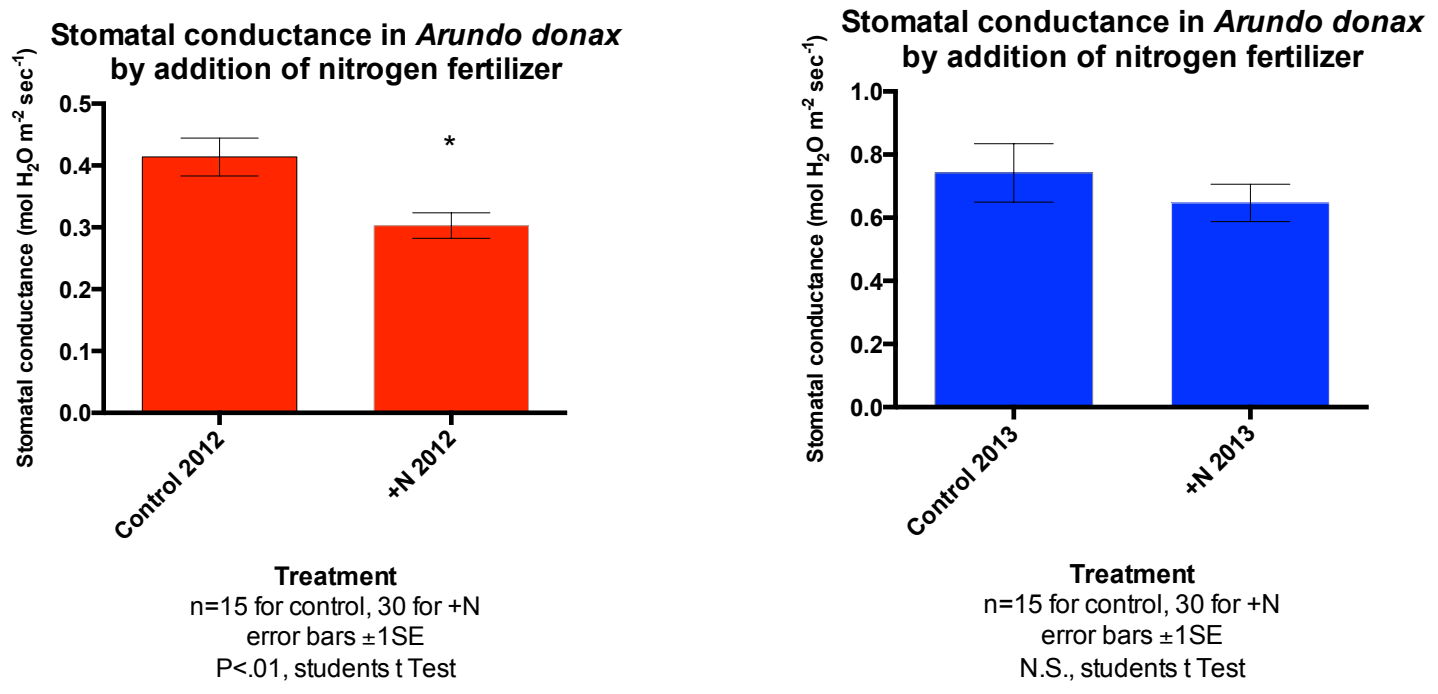

In 2012, under dry and cool conditions, stomatal conductance decreased by approximately $36 \%$ with the addition of nitrogen. This difference was statistically significant $(P<.01$, students t Test). In 2013, a similar decrease in stomatal conductance with the application of nitrogen was observed, however the effect was smaller (slightly less than $14 \%$ decrease) and was not statistically distinguishable from the possibility of random sampling error (students t Test). 
Sampling year differences: Stomatal conductance was higher in all treatment groups in 2013 (wet soil conditions) compared to 2012 (dry conditions). In the control group stomatal conductance increased by $79 \%$ between 2012 and $2013\left(.74 \mathrm{~mol} \mathrm{H}_{2} \mathrm{O} \mathrm{m}^{-2}\right.$ $\mathrm{sec}^{-1}$ in 2013, and $.41 \mathrm{~mol} \mathrm{H}_{2} \mathrm{O} \mathrm{m}^{-2} \mathrm{sec}^{-1}$ in 2012) however, due to high withintreatment error this increase was not statistically significant. In the mid N group, mean conductance nearly doubled from 2012 to $2013\left(0.34 \mathrm{~mol} \mathrm{H}_{2} \mathrm{O} \mathrm{m}^{-2} \mathrm{sec}^{-1}\right.$ in 2012 in 2012 and $0.66 \mathrm{~mol} \mathrm{H}_{2} \mathrm{O} \mathrm{m}^{-2} \mathrm{sec}^{-1}$ in 2012 in 2013;) but was also not statistically significant. The largest year-to-year increase in stomatal conductance was seen in the high $\mathrm{N}$ group (0.27 mol H $\mathrm{H} \mathrm{m}^{-2} \mathrm{sec}^{-1}$ in 2012 and $0.63 \mathrm{~mol} \mathrm{H}_{2} \mathrm{O} \mathrm{m}^{-2} \mathrm{sec}^{-1}$ in 2013) an increase of nearly $134 \%$, which was statistically significant $(P<.05$, students t Test). When the three treatment groups that were sampled both years (control, low $\mathrm{N}$ and high $\mathrm{N}$ ) were combined to isolate the effects of soil moisture, a large and significant increase in stomatal conductance was observed. Compared to the dry soil conditions of 2012, the moist soil conditions of 2013 lead to a $103 \%$ increase in stomatal conductance $(P<.0001$, students $t$ Test). 
Figure 20. Leaf stomatal conductance rate of Arundo donax by year-The mean stomatal conductance rate, \pm one s.e., for Arundo donax from the treatment groups that were grown in both sample years. Years were significantly different from each other $(\mathrm{P}<.0001$, students $\mathrm{t}$ Test).

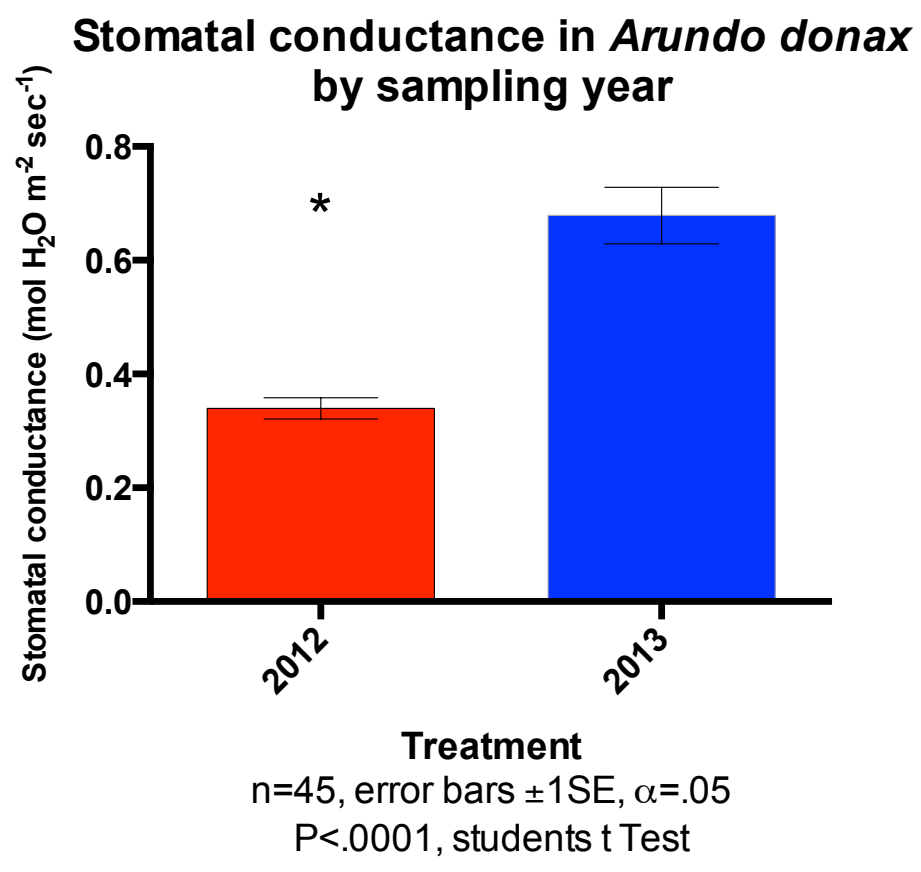


Air Temperature: Mean stomatal conductance was nearly $13 \%$ lower in the high temperature group than the low temperature plants $\left(.52 \mathrm{~mol} \mathrm{H}_{2} \mathrm{O} \mathrm{m}^{-2} \mathrm{sec}^{-1}\right.$ in low temp. plants and $.46 \mathrm{~mol} \mathrm{H}_{2} \mathrm{O} \mathrm{m}^{-2} \mathrm{sec}^{-1}$ in high temp. plants) but this difference was not significant (students t Test).

Figure 21. Effect of long term temperature acclimation on leaf stomatal conductance rate in Arundo donax - The mean stomatal conductance rate, \pm one s.e., for Arundo donax grown with an average temperature difference of $2^{\circ} \mathrm{C}$ in greenhouse conditions. Treatments were not significantly different from each other (students t Test).

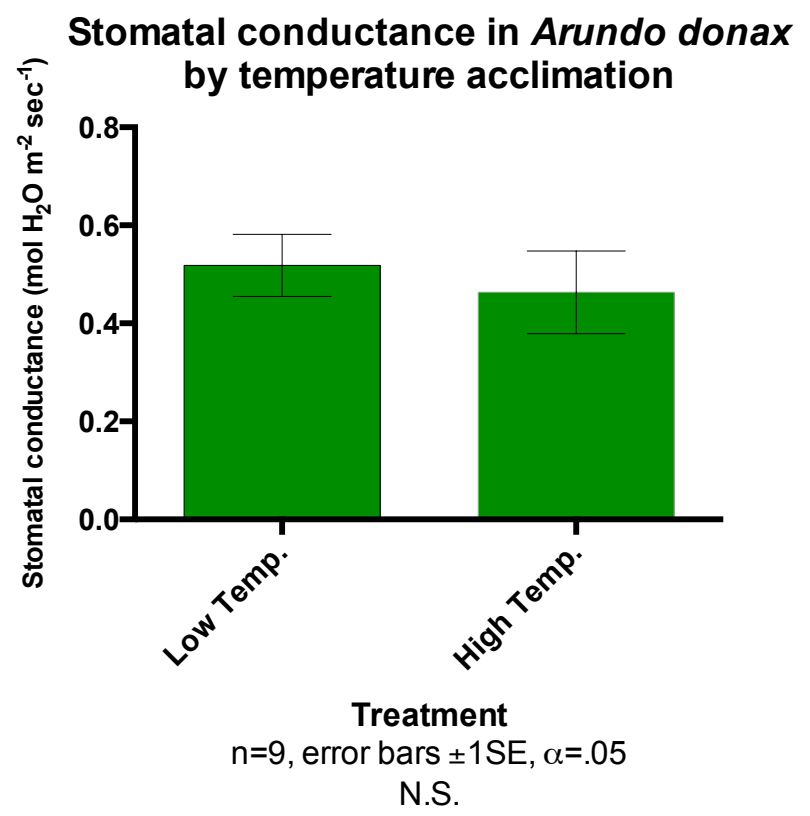




\section{D: Effect of fertilizer, water management and temperature on leaf water use efficiency in $A$. donax}

Because the application of fertilizers to $A$. donax lead to both an increase in photosynthesis and a decrease in stomatal conductance, there was a positive relationship between fertilizer amendment and water use efficiency (WUE) which is calculated as micromoles of carbon assimilated (photosynthesis) per mole of water lost to transpiration. WUE in $A$. donax was significantly affected by nitrogen application in 2012 (dry, cool conditions) as well as by the changes in soil moisture and temperature between 2012 and 2013 sampling periods, but was not significantly affected by temperature.

HAREC field data: In both 2012 and 2013 The WUE of control plants was lower than all the $+\mathrm{N}$ treatment groups. The highest WUE was recorded in the 2012 high- $\mathrm{N}$ treatment group plants, which on average were able to fix 7.59 umol of CO2 per mol of $\mathrm{H}_{2} \mathrm{O}$ loss, while the control plants in 2012 were able to fix only $4.35 \mu \mathrm{mol} \mathrm{CO} 2$ for the same amount of $\mathrm{H}_{2} \mathrm{O}$. In 2012 the WUE of control plants was significantly different from both the mid and high $\mathrm{N}$ treatment groups $(\mathrm{P}<.01$ for control to mid-N and $\mathrm{P}<.001$ for control to high-N; all post hoc Tukey's HSD). 
Figure 22. Leaf water use efficiency of Arundo donax by nitrogen treatment and year - The mean water use efficiency, \pm one s.e., for Arundo donax grown with different amounts of nitrogen fertilizer in two different years. Red bars indicate 2012 data and blue bars indicate 2013 data. If treatments do not share any of the same letters they are significantly different from each other at $\mathrm{P}<.05$ (Tukey's HSD).

Water use efficiency of Arundo donax by nitrogen treatment and year

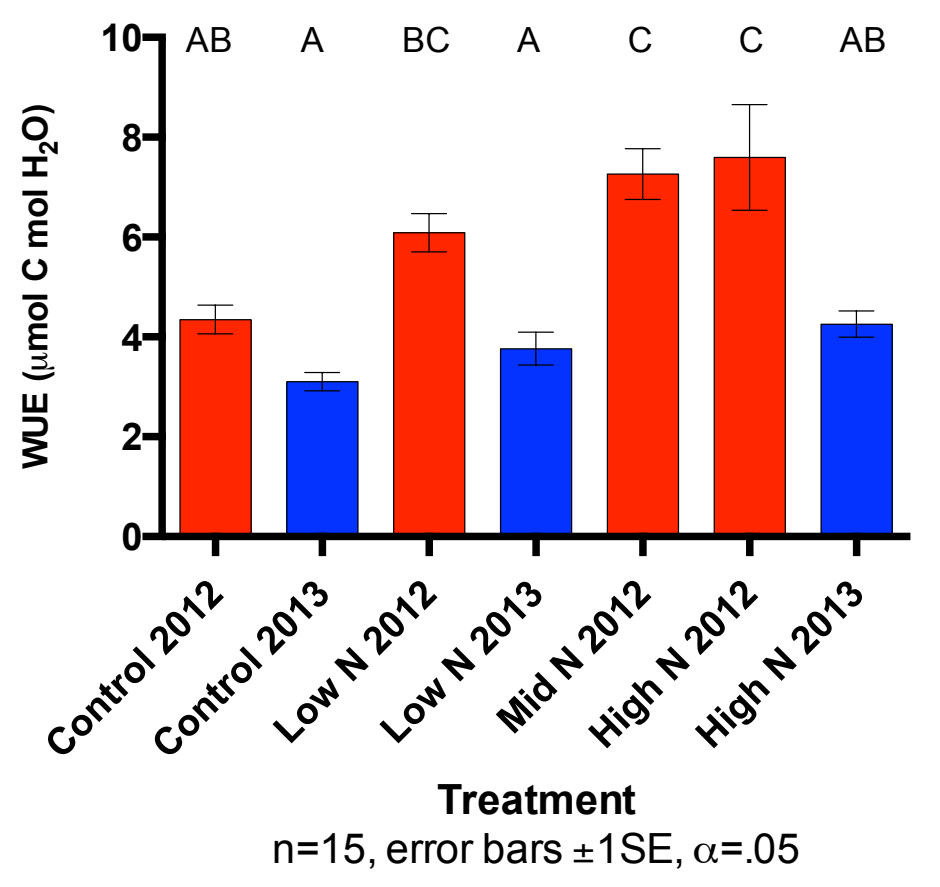

In 2013 a similar pattern was found in the data. WUE increased with the addition of nitrogen and other elemental fertilizers; the control plants were able to fix $3.1 \mu \mathrm{mol}$ C for each mol $\mathrm{H}_{2} \mathrm{O}$ lost to transpiration, while the high $\mathrm{N}$ group was able to fix 4.25 umol C for the same amount of water loss. The highest WUE for 2013 treatment 
groups was recorded in the $\mathrm{N}-\mathrm{KCl}-\mathrm{CaSO}_{4}-\mathrm{P}$ treatment plants, which fixed $4.30 \mu \mathrm{mol} \mathrm{C}$ per $\mathrm{mol} \mathrm{H}_{2} \mathrm{O}$

loss. However, due to sample error in WUE measurements in 2013 , differences

between individual treatment groups were not significant (post hoc, Tukey's HSD).

Figure 23. Leaf water use efficiency of Arundo donax by addition of elemental fertilizers-The mean water use efficiency, \pm one s.e., for Arundo donax grown with various elemental fertilizers in 2013 . No groups were significantly different from the control group (Tukey's HSD).

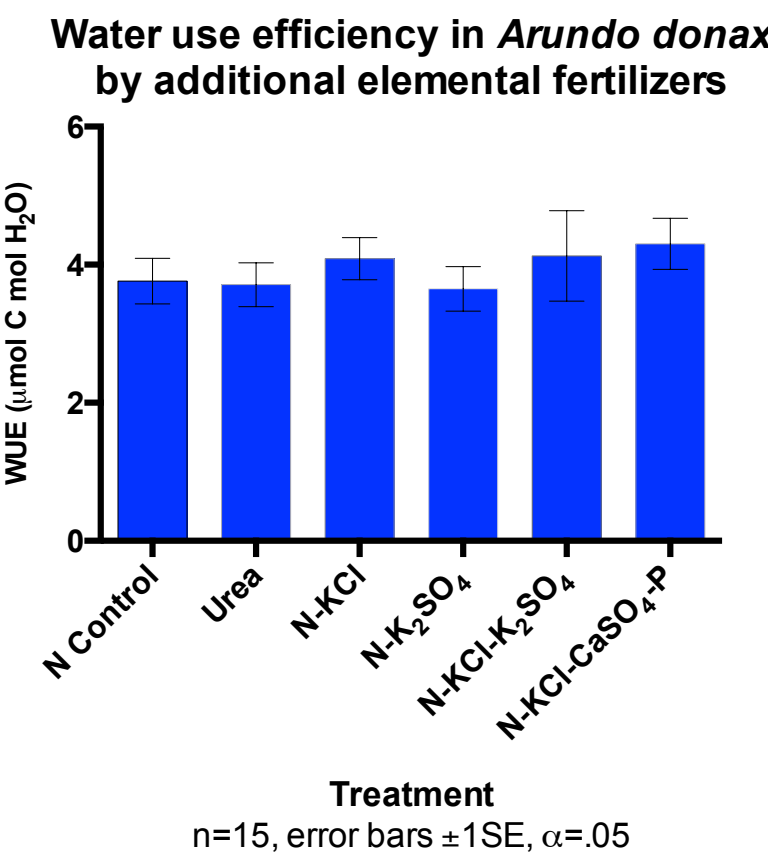


Nitrogen application: Three treatment groups were measured in both 2012 and 2013

(control, low-N and high-N). When the data from only these treatment groups is

batched to determine the effect of nitrogen amendment, the same relationship is

observed in both years; the addition of nitrogen increases the WUE of $A$. donax.

Figures 24A and 24B. Effect of nitrogen amendment on leaf water use efficiency in Arundo donax by individual years-The mean water use efficiencies, \pm one s.e., for Arundo donax as grouped by +/- nitrogen. Figure 24A (red bars) indicates 2012 data and figure 24B (blue bars) indicates 2013 data. Effect of nitrogen was significant in both $2012(P<.001$, students $t$ Test $)$ and $2013(P<.01$, students $t$ Test).
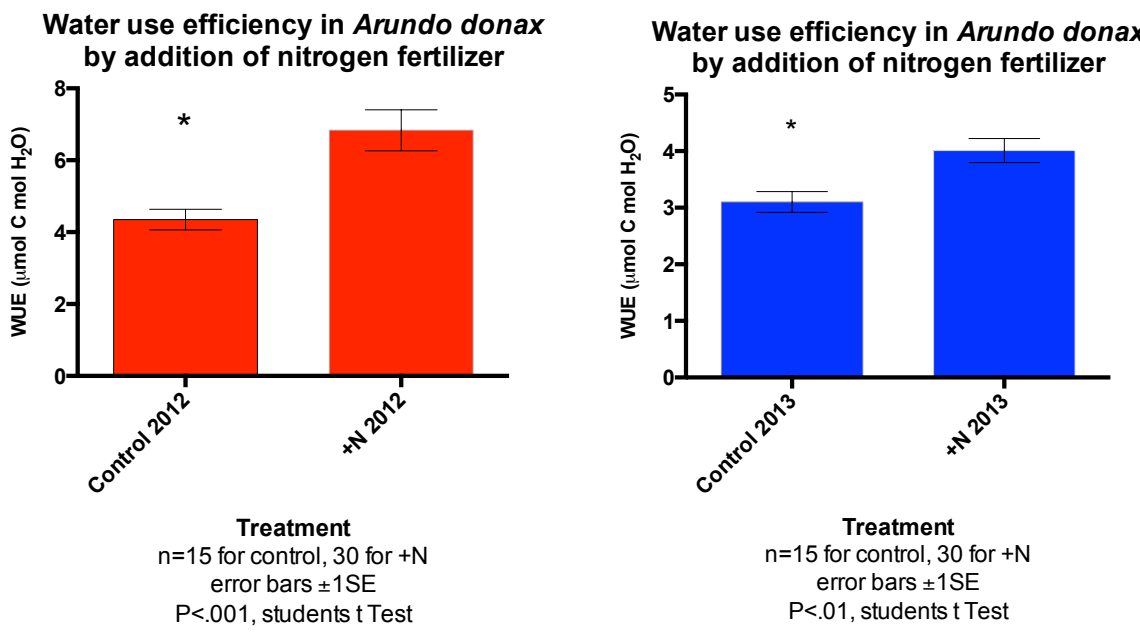

In 2012 the addition of nitrogen caused a 57\% increase in WUE, a difference that was statistically significant ( $P<.001$, students $t$ Test). In 2013, with wet and warmer conditions, a similar, but smaller increase in WUE efficiency (approximately 29\%) was observed when nitrogen was added. This increase in WUE was also statistically significant $(P<.01$, students t Test). 
Sampling year differences: When comparing the three treatment groups that were sampled both years a strong decrease in WUE was measured between 2012 (dry soil, cool air conditions) and 2013 (wet soil, warmer air conditions). Between the two years, overall WUE decreased $62 \%\left(3.71 \mu \mathrm{mol} \mathrm{C} \mathrm{mol} \mathrm{H}_{2} \mathrm{O}^{-1}\right.$ in 2013 vs. $6.01 \mu \mathrm{mol} \mathrm{C}$ mol $\mathrm{H}_{2} \mathrm{O}^{-1}$ in 2012) a difference that was statistically significant $(P<.0001$, students $\mathrm{T}$ test).

Figure 25. Leaf water use efficiency of Arundo donax by year-The mean water use efficiencies, \pm one s.e., for Arundo donax from the treatment groups that were grown in both sample years. Years were significantly different from each other $(P<.0001$, students $t$ Test).

Water use efficiency in Arundo donax by sampling year

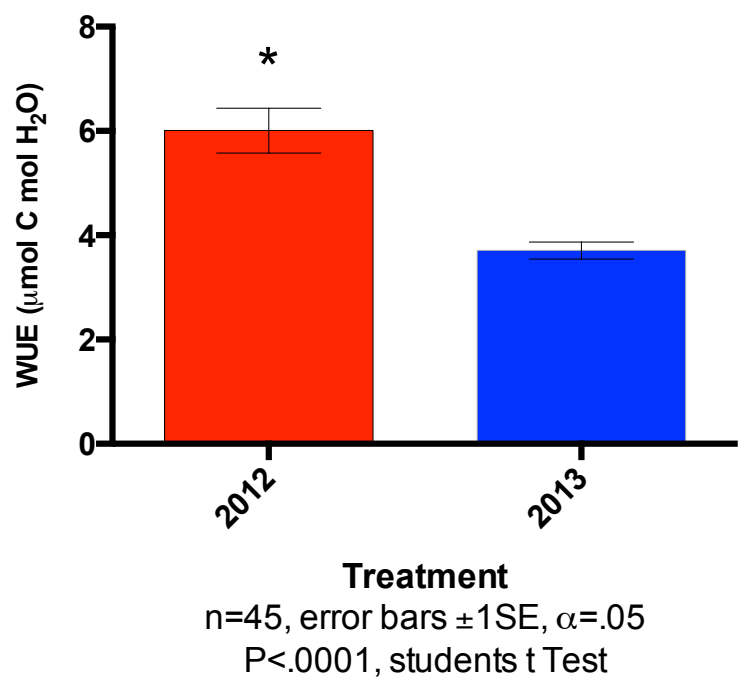


Air Temperature: Water use efficiency increased slightly nearly $4 \%$ in the high temperature plants compared to the low temperature group $\left(3.15 \mu \mathrm{mol} \mathrm{C} \mathrm{mol} \mathrm{H}_{2} \mathrm{O}^{-1}\right.$ in high temp. plants compared to $3.04 \mu \mathrm{mol} \mathrm{C} \mathrm{mol} \mathrm{H}_{2} \mathrm{O}^{-1}$ in low temp. plants), however, this difference was not statistically significant (students t Test).

Figure 26. Effect of long term temperature acclimation on leaf water use efficiency in Arundo donax - The mean water use efficiencies, \pm one s.e., for Arundo donax grown with an average temperature difference of $2^{\circ} \mathrm{C}$ in greenhouse conditions. Treatments were not significantly different from each other (students t Test).

Water use efficiency in Arundo donax by temperature acclimation

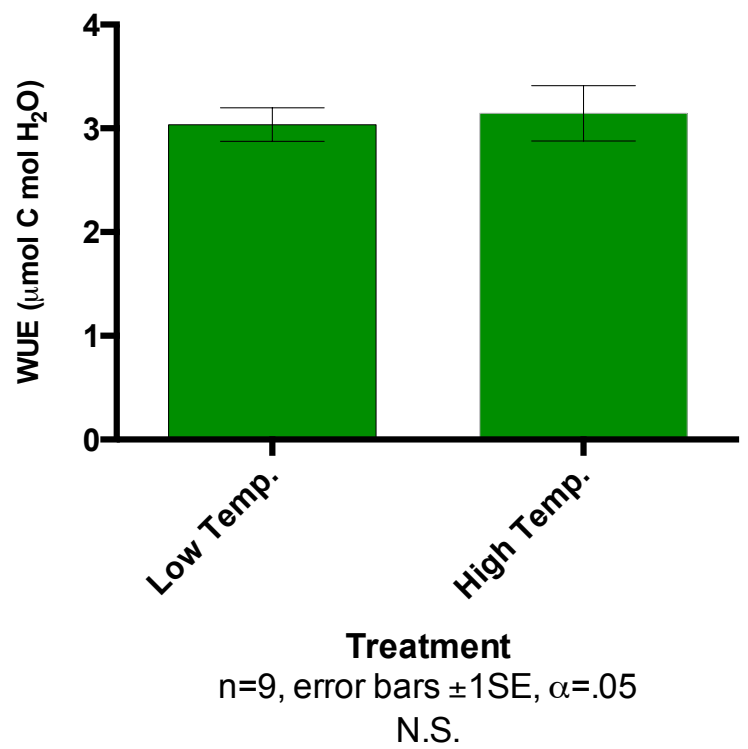


3.E: Effect of fertilizer, water management and temperature on specific leaf mass in in A. donax

In order to determine specific leaf mass ( $\mathrm{g} \mathrm{m}^{-2}$ dry weight of leaf tissue) leaf tissue was sampled from all A. donax plants included in the HAREC field trials in both 2013 and 2014. Some variation in mean SLM was observed in the various +fertilizer treatment groups but these differences were not significant for treatments within the same year (post hoc Tukey's HSD). Specific leaf mass was also not significantly affected by the addition of nitrogen. Between the two sampling years, 2012 and 2013, differences in mean SLM were statistically significant (post hoc Tukey's HSD).

HAREC field trials: In the various fertilizer addition treatment groups sampled as part of the HAREC field trials, SLM varied from a low value of $191.4 \mathrm{~g} \mathrm{~m}^{-2}$ in the $\mathrm{N}-\mathrm{K}_{2} \mathrm{SO}_{4}$ treatment group, to a high value of $230.4 \mathrm{~g} \mathrm{~m}^{-2}$ for plants in the 2012 mid-N group. Among 2012 samples, the control group had the lowest mean SLM at $222 \mathrm{~g} \mathrm{~m}^{-2}$. None of the differences between treatment groups in 2012 were statistically significant (post hoc Tukey's HSD). 
Figure 27. Specific leaf mass of Arundo donax by nitrogen treatment and year-The mean specific leaf mass, \pm one s.e., for Arundo donax grown with different amounts of nitrogen fertilizer in two different years. Red bars indicate 2012 data and blue bars indicate 2013 data. If treatments do not share any of the same letters they are significantly different from each other at $\mathrm{P}<.05$ (Tukey's HSD).

\section{Specific Leaf Mass in Arundo donax by nitrogen treatment and year}

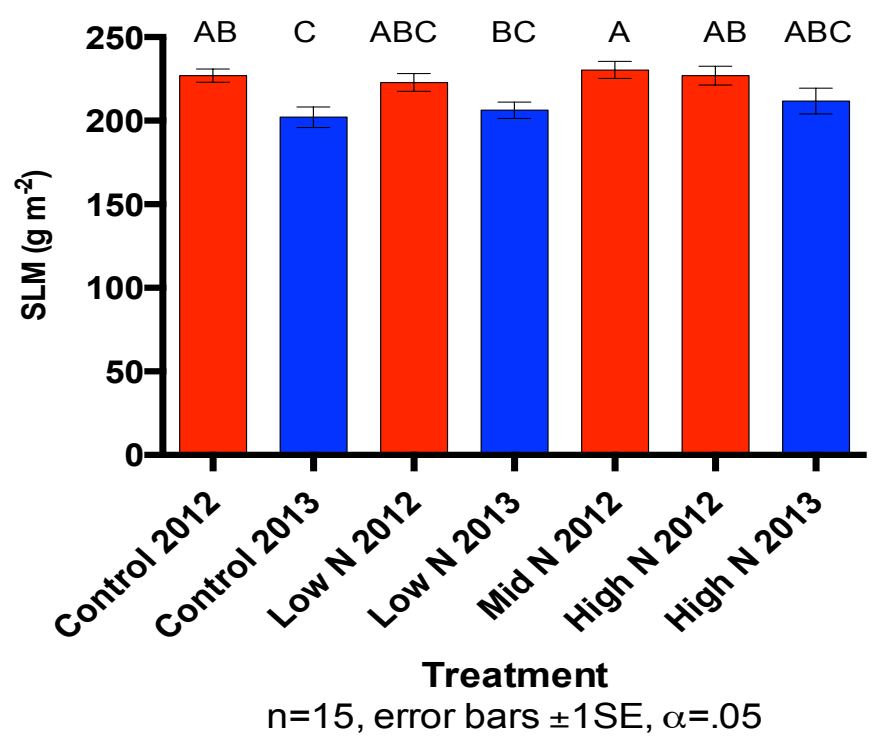


For the treatment groups sampled in 2013, SLM of the control plants was $202.1 \mathrm{~g} \mathrm{~m}^{-2}$, which did not vary significantly from any other 2013 fertilizer treatment group (post hoc Tukey's HSD). There were no other significant differences among 2013 treatment groups. Between the two years, the control groups differed from each other by nearly $25 \mathrm{~g} \mathrm{~m}^{-2}$, a difference that was statistically significant $(P<.05$, post hoc Tukey's HSD).

Figure 28. Specific leaf mass of Arundo donax by addition of elemental fertilizersThe mean specific leaf mass, \pm one s.e., for Arundo donax grown with various elemental fertilizers in 2013. No groups were significantly different from the control group (Tukey's HSD).

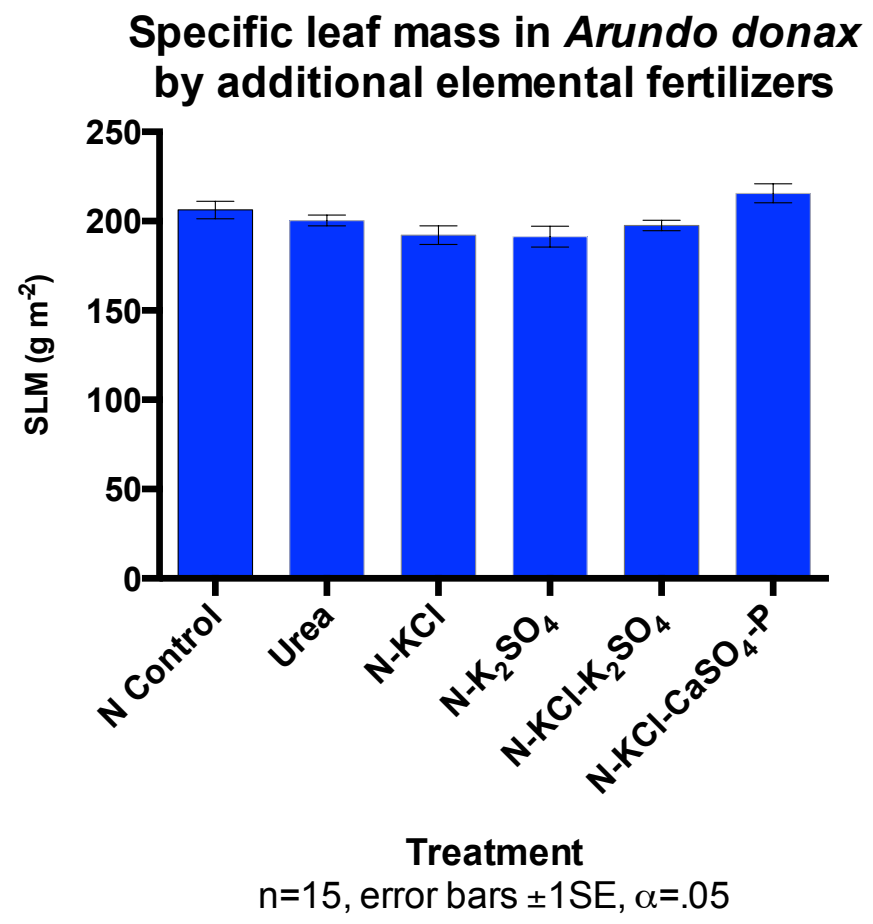


Nitrogen application: When the HAREC field data is analyzed for the specific effects of increased nitrogen application on SLM in A. donax (including only the treatments that were measured in both years: control, low- $\mathrm{N}$, and high-N), no significant effect was detected for either 2012 or 2013.

Figure 29. Effect of nitrogen amendment on specific leaf mass in Arundo donax by year-The mean specific leaf mass, \pm one s.e., for Arundo donax as grouped by +/nitrogen. Red bars indicate 2012 data and blue bars indicate 2013 data. If treatments do not share any of the same letters they are significantly different from each other at $\mathrm{P}<.05$ (Tukey's HSD).

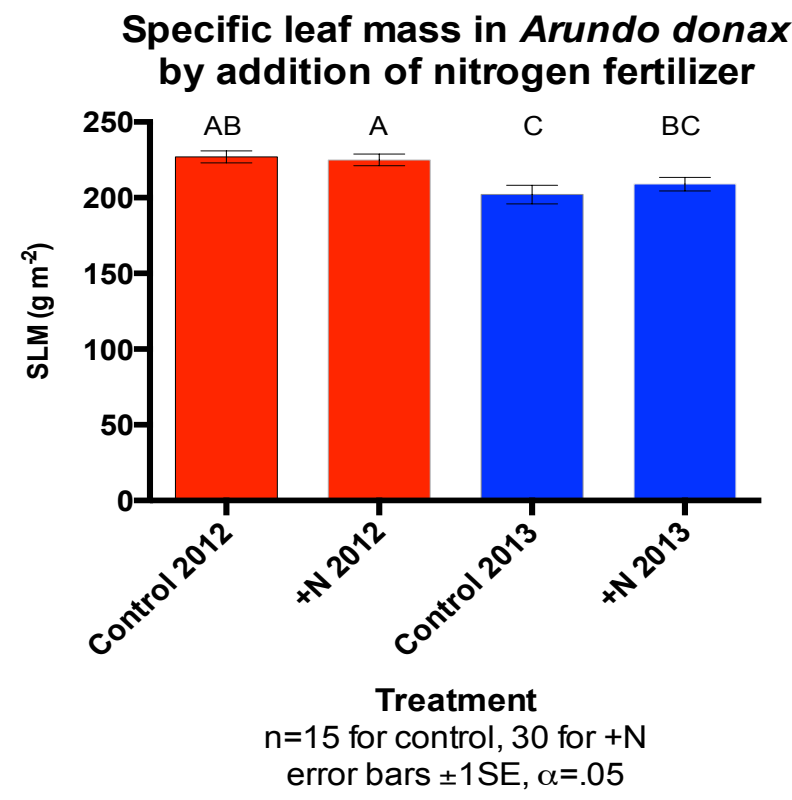

In 2012, a small decrease in SLM was measured in the plants that received additional $\mathrm{N}$ application (227.0 $\mathrm{g} \mathrm{m}^{-2}$ in control plants, $225.0 \mathrm{~g} \mathrm{~m}^{-2}$ in $+\mathrm{N}$ plants), but this effect was not significant (post hoc Tukey's HSD). In 2013 a small increase in SLM was 
detected in plants that received additional nitrogen fertilizer $\left(202.1 \mathrm{~g} \mathrm{~m}^{-2}\right.$ in control plants, $209.0 \mathrm{~g} \mathrm{~m}^{-2}$ in $+\mathrm{N}$ plants), but this effect was also not significant (post hoc, Tukey's HSD).

Sampling year differences: Between 2012 (dry, cool conditions) and 2013 (wet, hot conditions) there was a large change in SLM. When only the three treatments that were sampled in both years (control, low $\mathrm{N}$ and high $\mathrm{N}$ ) are considered, SLM decreased more than $8 \%\left(225.6 \mathrm{~g} \mathrm{~m}^{-2}\right.$ in $2012,206.7 \mathrm{~g} \mathrm{~m}^{-2}$ in 2013$)$ this change was statistically significant $(\mathrm{P}<.0001$, students $\mathrm{t}$ Test).

Figure 30. Specific leaf mass of Arundo donax by year-The mean specific leaf mass, \pm one s.e., for Arundo donax from the treatment groups that were grown in both sample years. Years were significantly different from each other $(P<.001$, students $t$ Test).

Specific leaf mass in Arundo donax by sampling year

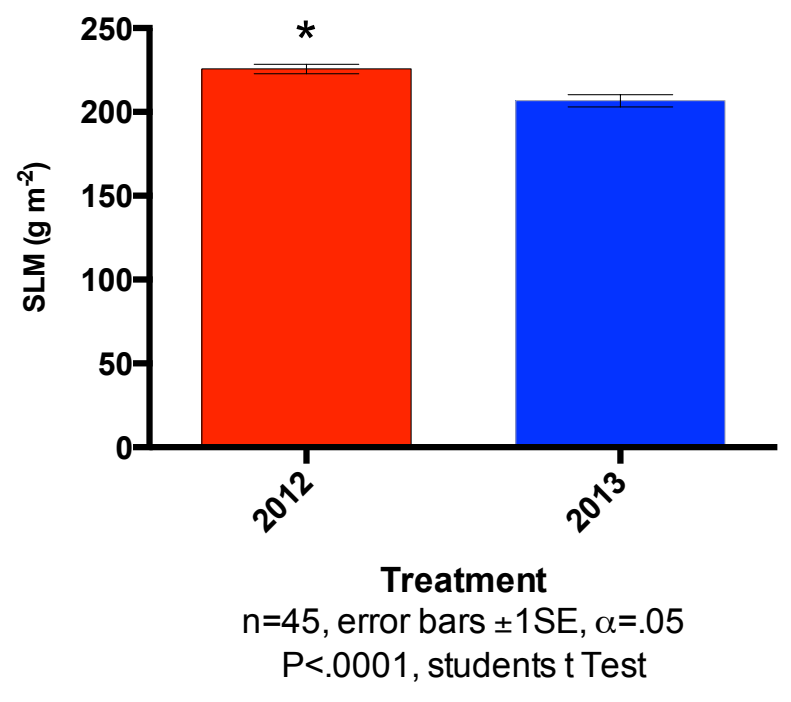


3.F: Effect of fertilizer, water management, temperature, canopy height and light level on isoprene emission in A. donax

Isoprene emission in A. donax, (recorded as nmol of isoprene $\cdot \mathrm{m}^{-2}$ leaf tissue $\cdot \sec ^{-1}$ ) varied dramatically across our trials. The lowest emission rate was recorded in the 2012 control treatment plants, which averaged $16.96 \mathrm{nmol} \mathrm{m}^{-2} \mathrm{sec}^{\mathrm{i}}$ of isoprene emission, while the highest emission rates were recorded in the 2013 control plants, which averaged $253.54 \mathrm{nmol}$ isoprene $\mathrm{m}^{-2}$ se, representing a nearly 15 -fold increase in isoprene flux.

HAREC field trials: Isoprene flux from $A$. donax in our HAREC field trials responded to changes in Nitrogen treatment as well as the varied conditions between our two sampling years.

As mentioned above, the control treatments in 2012 and 2013 were the lowest and highest emitting treatment groups, respectively and were significantly different from each other $(P<.001$, post hoc Tukey's HSD). When the other $+\mathrm{N}$ treatments that were sampled both years (low $\mathrm{N}$ and high $\mathrm{N}$ ) are compared to each other, the same relationship is present; isoprene flux in 2013 was higher than in 2012 for each pair of treatments, (in fact, all treatment groups sampled in 2013 had higher mean isoprene flux than all groups measured in 2012) however, due to high sample error, the year-to-year comparison of low- $\mathrm{N}$ and high- $\mathrm{N}$ groups were not significantly different from each other (post hoc, Tukey's HSD). 
Figure 31. Isoprene emission rate of Arundo donax by nitrogen treatment and year-The mean isoprene emission rate, \pm one s.e., for Arundo donax grown with different amounts of nitrogen fertilizer in two different years. Red bars indicate 2012 data and blue bars indicate 2013 data. If treatments do not share any of the same letters they are significantly different from each other at $\mathrm{P}<.05$ (Tukey's HSD).

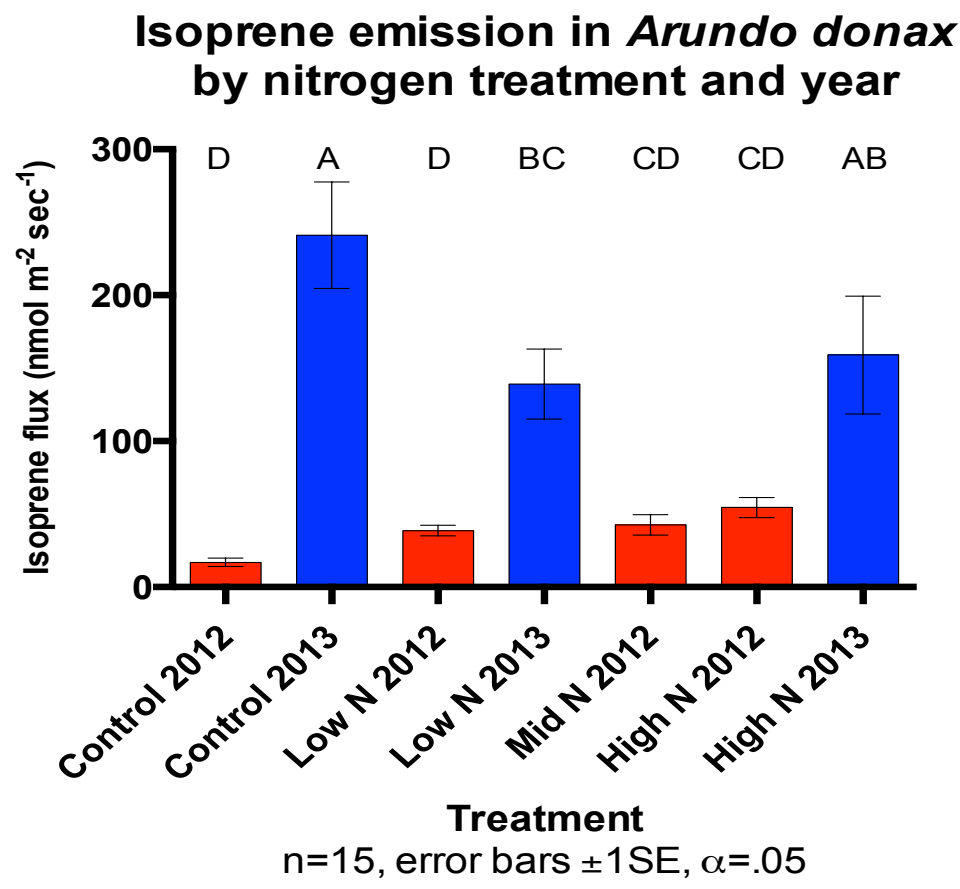

The large range of isoprene emission rates as well as the high variance in the 2013 samples suppresses the effect of the differences among the 2012 treatments. When the 2012 treatments are examined independently a more significant affect of individual nitrogen treatments is apparent; the control group is significantly different from all other $+\mathrm{N}$ treatment groups (post hoc Tukey's HSD). 
Figure 32. Isoprene emission rate of Arundo donax by nitrogen treatment, 2012 only-The mean isoprene emission rate, \pm one s.e., for Arundo donax grown with different amounts of nitrogen fertilizer in 2012. If treatments do not share any of the same letters they are significantly different from each other at $\mathrm{P}<.05$ (Tukey's HSD).

\section{Isoprene emission in Arundo donax by nitrogen treatment and year}

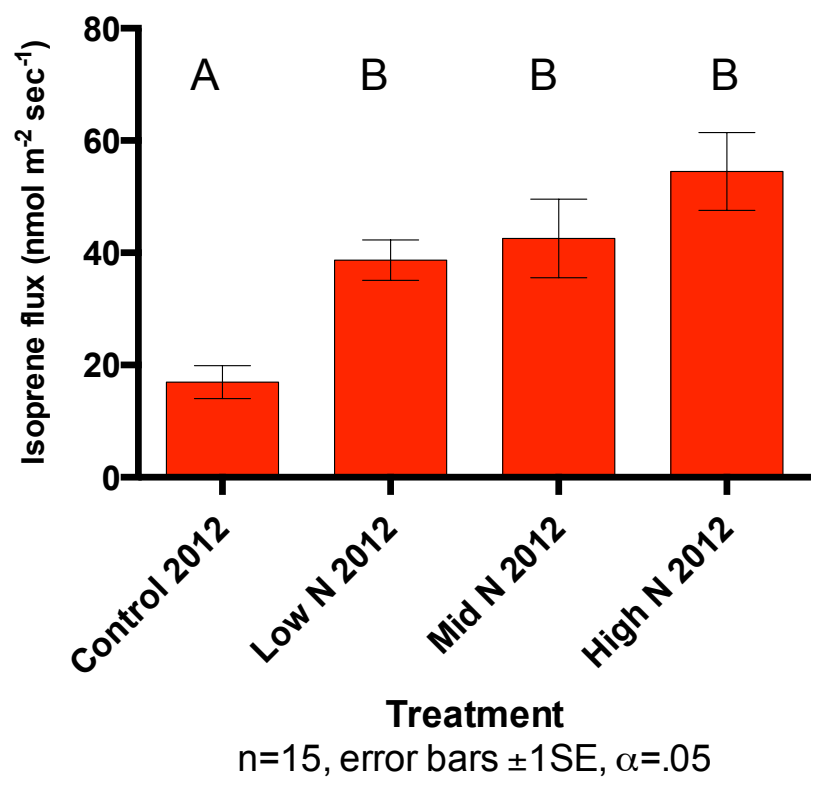


The addition of other elemental fertilizers (other than N) in our 2013 trials did not appear to significantly change isoprene emission in $A$. donax as no trend was apparent and no significant differences existed between any of the additional element treatment groups and the control, low- $\mathrm{N}$ or high- $\mathrm{N}$ treatment groups (post hoc, Tukey's HSD).

Figure 33. Isoprene emission rate of Arundo donax by addition of elemental fertilizers -The mean isoprene emission rate, \pm one s.e., for Arundo donax grown with various elemental fertilizers in 2013. No groups were significantly different from the control group (Tukey's HSD).

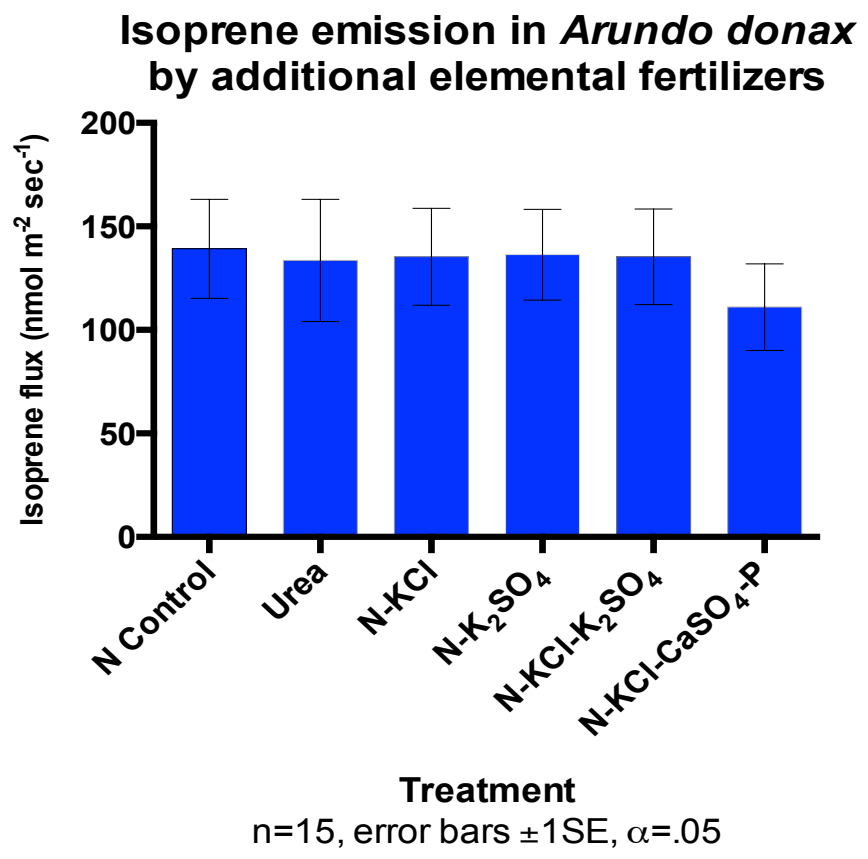


Nitrogen application: The addition of nitrogen fertilizer significantly affected isoprene emission in Arundo donax. In 2012 the addition of nitrogen nearly tripled isoprene emission in $2012\left(16.96 \mathrm{nmol} \mathrm{m}^{-2} \mathrm{sec}^{-1}\right.$ for control treatments, $46.61 \mathrm{nmol}$ $\mathrm{m}^{-2} \mathrm{sec}^{-1}$ for $+\mathrm{N}$ treatments $)$ a difference that was strongly significant $(\mathrm{P}<.0001$, students t Test). In 2013, the addition of nitrogen caused a decrease in isoprene emission from $241.14 \mathrm{nmol} \mathrm{m} 2 \mathrm{sec}^{-1}$ in the control plants to $149.14 \mathrm{nmol} \mathrm{m}^{-2} \mathrm{sec}^{-1}$ in the $+N$ plants. This difference was also significant $(P<.05$, students $t$ Test).

Figures 34A and 34B. Effect of nitrogen amendment on isoprene emission rate in Arundo donax by individual years - The mean isoprene emission rates, \pm one s.e., for Arundo donax as grouped by +/- nitrogen. Figure 34A (red bars) indicates 2012 data and figure 34B (blue bars) indicates 2013 data. Effect of nitrogen was significant in both 2012 ( $P<.0001$, students $t$ Test) and 2013 ( $P<.05$, students $t$ Test).
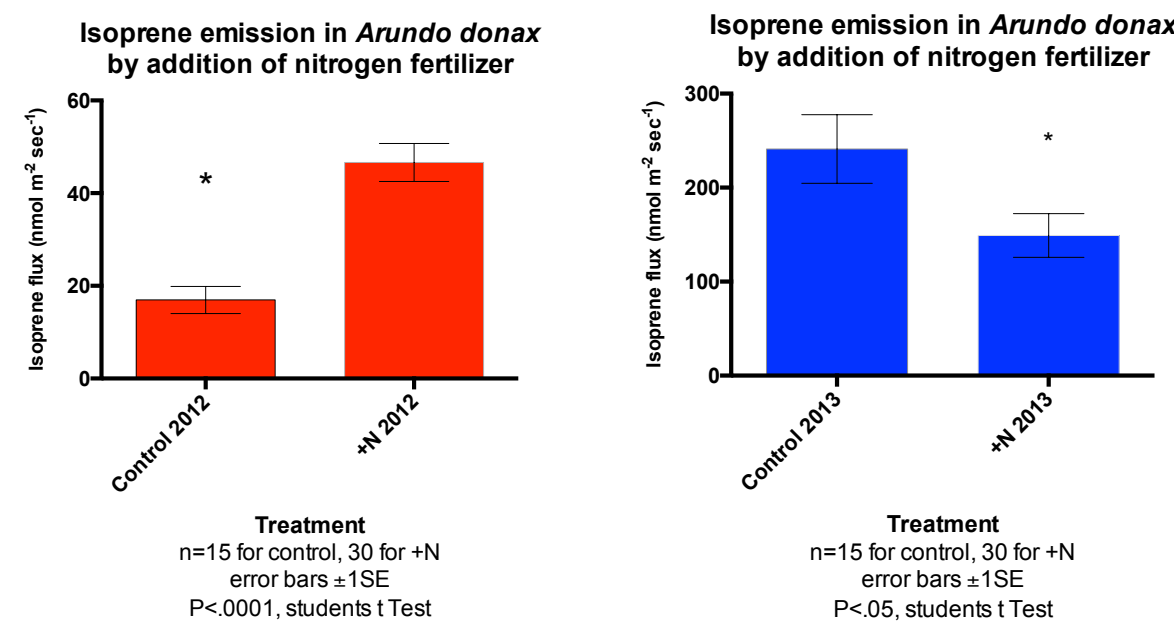

Sampling year differences: In comparing the treatments that were sampled in both 2012 and 2013 (control, low N and high N) in order to determine how much isoprene emission was effected by the factors that differed between the two sampling periods 
(soil moisture, air temperature, relative humidity and sampling dates) a profound difference is clear in the data; isoprene flux from A. donax was much higher in 2013 than in 2012. The mean isoprene flux from 2012 was $36.73 \mathrm{nmol} \mathrm{m}^{-2} \mathrm{sec}^{-1}$, and in 2013 it was $179.79 \mathrm{nmol} \mathrm{m}^{-2} \mathrm{sec}^{-1}$, an increase of 389\%. This increase was statistically significant $(\mathrm{P}<.0001$, students $\mathrm{t}$ Test $)$.

Figure 35. Isoprene emission rate of Arundo donax by year-The mean isoprene emission rate, \pm one s.e., for Arundo donax from the treatment groups that were grown in both sample years. Years were significantly different from each other $(\mathrm{P}<.0001$, students $\mathrm{t}$ Test).

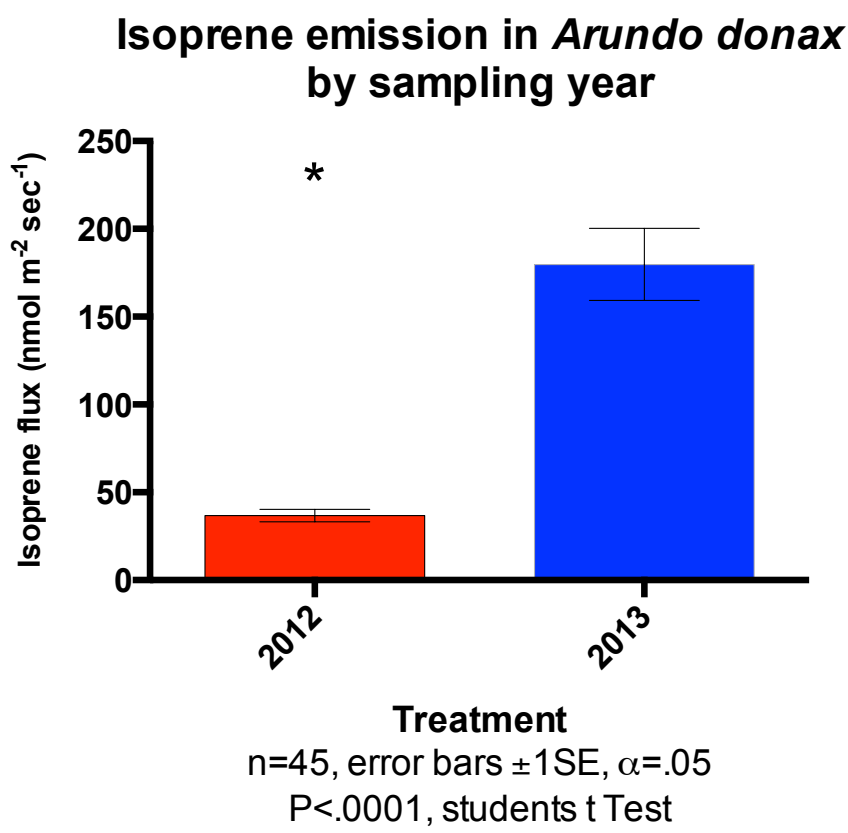

Air temperature: Our data from $A$. donax grown at different temperatures in the EPA growth chamber trials show that a modest increase in temperature (approximately $2^{\circ} \mathrm{C}$ ) lead to a small increase in isoprene emission. Mean isoprene emission for the 
low temperature plants was $16.40 \mathrm{nmol} \mathrm{m}^{-2} \mathrm{sec}^{-1}$ and $19.47 \mathrm{nmol} \mathrm{m}^{-2} \mathrm{sec}^{-1}$ for the high temperature plants. This approximately $19 \%$ increase approached statistical significance $(P=.0516$, students $t$ Test) but ultimately was not distinguishable from possible sampling error.

Figure 36. Effect of long term temperature acclimation on isoprene emission rate in Arundo donax -The mean isoprene emission rate, \pm one s.e., for Arundo donax grown with an average temperature difference of $2^{\circ} \mathrm{C}$ in greenhouse conditions. Treatments were not significantly different from each other $(P=.0516$, students $t$ Test).

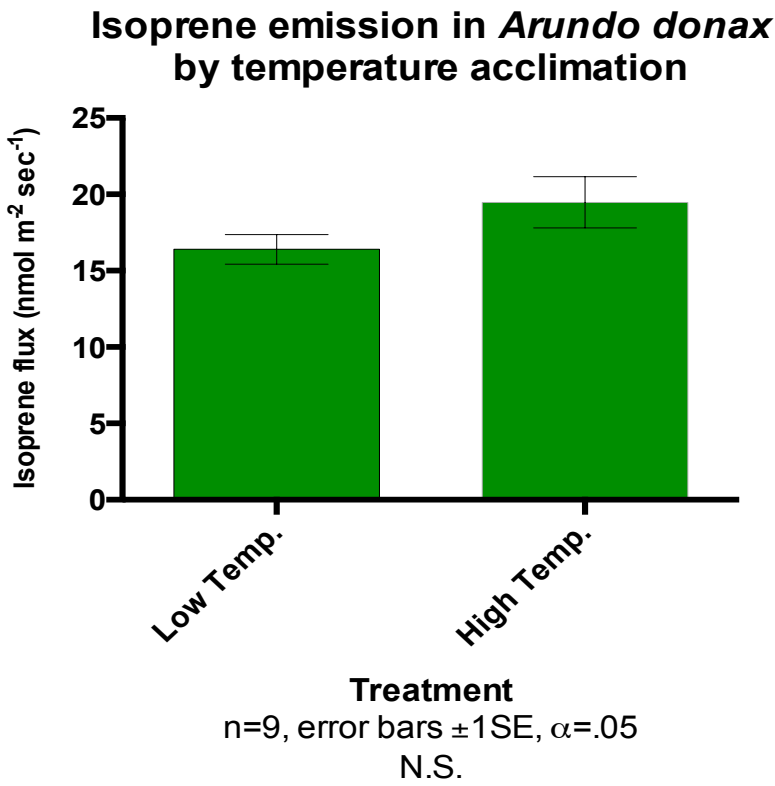


Isoprene emission by canopy height: Isoprene emission rates did not show a strong relationship with canopy height. For samples from the control treatment there was a small trend toward decreases mean isoprene emission levels as canopy height increased. However this relationship was statistically weak and was strongly influenced by a single high emission sample from the lower canopy. The relationship between isoprene emission and canopy height was not significant $(P=.387$, linear regression).

Figure 37. Isoprene emission by leaf height in Arundo donax, control treatmentThe effect of canopy location on isoprene emission rate in Arundo donax in control treatment plants.

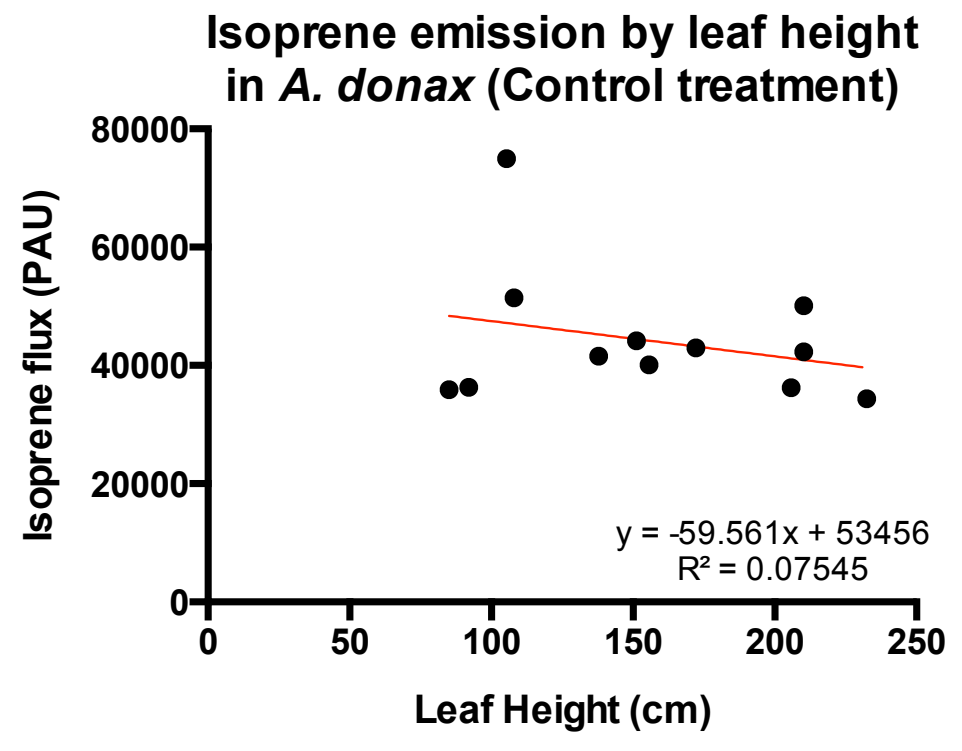


Plants in the High $\mathrm{N}$ treatment group showed the opposite trend; mean isoprene emission levels increased somewhat as canopy height increased. This trend, however was similarly statistically weak and was likely influenced by a single low emission value from the lower canopy. The relationship between isoprene emission and canopy height was not significant ( $P=.147$, linear regression).

Figure 38. Isoprene emission by leaf height in Arundo donax, high $\mathbf{N}$ treatmentThe effect of canopy location on isoprene emission rate in Arundo donax in high $\mathrm{N}$ treatment plants.

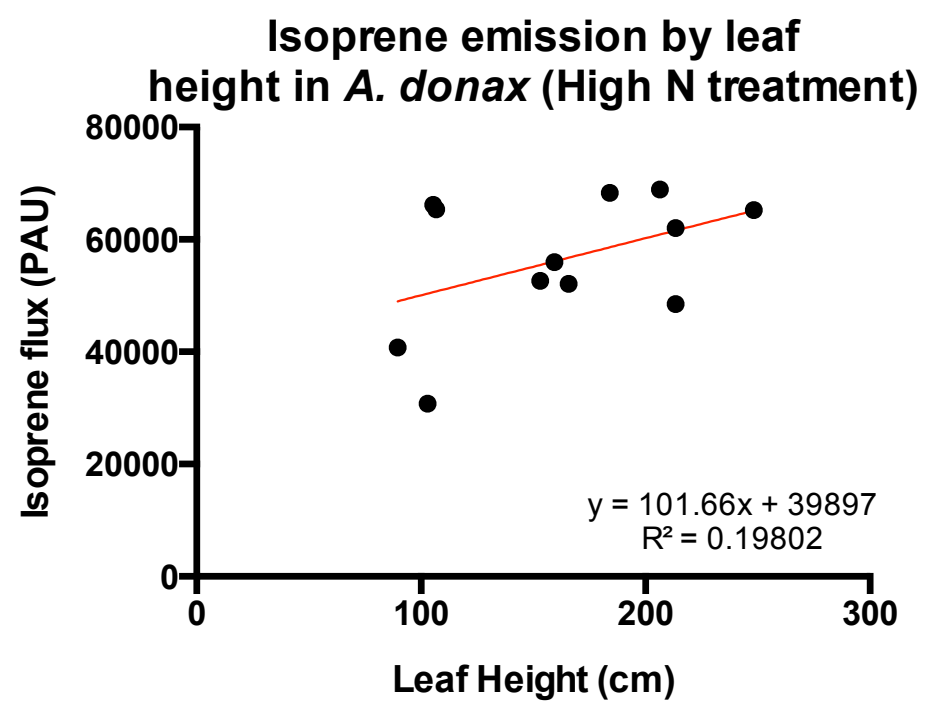


When samples from both treatment groups are combined for analysis, a small

positive effect on isoprene emission levels with increasing height is still observed,

however the slope is low and statistical power of the model is very weak;

consequently, it is likely that the overall trend is simply a result of sampling error, not

evidence of an actual effect. The relationship between isoprene emission and canopy

height was not significant ( $P=.534$, linear regression).

Figure 39. Isoprene emission by leaf height in Arundo donax, combined treatments-The effect of canopy location on isoprene emission rate in Arundo donax in both control and high $\mathrm{N}$ treatment plants.

Isoprene emission by leaf height

in A. donax (Control and High N)

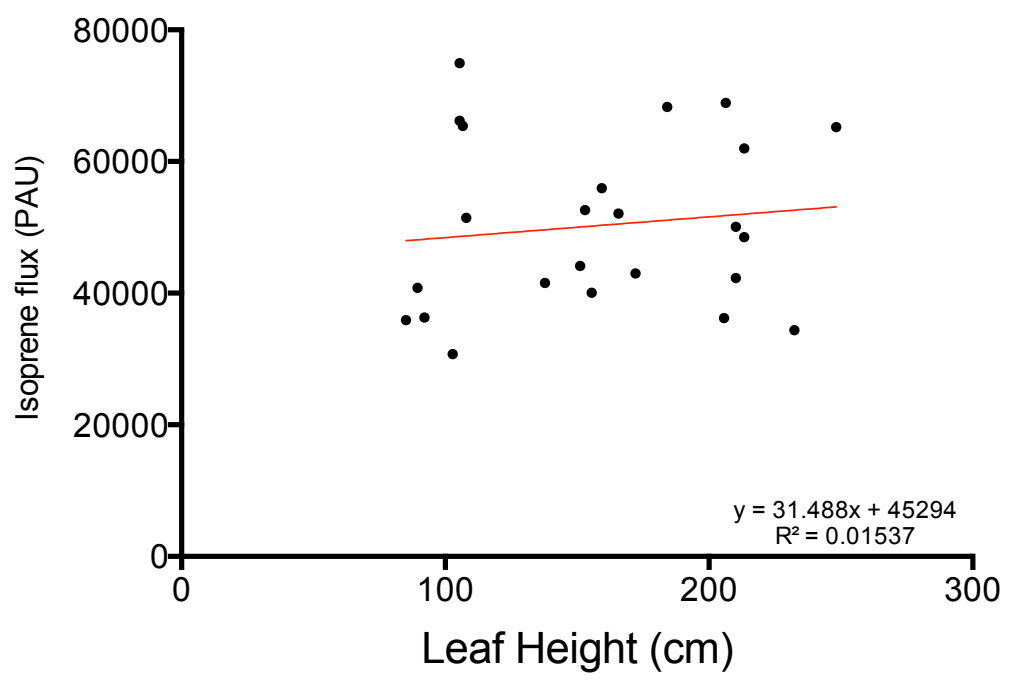


Isoprene emission by light level: Mean isoprene emission levels in $A$. donax

increased with photosynthetically active light levels. At $1000 \mathrm{E}$, mean isoprene flux was $17.79 \mathrm{nmol} \mathrm{m}^{-2} \mathrm{sec}^{-1}$ and at 2,000E it had increased to $24.82 \mathrm{nmol} \mathrm{m}^{-2} \mathrm{sec}^{-1}$. The statistical strength of this model, was fairly weak (RSquare=.3809), due to high variance between the two plants sampled, however, the relationship between light level and isoprene emission was significant $(P<.01$, linear regression).

Figure 40. Isoprene emission response to photosynthetically active radiation levels in Arundo donax - The effect of PAR levels on isoprene emission rate in Arundo donax in greenhouse plants.

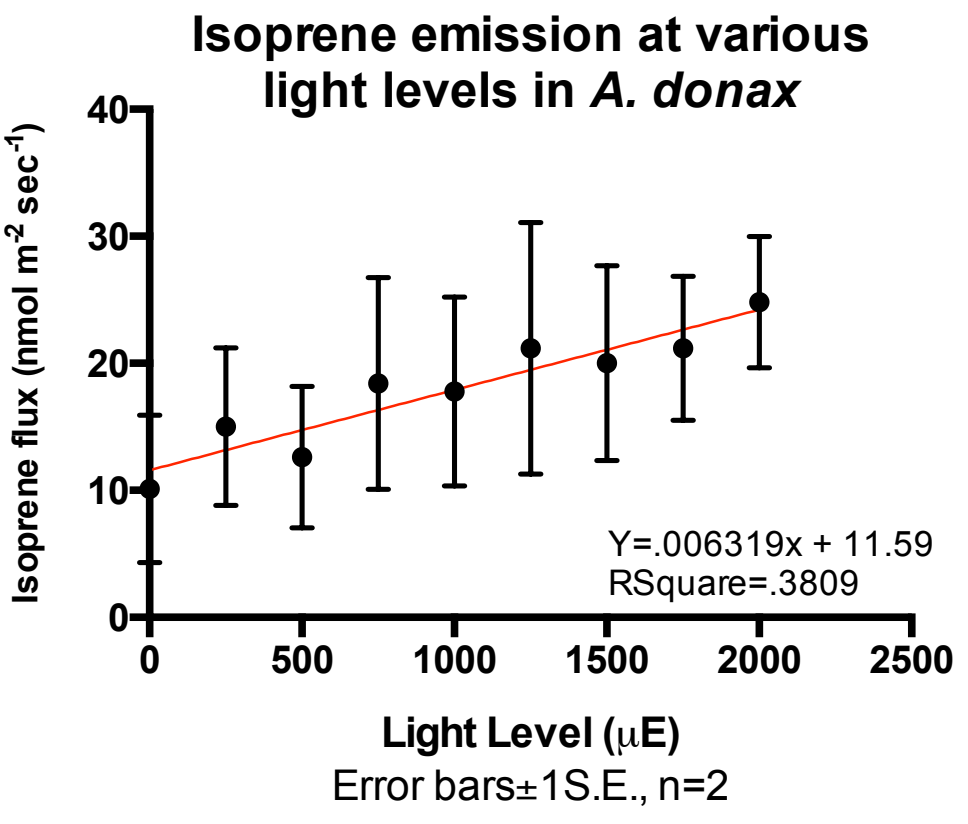




\section{G: Effect of nitrogen amendment and temperature on gas exchange in A. donax}

The effect of fertilizer application on gas exchange in $A$. donax was profound; the addition of nitrogen reduced $C_{i}$ at various $C_{a}$ levels, while simultaneously increasing the carbon assimilation rate.

Figure 41. Effect of fertilizer amendment on gas exchange in Arundo donax-The effect of fertilizer amendment on carbon assimilation rate and internal $\mathrm{CO}_{2}$ concentration in Arundo donax when provided with ambient $\mathrm{CO}_{2}$ levels between Oppm and 1400ppm.

\section{$\mathrm{A} / \mathrm{C}_{\mathrm{i}}$ curves for $A$. donax with various nutrient treatments}

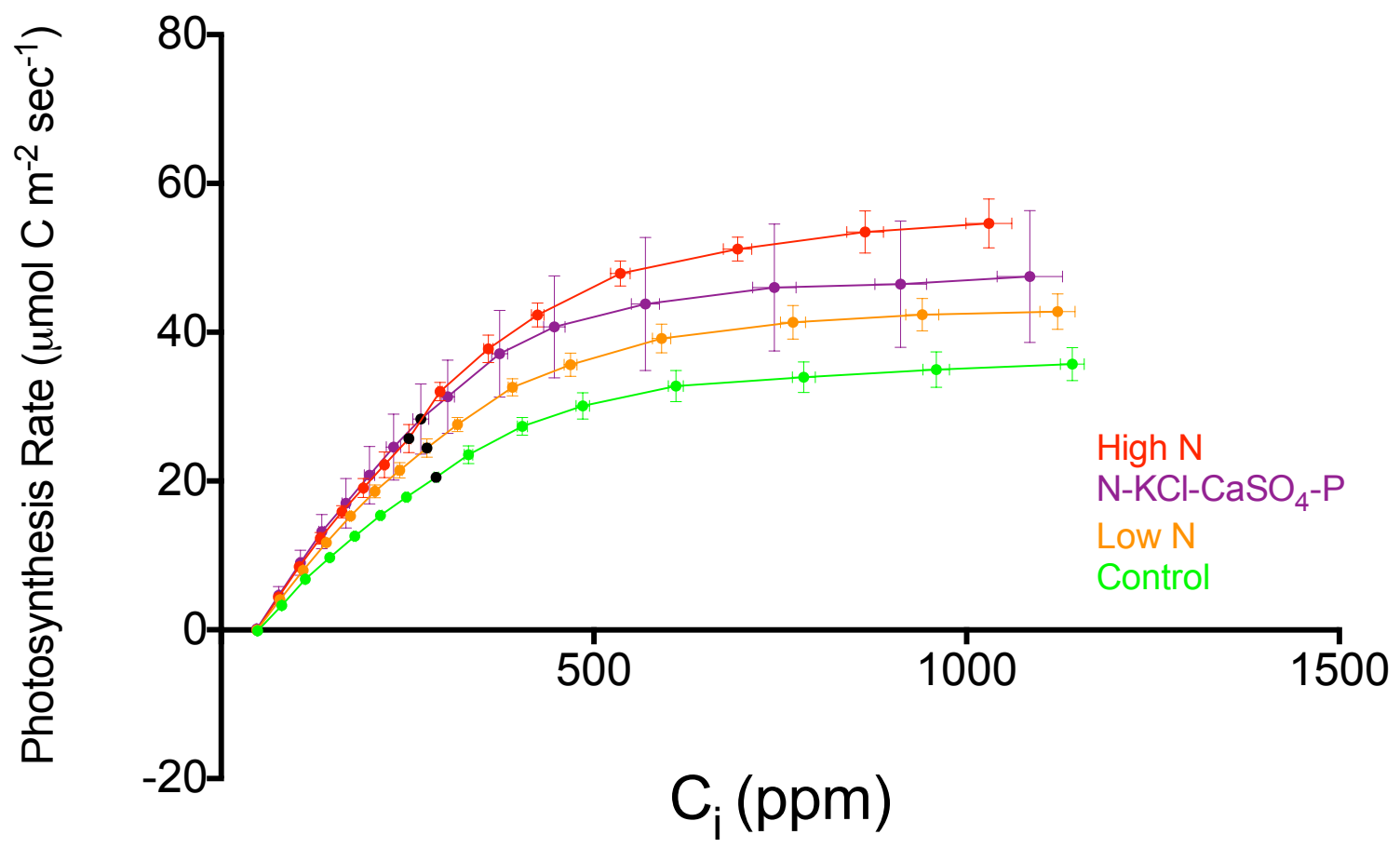

Error bars $= \pm 1$ S.E, $n=4$ 
Interestingly, a more complex relationship between the high N and NPKS

treatment groups was observed; at $\mathrm{C}_{\mathrm{a}}$ values below 400 the $\mathrm{N}-\mathrm{KCl}-\mathrm{Gypsum}-\mathrm{P}$

treatment group showed higher assimilation rates compared to the high $\mathrm{N}$ group, but at $\mathrm{C}_{\mathrm{a}}$ values above 400 the relationship was reversed. Although the $\mathrm{N}-\mathrm{KCl}-\mathrm{Gypsum}-\mathrm{P}$ had fairly high variance and the high $\mathrm{N}$ assimilation values were often within the standard error of the N-KCl-Gypsum-P measurements, the pattern was consistent. At all $\mathrm{C}_{\mathrm{a}}$ values below 400, A was higher in the $\mathrm{N}-\mathrm{KCl}-\mathrm{Gypsum}-\mathrm{P}$ group and at all $\mathrm{C}_{\mathrm{a}}$ values above 400 it was lower.

Figure 42. Effect of fertilizer amendment on gas exchange in Arundo donax, narrow range-The effect of fertilizer amendment on carbon assimilation rate and internal $\mathrm{CO}_{2}$ concentration in Arundo donax when provided with ambient $\mathrm{CO}_{2}$ levels between Oppm and 550ppm.

\section{$A / C_{i}$ curves (narrow range) for $A$. donax with various nutrient treatments}

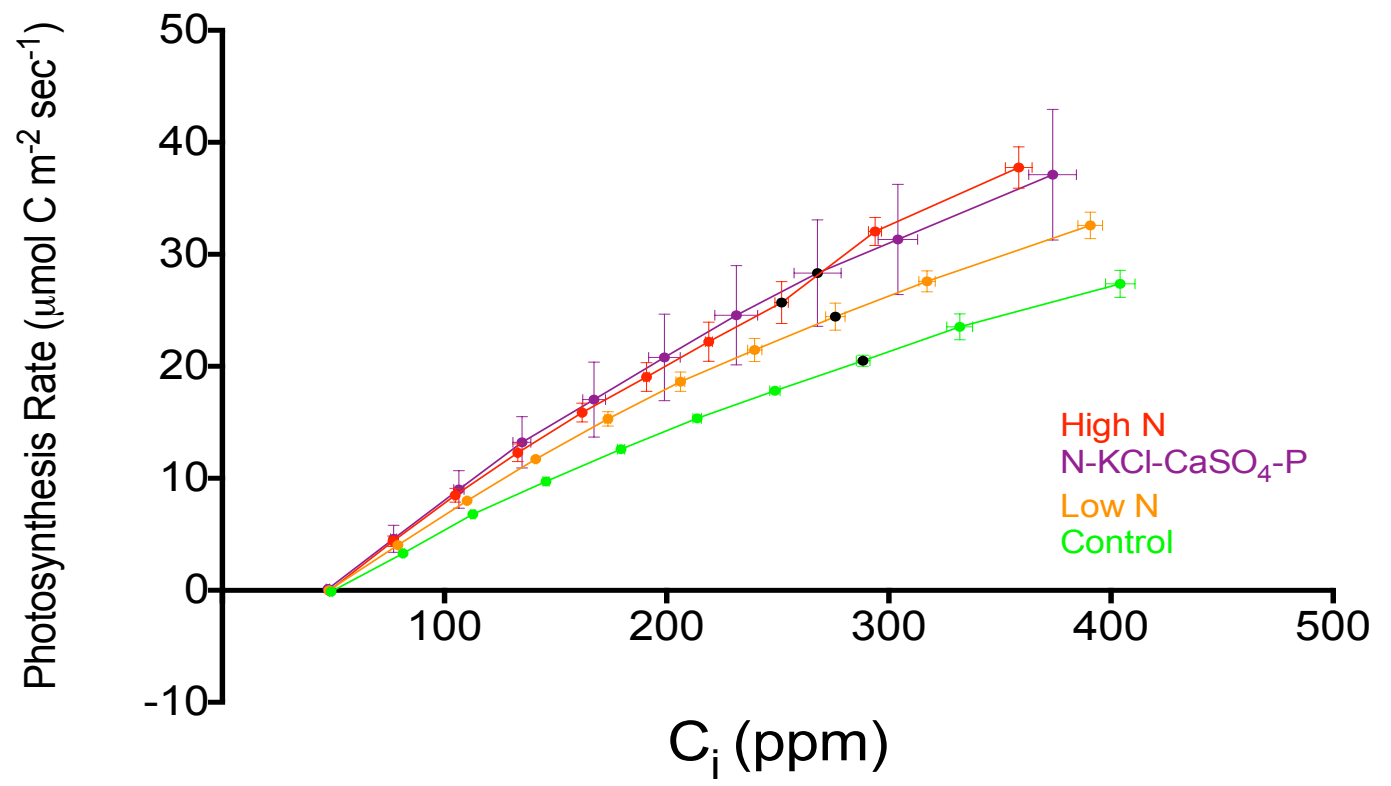

Error bars $= \pm 1$ S.E, $n=4$ 
Figure 43. Comparison of gas exchange rates in greenhouse grown Arundo donax and Miscanthus $\boldsymbol{x}$ giganteus - The effect of fertilizer amendment on carbon assimilation rate and internal $\mathrm{CO}_{2}$ concentration in greenhouse grown Arundo donax and Miscanthus $x$ giganeteus when provided with ambient $\mathrm{CO}_{2}$ levels between 0ppm and $1200 \mathrm{ppm}$.

\section{$A / C_{i}$ curves for $A$. donax and $M$. giganteus in greenhouse conditions}

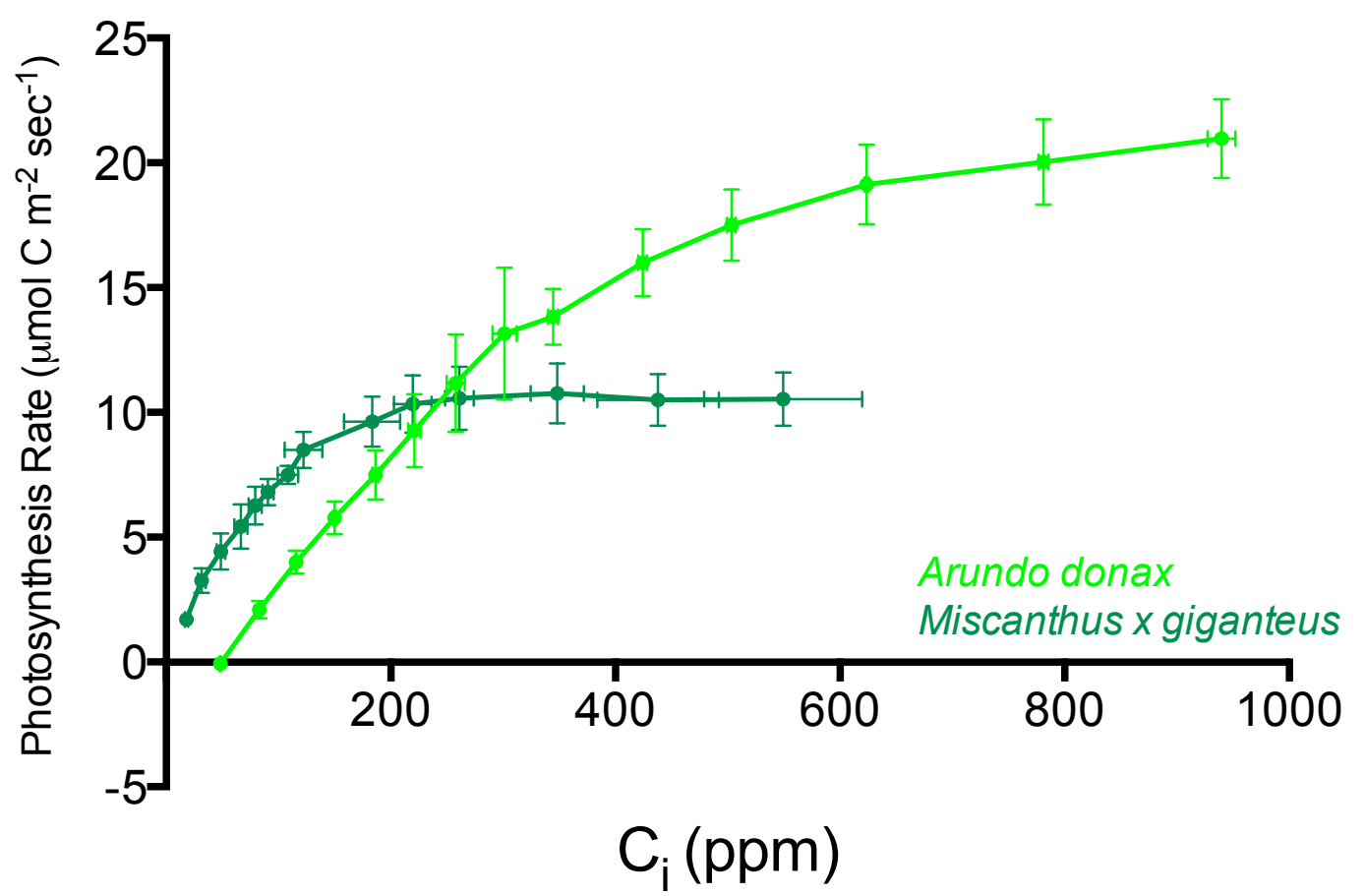

Error bars $= \pm 1$ S.E, $n=3$ 


\section{Chapter 4: Discussion}

4.A: Biofuels, air quality and Arundo donax: Land use change for biofuel production is likely to accelerate during the next century. Many proposed biofuel crops, including $A$. donax, emit significantly greater quantities of volatile organic compounds (VOCs) than traditional agricultural crops. VOCs can impact air quality by interacting with anthropogenic NOx, leading to the production of ozone in the troposphere. Consequently, the widespread cultivation of many biofuel crops will change the composition of the atmosphere, both regionally and globally. This will profoundly affect atmospheric chemistry, air quality, biogeochemical cycles, global temperature and human health (Sharkey, et al., 2008; Papiez, et al., 2009; Kulama, et al., 2004; Porter, et al., 2012). The extent of these possible impacts is not presently predictable, given our limited understanding of atmospheric chemistry and the physiological responses of bioenergy crops to agricultural management practices.

Biofuel projects such as PGE's conversion of the Boardman Coal Plant (Boardman, OR, USA) are motivated by the desire to reduce $\mathrm{CO}_{2}$ emissions from electrical power generation. A study commissioned by PGE calculated that this proposed project would be $\mathrm{CO}_{2}$ neutral, or perhaps a bit positive due to soil carbon sequestration (Lewis et al., 2012). Although such closed-loop power generation holds much promise, national and global energy policies that encourage the development of renewable bioenergy sources, however, do not generally account for the 
atmospheric consequences of the VOCs released from bioenergy crops. Proposed bioenergy projects are generally subject only to local reviews, which also rarely address VOC impacts. In order to avoid unintended negative consequences associated with expanding bioenergy production, it is imperative that data-driven recommendations and regulations are developed and enforced to address VOC emission from biofuel crops. Careful study of biofuel crops increases the possibility of developing agroecosystems that are capable of high rates of bioenergy production with limited negative impacts on air quality and climate. However, failure to recognize the potential impact of VOC emissions from plants may simply result in offsetting one atmospheric pollutant (carbon dioxide) with others (VOCs) and thus simply exchanging problems rather than improving the overall situation.

The purpose of the research presented in this thesis is to provide a foundation for understanding how A. donax, will perform physiologically in the Columbia River basin agricultural region. We provide base line measurements, collected over two seasons, of $A$. donax physiological performance, under cultivation in a region thousands of miles from its native habitat, with profoundly different climate and weather than the regions where it evolved. Most importantly, we provide data demonstrating the likely range of isoprene emissions from $A$. donax grown in this region. Finally, we explore how $A$. donax physiology and VOC emissions are affected by agricultural practices, such as fertilizer use and water management choices, with 
the goal of identifying crop management strategies that could be employed to reduce overall VOC emissions and increase biomass production.

The data presented in this thesis indicates that $A$. donax thrives in the Columbia River basin agricultural area, but that it also produces significantly greater amounts of VOCs than previously published literature suggests (Hewitt et al., 1990;

Melnychenko, 2013). Thus, the impact of this plant on regional air quality could be significantly less positive than currently predicted (Porter, et al., 2012; Lewis, et al., 2012). However, our research also indicates that the amount of VOCs produced by $A$. donax is highly variable and profoundly affected by nitrogen amendment and possibly also water management.

The overarching goal of this thesis is to provide a data framework, which can inform decisions about the cultivation of $A$. donax in eastern Oregon. We hope to facilitate the economically successful cultivation of this crop while minimizing negative impacts on regional air quality. Due to the large range of potential management decisions that could be made and the limited slice of this potential range that we were able to explore, many of the conclusions reached here are by necessity preliminary. Much research remains to be done, which we discuss below. Some conclusions, however, are clear: VOC emission from A. donax in the Columbia river basin is high, highly variable and profoundly impacted by management practices such as fertilizer and water use. Consequently, decisions by policy makers, energy 
producers and farmers will determine weather the use of $A$. donax as a regional fuel source will meaningfully improve air quality.

4.B: Arundo donax physiology: Despite humanity's long relationship with $A$. donax, it has not been the subject of much scientific study. Most of the peer-reviewed literature concerns techniques for cultivating and harvesting $A$. donax, or studies of its invasibility in riparian areas. Very little data has been published on the physiology of this plant, and the studies that do exist were almost exclusively conducted on plants grown in greenhouse conditions, rather than in an agricultural setting. If $A$. donax is to be widely used as a bioenergy crop, it will be important to understand how this plant performs in the field in order to accurately predict how it will respond to increasing atmospheric $\mathrm{CO}_{2}$ levels, changing global weather patterns and cultivation in non-native areas. This information will allow the productive, sustainable and economically successful use of $A$. donax as a source of locally produced fuel for electric power generation.

Ultimately, like all plants, the goal of $A$. donax is to capture radiation from the sun and productively use the energy to assimilate carbon in order to grow, develop and reproduce. In order to do so, $A$. donax must also absorb nutrients and water from the soil and fix carbon from atmospheric $\mathrm{CO}_{2}$. These processes, photosynthesis, carbon fixation, nutrient absorption and water acquisition, are linked together through the physiology of $A$. donax. 
To understand how $A$. donax will perform in the Columbia River basin, we measured the effect of nitrogen and other elemental fertilizers on several aspects of its physiology including leaf chlorophyll content, specific leaf mass, photosynthesis rate, isoprene production, gas exchange, stomatal conductance and water use efficiency. The majority of these measurements were repeated over two years in order to better understand the range of possible physiological responses of $A$. donax to changes in weather, soil water status and phenology.

Leaf chlorophyll content in Arundo donax: Leaf chlorophyll content is an important indicator of overall plant fitness because it represents the ultimate limit to the amount of radiation the plant can productively absorb, and thus how much it can grow and develop. Thus, for a crop like $A$. donax, increasing leaf chlorophyll content may provide a path to improving biomass production. Chlorophyll is also a relatively easy attribute to measure in the field and can be used as a quick indicator of overall plant fitness and nitrogen status (Schepers, et al., 1992). Chlorophyll abundance is coupled to nitrogen availability, because each chlorophyll molecule contains four nitrogen atoms.

In our field data, nitrogen amendment increased chlorophyll content in $A$. donax and consequently its ability to fix carbon. Across the treatment groups in our study, nitrogen amendment was the only factor that significantly affected leaf chlorophyll content. In both sampling years, nitrogen fertilizers significantly increased 
the abundance of chlorophyll in leaf tissue. The highest leaf chlorophyll levels were recorded in the high N treatment groups in both years. The 2012 and 2013 high $\mathrm{N}$ treatment groups contained 430.32 and $415.60 \mu \mathrm{mol}$ chl. $\mathrm{m}^{-2}$ respectively. The control groups in both years contained the lowest abundance of leaf chlorophyll, $256.22 \mu \mathrm{mol}$ chl. $\mathrm{m}^{-2}$ in 2012 and $304.83 \mu \mathrm{mol}$ chl. $\mathrm{cm}^{-2}$ in 2013. Chlorophyll content was not significantly affected by the addition of any other non-nitrogen fertilizers. It also did not vary significantly in our temperature experiment, or between our two sample periods.

Leaf photosynthesis in Arundo donax: The assimilation of carbon is the immediate goal of photosynthesis. This process is limited by the amount of energy captured by chlorophyll as well as by the abundance and kinetics of enzymes involved in electron transport, carbon fixation and triose phosphate utilization. We measured net photosynthesis (carbon fixation minus carbon lost to respiration) in order to determine the rate of carbon assimilation in $A$. donax as this represents the available supply of carbon for incorporation into biomass and ultimately available for combustion.

Our data shows that photosynthesis rates in A. donax are somewhat variable, but are not significantly impacted by fertilizer application. Among all the treatment groups sampled in the HAREC field trials, the highest mean photosynthesis level for an entire treatment group was recorded in 2013's N- ${ }_{2} \mathrm{SO}_{4}$ plants, which assimilated 
24.99 $\mu \mathrm{mol} \mathrm{C} \mathrm{m} \mathrm{sec}^{-1}$. The lowest photosynthesis level was recorded in the 2012 control plants, which assimilated $17.33 \mu \mathrm{mol} \mathrm{C} \mathrm{m} \mathrm{sec}^{-1}$. These treatments were significantly different from each other $(P<.01$, Tukey's HSD) however, the difference cannot be ascribed to fertilizer treatment alone as they were sampled in separate years and thus the results are confounded by seasonal and age class differences. Our recorded photosynthesis rates are comparable to other reported data for $A$. donax; Papazoglou, et al. (2004) reported net photosynthesis rates of $15.3-34.0 \mu \mathrm{mol} \mathrm{C} \mathrm{m}{ }^{-2}$ $\sec ^{-1}$ in A. donax for plants grown in greenhouse conditions.

Photosynthesis rates among the various fertilizer treatments within the same year were not significantly different from each other (post hoc Tukey's HSD). The addition of nitrogen also did not significantly change photosynthesis rates, although in both years there was a trend toward increasing net photosynthesis with the addition of nitrogen, though these differences were not significant (post hoc Tukey's HSD).

Photosynthesis was significantly different between the two sample years $(P<.001$, students $t$ Test $)$ and was approximately 19\% higher in 2013 among the fertilizer treatments sampled in both years. This change in net assimilation rates could be due to differences in phenology or ambient climate (the sampling periods varied by approximately 5 weeks, and the weather was warmer with higher humidity in 2012, for details see Table 3, Appendix). However, our data does not show any significant effect on assimilation rates due to temperature change, although the 
temperature difference between our two sample periods exceeded that of the temperature effect experiment. It is also possible that the difference in photosynthetic rate between the two sampling periods is due to an age-class effect; the plants sampled in 2013 were regrown from the same rhizomes and were thus one year older (the rhizomes were originally planted in spring 2012). Papazoglou, et al. (2004) also reported a net increase in photosynthesis rates for $A$. donax, for twoyear-old plants, in an experiment that controlled for soil moisture between the two years of the study. In combination, these data indicate that $A$. donax may make a greater investment in leaf-chlorophyll in the second year of growth, perhaps by utilizing stored photosynthate from the previous year. Such an effect would also be consistent with published data showing a large increase in biomass productivity for $A$. donax in the second year after establishment (Nassi o Di Nasso, et al., 2011).

Leaf stomatal conductance in Arundo donax: In order for plants to fix carbon they must expose active enzymes to $\mathrm{CO}_{2}$ in the atmosphere. This is accomplished through the stomata, small pores in the leaf surface. Through stomata, $\mathrm{CO}_{2}$ can diffuse into leaf tissue where it is available for fixation. $\mathrm{H}_{2} \mathrm{O}$ also diffuses out through stomata however, thus, there is an inherent trade of water loss for carbon gain. Because water is often a limited resource, plants have evolved the ability to actively regulate their stomata by opening and closing them in order to maximize carbon capture while minimizing water loss. We measured stomatal conductance as the total 
potential for water vapor diffusion through the membrane. This indicates how much surface area the leaf has exposed for carbon capture and higher stomatal conductance values correlate with greater potential water loss. Actual water loss, evapotranspiration, depends both on total stomatal conductance and the relative temperature, humidity and motion of the air near the stomatal pore.

Because plants can also vary the abundance of carbon fixation enzymes within the stomatal pore, stomatal conductance is not necessarily indicative of overall photosynthetic rate; with a greater number of enzymes a plant could capture more carbon at the same level of stomatal conductance. Thus, if a plant is enzymatically limited in the amount of carbon it can capture per stomata it may respond by increasing stomatal conductance, thus losing more water to evapotranspiration. Consequently stomatal conductance represents an important attribute to monitor and manipulate in order to minimize water usage in $A$. donax while maximizing biomass production.

Stomatal conductance was highly variable across the treatment groups in our study. The lowest rates of stomatal conductance were recorded in the high-nitrogen plants in $2012\left(0.27 \mathrm{~mol} \mathrm{H}_{2} \mathrm{O} \mathrm{m}^{-2} \mathrm{sec}^{-1}\right)$, and the highest rates were recorded in the $\mathrm{N}$ $\mathrm{K}_{2}-\mathrm{SO}_{4}$ treatment group in $2014\left(0.76 \mathrm{~mol} \mathrm{H}_{2} \mathrm{O} \mathrm{m}^{-2} \mathrm{sec}^{-1}\right)$. This represents a net increase of more than $180 \%$ in stomatal conductance, a difference that was highly significant $(P<.001$, Tukey's HSD). Once again, however, the difference cannot be 
ascribed to fertilizer treatment alone as these treatments were sampled in separate years and the results are confounded by seasonal, weather and age class differences.

The addition of nitrogen did significantly reduce the stomatal conductance rates in $A$. donax. This effect is consistent with our data showing that nitrogen amendment also leads to an increase in chlorophyll content and assimilation rates as well as our gas exchange data that show decreased mesophyll $\mathrm{CO}_{2}$ concentration at various ambient $\mathrm{CO}_{2}$ levels. We propose that these changes reflect an overall increased investment in photosynthesis, driven by an increase in soil nitrogen levels. Thus, the addition of nitrogen allows $A$. donax to fix more carbon for the same amount of stomatal conductance, or conversely to fix the same amount of carbon with lower conductance. Thus, the cost of water loss to transpiration in order to fix carbon is significantly improved by the addition of nitrogen. The same is not true of amendment with other elemental fertilizers, perhaps because these ions do not represent a limiting factor in protein or chlorophyll creation.

Leaf water use efficiency: Water use efficiency (WUE), the amount of carbon fixed per unit of water lost to evapotranspiration, is an important consideration in evaluating the impact of proposed bioenergy crops (de Fraiture, et al., 2008; Berndes, 2002; de Vries et al., 2010). In many regions of the world water supplies for human use are limited and decreasing. In most places, the production of significant amounts of bioenergy will require irrigation and thus will increase demand for water resources. 
Consequently, management techniques that increase water use efficiency in bioenergy crops will positively contribute to the overall impact of bioenergy production (Groom, et al., 2008).

As discussed above, the addition of nitrogen fertilizers significantly increased photosynthesis rates in $A$. donax, while simultaneously decreasing stomatal conductance, which leads to less water lost to evapotranspiration. In concert, these changes lead to a large increase in water use efficiency; with the addition of nitrogen, A. donax is able to fix significantly more carbon for the same cost in water loss. This effect was significant in both sample years (students t Test).

In both years, the lowest WUE was recorded in the control group plants. In 2012 the control plants fixed $4.35 \mu \mathrm{mol} \mathrm{CO}$ for each mole of water lost to transpiration, while in 2013 , for the same cost in water loss, the control plants were only able to fix $3.10 \mu \mathrm{mol} \mathrm{CO}$. The highest overall WUE in 2012 was recorded in the high $\mathrm{N}$ group, which fixed $7.59 \mu \mathrm{mol} \mathrm{CO}_{2}$ for each mole of water lost to transpiration. These WUE rates are consistent with other published values for C3 grass species (Nippert, et al., 2007). Other published reports indicate that the WUE of $A$. donax compares favorably to other biofuel crops (Mantineo, et al., 2009), however, in this case WUE was calculated in terms of total water use for total biomass production, rather than leaf level carbon assimilation rate per transpiration rate. A direct comparison of our data is not possible as total field water use was not recorded during our study. 
A large decrease in WUE was observed between our two sample years. In the treatment groups sampled over both years, $A$. donax lost far more water per $\mu$ mol $\mathrm{CO}_{2}$ fixed in 2013 than in 2012. This could be due to plant age class or phonological and weather differences between the two sample periods, but we suspect it was largely driven by soil water status. In 2012 , water was a more limiting resource, thus the tradeoff between carbon fixation and water retention may have been more biased to favor water. On the other hand, soil water was much more abundant in 2013 and thus stomatal conductance did not need to be limited and opportunities for carbon fixation could be maximized. Although relative ambient humidity also varied between the sample years, it was held relatively constant for the leaves that were sampled in this study; consequently vapor pressure deficit for water is not expected to have influenced stomatal conductance rates or our calculations of water use efficiency.

Specific leaf mass: Maximizing specific leaf mass may be an important goal of biofuel producers, as published reports from species, including other biofuel crops, indicate that there is a relationship between SLM and overall growth rate and biomass yield (Ahmed, et al., 2007; Shipley, 2006). Increasing yield per acre will minimize the physical footprint of land use for bioenergy production and thus leave more land available for food production or non-human use. Because leaf area index (LAI) is often limited by genetically controlled shade avoidance responses (Devlin, et 
al., 2003), increasing SLM may allow the production of greater amounts of biomass once maximum LAl is reached.

Dry specific leaf mass in $A$. donax varied slightly with the addition of nitrogen and other elemental fertilizers, but no overall trend was observed and no significant results based on fertilizer treatment were recorded. However, a significant change in SLM was recorded between our two sample years; SLM was approximately $8 \%$ higher in 2012 than in 2013. Although this effect is modest, if overall biomass scales with SLM (at the time of this writing we are still awaiting biomass data as the study plants have not yet been harvested), an $8 \%$ increase could significantly change the economic or ecological cost of a large-scale biofuel project. The fact that plants grown in 2012 exhibited both higher SLM and WUE, suggests that water management may be an important part of the strategy for limiting the environmental and social costs of biofuel production from A. donax.

4.C: Isoprene emission in Arundo donax: Because of its impact on air quality, outlined above, limiting isoprene emission from $A$. donax will be an important concern for energy producers, farmers and policy makers. Large fluxes of isoprene have the potential to perturb air chemistry and lead to the creation of significant amounts of tropospheric ozone. This would significantly reduce the potential benefits of using $A$. donax as a bioenergy crop. Isoprene emission also represents a net loss of carbon and, all else being equal, this results in less carbon being available for use as 
fuel. Manipulating isoprene emission in $A$. donax thus represents a possible pathway for increasing biomass.

Factors influencing isoprene emission from Arundo donax: Isoprene emission in A. donax varied widely across our study, with total carbon flux to isoprene emission representing approximately $0.5-5 \%$ of photosynthetically fixed carbon (net photosynthesis rate). This percentage is consistent with relative rates reported for other high-emitting species (Sharkey and Yeh, 2001) however, many of these measurements for other species were conducted at $30^{\circ} \mathrm{C}$ in order to measure maximum isoprene production rates, while ours were conducted at $20^{\circ} \mathrm{C}$ in order to better match the actual growing conditions for the Columbia River basin. The emission rates we report are similar to (and in the most extreme case, exceed by nearly a factor of five) the high-end values reported for Eucalypts, another family of candidate biofuel crops known to be high isoprene emitters (He et al., 2000).

The most dramatic variation we observed was between the control treatments in the two sampling years. In 2012 the emission rate for control plants was slightly less than $17 \mathrm{nmol} \mathrm{m}^{-2} \mathrm{sec}^{-1}$ but in 2013 the control plants mean emission rate exceeded $240 \mathrm{nmol} \mathrm{m}^{-2} \mathrm{sec}^{-1}$, a nearly 15 -fold increase. In these same two groups, assimilation rates were nearly $4.7 \mu \mathrm{mol} \mathrm{CO} \mathrm{m}^{-2} \mathrm{sec}^{-1}$ higher in the 2013 group. Consequently, the increase in isoprene emission between the two years represents nearly $25 \%$ of the additional assimilated carbon. Overall, when the three treatments that were sampled in both years are batched in order to compare the effect of the 
different sampling periods, the isoprene emission rates were nearly 5 times higher in 2013, compared to 2012 and this increase was highly statistically significant $(P<.0001$, students t Test).

Because many factors were different between these two years, confidently assigning a cause to this increase in isoprene emission is difficult. However, we consider it likely that the large increase in temperature (average daily temperatures were approximately $7^{\circ} \mathrm{C}$ warmer during and in the two weeks prior to our sample period in 2013 compared to 2012; Table 3, Appendix) is at least partly responsible for the increase. Although long-term acclimation to warm climates is not known to increase isoprene emission rates (Sharkey et al., 2008), isoprene emission is generally considered to be a response to abiotic stresses, including temperature (Vickers et al., 2009) and the presence of more heat fleck events during hot weather may cause developing leaves of $A$. donax to invest in the production of more isoprene synthase enzyme (Wiberley et al., 2005). Because leaf temperature was kept relatively constant during our data collection, we believe that the higher isoprene production recorded in our 2013 data reflects an overall increase in investment in the enzymatic machinery for isoprene production.

The lower end of emission rates we recorded are consistent with other published flux measurements for A. donax (Hewitt, et al., 1990; Malnychenko, 2013), while the highest mean emission rates in our study were more than an order of magnitude greater than the literature suggests for this species. These other 
published reports, however, were all conducted on plants grown in pots under greenhouse conditions. The plants in both our temperature and light response surveys, which were also grown in pots in greenhouse-type conditions, emitted isoprene at substantially lower rates than nearly all the field grown plants, and at levels consistent with the published literature. This suggests that the actual emission of isoprene may be much greater in field conditions than when grown in greenhouse conditions and that the overall environmental impact of bioenergy production using A. donax may be more negative that currently predicted. Consequently, we suggest a reappraisal of efforts to model the air quality impacts of growing $A$. donax for biofuel, which up to this point have been based on published isoprene emission rates from greenhouse plants (Porter, et al., 2012). Additionally, if we seek to minimize the indirect costs of using $A$. donax as a biofuel, it is important that policy recommendations reflect its actual performance under field conditions rather than data obtained from plants grown in artificial environments.

Although our data shows that, when grown in the Columbia River basin, $A$. donax will potentially emit much greater amounts of isoprene than currently assumed, our results also suggest that there are management strategies available to reduce these isoprene emissions. Perhaps the most interesting facet of our data set is the effect of nitrogen amendment on isoprene emission in A. donax. In the two sampling years, the effect was exactly opposite; in 2012 the addition of nitrogen caused isoprene emission rates to nearly triple (16.96 nmol isoprene $\mathrm{m}^{-2} \mathrm{sec}^{-1}$ in 
control plants, $46.61 \mathrm{nmol}$ isoprene $\mathrm{m}^{-2} \mathrm{sec}^{-1}$ in $+\mathrm{N}$ plants), while in 2013 the addition of nitrogen caused a decrease in isoprene emission of about $40 \%(241.14 \mathrm{nmol}$ isoprene $\mathrm{m}^{-2} \mathrm{sec}^{-1}$ for control plants, $149.11 \mathrm{nmol}$ isoprene $\mathrm{m}^{-2} \mathrm{sec}^{-1}$ in $+\mathrm{N}$ plants). On the surface, this data seems contradictory and difficult to interpret. However, we hypothesize that the differential effects of nitrogen amendment in the two years of data make sense in terms of other published reports on adaptive purposes and factors that influence isoprene emission by plants.

Isoprene emission and Arundo donax physiology: It is well established that isoprene emission is linked to photosynthesis rates in plants (Lerdau and Throop, 2000) and in our 2012 data, isoprene emission rates followed this pattern; the $+\mathrm{N}$ plants had both higher photosynthesis rates and higher isoprene emission. The same relationship between nitrogen, photosynthesis and isoprene emission has also been reported in both aspen and oak trees (Litvak et al., 1996). We suspect that the levels of isoprene emission recorded in 2012 may simply represent constitutive emission levels, coupled to photosynthesis. In other words, all other things being equal, when photosynthesis increases in A. donax, so does isoprene emission.

Isoprene emission, however, is not simply a constitutive metabolic pathway linked to photosynthesis. If it were, enzymatic emission of isoprene would likely have been selected against as it imposes large costs on the emitting plants. The creation of each 5-carbon isoprene molecule requires the input of 20 ATP and $14 \mathrm{NADPH}$ (Sharkey and Yeh, 2001). Given this cost, the fact that enzymatic isoprene emission 
seems to have evolved independently several times among successful plant clades (Monson, et al., 2013), strongly suggests that it would serve one or more significant adaptive purposes. The literature bears this out as published research indicates that plants which emit isoprene are better protected from short term heat stress (Behnke, et al., 2007; Velikova et al., 2006) and that longer term acclimation to higher temperatures increases the expression of the IspS (isoprene synthase) gene and the abundance of isoprene synthase enzymes (Wiberley, et al., 2005; Lehning, et al., 2001; Sharkey and Yeh, 2001; Sharkey, et al., 2008; Velikova and Loreto, 2005;

Rasulav, et al., 2009).

It is, perhaps, surprising that isoprene emission increased in 2013 along with both stomatal conductance and transpiration. Transpiration and isoprene emission are both strategies used to protect leaves from heat-induced damage and a tradeoff between the two is often invoked to explain isoprene emission dynamics (Sharkey, et al., 2008). This does not necessarily represent a contradiction in our data, however, as it could be that the large temperature difference (during data collection, average temperatures were approximately $6.3^{\circ} \mathrm{C}$ warmer in 2013 than 2012 and daily highs were approximately $3.3^{\circ} \mathrm{C}$ warmer) lead $A$. donax to simultaneously employ both strategies fully. Additionally, photosynthesis and stomatal conductance also increased in 2013 and these changes could have resulted in constitutive increases in both isoprene emission and stomatal conductance. 
As discussed above, we believe the thermotolerance hypothesis for isoprene emission may adequately explain the significant increase in isoprene flux recorded in 2013; the leaves measured in 2013 experienced warmer conditions and thus would be expected to make a larger investment in isoprene synthase enzyme, leading to higher emission rates. Our temperature acclimation experiment also showed a trend toward higher isoprene emission in plants grown at higher temperatures. This effect was not statistically significant, due to high variance in the data, but due to its correspondence to the literature, we expect this finding was accurate.

Less obvious, however, is the reason for the decrease in isoprene emission with the addition of nitrogen seen in 2013. As already mentioned, the addition of nitrogen has previously been linked to increases in isoprene emission (Litvek, et al, 1996) so it is not immediately clear why we would see the opposite result in our 2013 field trials. One possibility is that the addition of nitrogen allowed the plants to employ other strategies for responding to heat stress, specifically the upregulation of heat shock proteins, which require significant input of nitrogen. All plants employ heat shock proteins (Vierling, et al., 1991) and in plants that also emit isoprene, there may be an inherent tradeoff in the use of these two thermotolerance strategies; heat shock proteins impose a nitrogen cost, while isoprene emission imposes a carbon cost. It may be that our control plants were relatively nitrogen limited, making isoprene emission the favored strategy for combating heat stress, while in the $+\mathrm{N}$ plants, 
nitrogen limitation was not a problem and the creation of additional heat shock proteins was favored in order to maximize net carbon assimilation.

Additionally, the production of isoprene requires the reduction of DMADP, which requires electron transport chains to provide reducing power. Another major sink for this reducing power is the reduction of nitrate $\left(\mathrm{NO}_{3}{ }^{-}\right)$. The plants in our study were fertilized with urea $\left[\mathrm{CO}\left(\mathrm{NH}_{2}\right)_{2}\right]$ which is oxidized by soil bacteria (Kaye and Hart, 1997), resulting in nitrate, which is readily uptaken by plants (Tischner, 2001). Consequently, we expect that much of the nitrogen actually absorbed by the study plants was in the form of nitrate, which must be reduced to $\mathrm{NH}_{4}$ before incorporation into organic molecules. Therefore, the application of urea in our study may have lead to high intracellular nitrate concentrations, which would compete with the isoprene production pathway for reducing power, leading to decreased overall isoprene emission (Rosenstiel, et al., 2004).

The decrease in isoprene emissions seen with the addition of nitrogen in 2013 may also be related to isoprene's role as a chemical signal that regulates interactions between plants and insects. Isoprene is known to affect the behavior of both herbivorous insects and the insects that predate upon them (Loivamäki, et al., 2008; Laothawornkitkul, et al., 2008). Additionally, the availability of nitrogen in the soil has been found to affect a plant's investment in defensive compounds. In nitrogen abundant conditions, plants increase investment in nitrogen rich, cyano-based defensive compounds, however in lower nitrogen conditions, plants preferentially 
upregulate the production of carbon-based defensive compounds, including terpenoids (Lou and Baldwin, 2004). To our knowledge, no published studies have looked at whether $A$. donax produces significant amounts of nitrogen-based defensive chemicals, however, isoprene is a carbon rich compound and thus its increased emission in the nitrogen-limited control plants is consistent with an herbivore-defense strategy tradeoff between carbon and nitrogen rich compounds.

Some published reports have proposed that isoprene emission may represent a strategy for shunting excess carbon (Logan, et al., 2000) or for avoiding the accumulation of DMADP (the substrate for isoprene synthase) (Wagner, et al., 1999). In such a scenario, the emission of isoprene can be seen as a metabolic efficiency strategy wherein the cost of isoprene emission is tolerated as a necessary burden that permits the maximization of other metabolic goals for the plant. Therefore, the decrease in isoprene emission seen in $+\mathrm{N}$ plants in 2013 may reflect the overall fitness of these plants and the higher emission rates in the control plants may represent a strategy for regulating $\mathrm{C}: \mathrm{N}$ ratios and thus an indirect symptom of nitrogen stress.

One other possible role for isoprene emission in $A$. donax suggested by our data relates to the phosphorus status of the plants. The metabolic precursor to isoprene (and all larger terpenoids) is DMADP, which contains two phosphate groups. Many important biological molecules are made from DMADP and consequently, plants have an incentive to maintain large pools of this substrate. However, doing so 
sequesters substantial amounts of phosphate, which is necessary for many metabolic processes. Therefore, plants experiencing phosphate stress may be incentivized to convert DMADP to isoprene in order to reclaim phosphates. Our data does not convincingly answer this hypothesis, but we did record some supporting data in our $\mathrm{N}-\mathrm{KCl}-\mathrm{CaSO} 4-\mathrm{P}$ treatment group. The members of this group, which were the only plants that received phosphorus amendment, showed the lowest isoprene emission rates of any group measured in 2013 , approximately $20 \%$ lower than the low $\mathrm{N}$ plants. Analysis of this data is complicated by the fact that this treatment group was also the only group to receive calcium amendment, confounding our ability to causally attribute this effect to phosphorus. The decrease in isoprene emission was also not statistically distinguishable from random error due to high variance, but it does represent a possible signal of a role for phosphorus amendment in mitigating isoprene emission.

Our data also indicates that isoprene emission levels in $A$. donax are positively linked to light levels, which has been demonstrated in other plants as well (Loreto and Sharkey, 1990; Monson and Fall, 1989). Perhaps surprisingly, however, we also found that in $A$. donax, the capacity for isoprene emission does not vary significantly with canopy location. Leaves growing low in the canopy had essentially the same capacity for isoprene emission as leaves from the top of the canopy. This conflicts with published reports for other species, which show a strong increase in isoprene emission capacity for leaves in the upper canopy compared to leaves from the lower 
canopy (Harley, et al. 1996; Sharkey, et al 1996) as well as an increase in isoprene synthase activity (Lehning, et al., 2001). This is possibly due to the annual growth habit of $A$. donax and the agricultural practice of clearing all vegetation in the field. New A. donax leaves only emerge from the apical tip of the growing cane and as canes increase in height, there is no canopy to provide shade. Consequently each new $A$. donax leaf develops in a full light environment. This contrasts with the growth habit of many isoprene-emitting trees such as poplar and oak, where the entire canopy leafs out at the same time, and lower canopy leaves are more shaded while they develop. Another possible reason for the canopy height data discrepancy may be that the plants we sampled were growing relatively sparsely, resulting in more similar light environments through the canopy than may be experienced in a fully mature A. donax canopy. Consequently, we consider these results to be preliminary and we suggest that a similar survey should be conducted on $A$. donax plants growing in a dense, mature stand with more variation in light levels.

4.D: Gas exchange measurements: The $A / C_{i}$ curves we generated for $A$. donax at the HAREC field trials are consistent with the rest of our data and with other published curves for $\mathrm{C} 3$ species. The addition of nitrogen lead to lower $C_{i}$ and higher photosynthesis rates at all ambient $\mathrm{CO}_{2}$ levels. We propose that this reflects a nitrogen driven increase in carboxylation enzymes (particularly rubisco) that allows $A$. donax to achieve higher rates of carbon fixation at all ambient $\mathrm{CO}_{2}$ levels. 
One interesting effect we observed in the $A / C_{i}$ data was the behavior of the $N$ $\mathrm{KCl}-\mathrm{CaSO}_{4}-\mathrm{P}$ plants. This group had wide variation in assimilation rates and they showed lower $\mathrm{C}_{\mathrm{i}}$ values and higher $\mathrm{A}$ at all temperatures compared to the Low- $\mathrm{N}$ plants (which contained the same level of $\mathrm{N}$ ). When compared to the High-N group, the $\mathrm{N}-\mathrm{KCl}-\mathrm{CaSO}_{4}-\mathrm{P}$ group showed lower $\mathrm{A}$ at $\mathrm{C}_{\mathrm{a}}$ levels below 400 and higher $\mathrm{A}$ at $\mathrm{C}_{\mathrm{a}}$ levels above 400 .

Overall, our $A / C_{i}$ curves indicated no discernable decrease of $A$ at high $\mathrm{Ca}$, indicating that triose-phosphate utilization does not substantially affect the kinetics of photosynthesis under these conditions (Long and Bernacchi, 2003). Our assimilation data from the HAREC field trials show high rates of carbon fixation that greatly exceed other published reports (Moore, et al., 2010) however, the plants in these reports were grown in in pots in greenhouse conditions, and the $\mathrm{A} / \mathrm{Ci}$ curves we generated for greenhouse plants are in line with other published data. This indicates, once again, that $A$. donax behaves very differently in field conditions compared to greenhouse conditions. Consequently, we suggest that future studies of the physiology of this species should be conducted on field grown plants whenever possible. 
4.E: Conclusions and future directions: $A$. donax is a promising candidate crop for bioenergy production due to its high productivity and low resource requirements. The use of $A$. donax as a biofuel can potentially be $\mathrm{CO}_{2}$ neutral (Lewis, et al., 2012), which contrasts with the large carbon footprint of fossil fuels. However, $\mathrm{CO}_{2}$ production does not tell the full story of the air quality impacts of using $A$. donax as a biofuel. A. donax also emits significant amounts of isoprene (Hewitt, et al., 1990, Melnychenko, 2013), which can disturb atmospheric chemistry, resulting in the production of significant amounts of ozone (Porter, et al., 2012) and thus negatively impacting other agricultural crops and human health (Papiez, et al., 2009). In order to predict or mitigate the effects of widespread cultivation of $A$. donax, it is imperative to know what the actual isoprene emission rates will be in a particular growing region and how agricultural management practices will impact these emission rates as well as the physiology of $A$. donax.

To the best of our knowledge, this study provides the first measurements of isoprene flux and gas exchange for $A$. donax grown in field conditions anywhere in the world. Our data shows that isoprene production in $A$. donax grown in the Columbia River basin agricultural area far exceeds the previously published data collected from plants grown in greenhouse conditions. We also show that agricultural practices, particularly the management of nitrogen and water, significantly affect the physiology of $A$. donax as well as the amount of isoprene it emits. These data suggest that the impact of growing $A$. donax in the Columbia River basin may be more 
negative than currently predicted (Porter, et al., 2012) and that a reappraisal of these modeling efforts is warranted. We also propose that policy makers should consider how management decisions affect VOC production from $A$. donax when crafting regulations or designing monitoring regimes for its use as a bioenergy crop. We believe that the impact of nitrogen amendment on VOC emissions from $A$. donax should be the subject of further study as it represents an available pathway for reducing potential negative impacts on air quality.

Our results indicate that $A$. donax has a widely ranging capacity for isoprene emission and that isoprene emission rates are variable based on phenological and weather differences and are also profoundly affected by fertilizer and water management. The results presented here, however, cannot all be considered complete. Our study cannot precisely determine how much isoprene $A$. donax will emit when grown in the Columbia River basin or to what extent agricultural management can reduce isoprene emission because we cannot definitively apportion the observed variability in isoprene emission rates to factors under human control (fertilizer and water use) as opposed to factors beyond human control (weather, climate, plant phenology).

Further studies will be needed in order to definitively answer these questions and ultimately to determine whether the use of $A$. donax as a bioenergy source is ultimately compatible with the goal of improving regional air quality. With more time and resources, it would be beneficial to conduct a factorial study to test the impact of 
nitrogen, phosphorus and water application on VOC emission from $A$. donax. We also suggest that isoprene flux should be measured throughout the growing season in order to determine how it is impacted by phenology and weather events and that any future studies should, if possible, be carried through several years so that lifehistory effects on isoprene emission can be measured.

If further modeling work indicates that isoprene emissions from $A$. donax pose a greater than expected risk to regional air quality, the development of low-VOC emitting $A$. donax plants may be an attractive option. Unfortunately, due to its clonal reproduction habit, there is comparatively little genetic diversity available in $A$. donax populations (Ahmed, et al., 2008) and thus selecting for low emitting lines or crossbreeding to develop the trait may not be available strategies. It may be possible, however, to genetically modify $A$. donax to reduce expression of the isoprene synthase gene and thus reduce isoprene emission. Such a technique has recently been successfully used to reduce isoprene emission in poplar (Behnke, et al., 2007) and we are aware of no reason that it would not work in $A$. donax. 


\section{References:}

Affek, H. P. \& Yakir, D. Protection by isoprene against singlet oxygen in leaves. Plant Physiology 129, 269-277 (2002).

Ahmad, R., Liow, P.S., Spencer, D. F. \& Jasieniuk, M. Molecular evidence for a single genetic clone of invasive Arundo donax in the United States. Aquatic Botany 88, 113-120 (2008).

Ahmed, A. G., Zaki, N. M. \& Hassanein, M. S. Response of grain sorghum to different nitrogen sources. Research Journal of Agriculture and Biological Sciences 3, 1002-1008 (2007).

Ashworth, K., Wild, O. \& Hewitt, C. N. Sensitivity of isoprene emissions estimated using MEGAN to the time resolution of input climate data. Atmos. Chem. Phys. 10, 1193-1201 (2010).

Ashworth, K., Folberth, G., Hewitt, C. N. \& Wild, O. Impacts of near-future cultivation of biofuel feedstocks on atmospheric composition and local air quality. Atmospheric Chemistry and Physics Discussions 11, 24857-24881 (2011).

Badri, D. V., Weir, T. L., van der Lelie, D. \& Vivanco, J. M. Rhizosphere chemical dialogues: plant-microbe interactions. Current Opinion in Biotechnology 20, 642-650 (2009).

Baldwin, I. T., Kessler, A. \& Halitschke, R. Volatile signaling in plant-plant-herbivore interactions: what is real? Current Opinion in Plant Biology 5, 351-354 (2002).

Behnke, K. et al. Transgenic, non-isoprene emitting poplars don't like it hot. The Plant Journal 51, 485-499 (2007).

Behnke, K. et al. RNAi-mediated suppression of isoprene biosynthesis in hybrid poplar impacts ozone tolerance. Tree Physiol. 29, 725-736 (2009).

Behnke, K. et al. Isoprene emission protects photosynthesis in sunfleck exposed Grey poplar. Photosynthesis research 104, 5-17 (2010).

Behnke, K. et al. Isoprene emission-free poplars - a chance to reduce the impact from poplar plantations on the atmosphere. New Phytologist 194, 70-82 (2012).

Behnke, K. et al. Isoprene function in two contrasting poplars under salt and sunflecks. Tree Physiol 33, 562-578 (2013). 
Berndes, G. Bioenergy and water-the implications of large-scale bioenergy production for water use and supply. Global Environmental Change 12, 253271 (2002).

Calfapietra, C., Scarascia Mugnozza, G., Karnosky, D. F., Loreto, F. \& Sharkey, T. D. Isoprene emission rates under elevated $\mathrm{CO} 2$ and $\mathrm{O} 3$ in two field-grown aspen clones differing in their sensitivity to 03. New Phytologist 179, 55-61 (2008).

Calfapietra, C., Fares, S. \& Loreto, F. Volatile organic compounds from Italian vegetation and their interaction with ozone. Environmental Pollution 157, 1478-1486 (2009).

De Vries, S. C., van de Ven, G. W. J., van Ittersum, M. K. \& Giller, K. E. Resource use efficiency and environmental performance of nine major biofuel crops, processed by first-generation conversion techniques. Biomass and Bioenergy 34, 588-601 (2010).

De Fraiture, C., Giordano, M. \& Liao, Y. Biofuels and implications for agricultural water use: blue impacts of green energy. Water Policy 10, 67 (2008).

Devlin, P. F., Yanovsky, M. J. \& Kay, S. A. A Genomic Analysis of the Shade Avoidance Response in Arabidopsis. Plant Physiol. 133, 1617-1629 (2003).

Fares, S. et al. Impact of high ozone on isoprene emission, photosynthesis and histology of developing Populus alba leaves directly or indirectly exposed to the pollutant. Physiologia Plantarum 128, 456-465 (2006).

FAOSTAT, Food and Agriculture Organization of the United Nations http://faostat.fao.org/site/377/DesktopDefault.aspx?PagelD=377(accessed June 12, 2012).

Groom, M. J., Gray, E. M. \& Townsend, P. A. Biofuels and Biodiversity: Principles for Creating Better Policies for Biofuel Production. Conservation Biology 22, 602609 (2008).

Harley, P., Guenther, A. \& Zimmerman, P. Effects of light, temperature and canopy position on net photosynthesis and isoprene emission from sweetgum (Liquidambar styraciflua) leaves. Tree Physiol 16, 25-32 (1996).

Harrison, S. P. et al. Volatile isoprenoid emissions from plastid to planet. New Phytologist 197, 49-57 (2013).

He, C., Murray, F. \& Lyons, T. Monoterpene and isoprene emissions from 15 Eucalyptus species in Australia. Atmospheric Environment 34, 645-655 (2000). 
Hewitt, C. N. et al. Nitrogen management is essential to prevent tropical oil palm plantations from causing ground-level ozone pollution. PNAS 106, 1844718451 (2009).

Hewitt, C. N., Stewart, H., Street, R. \& Scholefield, P. Isoprene and monoterpeneemitting species survey 1997. (1997).

Hewitt, C. N., Monson, R. K. \& Fall, R. Isoprene emissions from the grass Arundo donax L. are not linked to photorespiration. Plant Science 66, 139-144 (1990).

Hickman, J. E., Wu, S., Mickley, L. J. \& Lerdau, M. T. Kudzu (Pueraria montana) invasion doubles emissions of nitric oxide and increases ozone pollution. PNAS 107, 10115-10119 (2010).

Holopainen, J. K. Loss of isoprene-emitting capacity: deleterious for trees? Tree Physiol 33, 559-561 (2013).

Hogsett, W. E., Tingey, D. T. \& Holman, S. R. A programmable exposure control system for determination of the effects of pollutant exposure regimes on plant growth. Atmospheric Environment 19, 1135-1145 (1985).

Jardine, K. J. et al. Within-plant isoprene oxidation confirmed by direct emissions of oxidation products methyl vinyl ketone and methacrolein. Global Change Biology 18, 973-984 (2012).

Jardine, K. J. et al. Emissions of putative isoprene oxidation products from mango branches under abiotic stress. J. Exp. Bot. 64, 3669-3679 (2013).

Johnson, M. et al. Seed production in Arundo donax? Cal-IPC News 14, 12-13 (2006).

Kaye, J. P. \& Hart, S. C. Competition for nitrogen between plants and soil microorganisms. Trends in Ecology \& Evolution 12, 139-143 (1997).

Kulmala, M. et al. A new feedback mechanism linking forests, aerosols and climate. Atmospheric Chemistry and Physics, 4, 557-562 (2004)

Laothawornkitkul, J. et al. Isoprene emissions influence herbivore feeding decisions. Plant, Cell \& Environment 31, 1410-1415 (2008).

Lee, W. Presentation on PGE A. donax biofuel project, given to T. Rosenstiel's Plant Physiology class, Portland State University (2013).

Lehning, A., Zimmer, W., Zimmer, I. \& Schnitzler, J.-P. Modeling of annual variations of oak (Quercus robur L.) isoprene synthase activity to predict isoprene emission rates. Journal of Geophysical Research: Atmospheres 106, 31573166 (2001). 
Lerdau, M. \& Throop, H. L. Sources of Variability in Isoprene Emission and Photosynthesis in Two Species of Tropical Wet Forest Trees1. Biotropica 32, 670-676 (2000).

Lewis, M. et al. Using Closed-loop Biomass to Displace Coal at Portland General Electric's Boardman Power Plant Carbon Implications. (2012)

Litvak, M. E., Loreto, F., Harley, P. C., Sharkey, T. D. \& Monson, R. K. The response of isoprene emission rate and photosynthetic rate to photon flux and nitrogen supply in aspen and white oak trees. Plant, Cell \& Environment 19, 549-559 (1996).

Logan, B. A., Monson, R. K. \& Potosnak, M. J. Biochemistry and physiology of foliar isoprene production. Trends in Plant Science 5, 477-481 (2000).

Loivamäki, M., Mumm, R., Dicke, M. \& Schnitzler, J.-P. Isoprene interferes with the attraction of bodyguards by herbaceous plants. PNAS 105, 17430-17435 (2008).

Long, S. P. \& Bernacchi, C. J. Gas exchange measurements, what can they tell us about the underlying limitations to photosynthesis? Procedures and sources of error. J. Exp. Bot. 54, 2393-2401 (2003).

Loreto, F. \& Sharkey, T. D. A gas-exchange study of photosynthesis and isoprene emission inQuercus rubra L. Planta 182, 523-531 (1990).

Loreto, F. \& Velikova, V. Isoprene produced by leaves protects the photosynthetic apparatus against ozone damage, quenches ozone products, and reduces lipid peroxidation of cellular membranes. Plant Physiology 127, 1781-1787 (2001).

Lou, Y. \& Baldwin, I. T. Nitrogen Supply Influences Herbivore-Induced Direct and Indirect Defenses and Transcriptional Responses in Nicotiana attenuata. Plant Physiol. 135, 496-506 (2004).

Melnychenko, A. Interspecific variation in leaf-level biogenic emissions of the Bambuseae. Masters degree thesis, Portland State University, department of Biology (2013).

Mantineo, M., D’agosta, G. M., Copani, V., Patanè, C. \& Cosentino, S. L. Biomass yield and energy balance of three perennial crops for energy use in the semi-arid Mediterranean environment. Field crops research 114, 204-213 (2009).

Mariani, C. et al. Origin, diffusion and reproduction of the giant reed (Arundo donax L.): a promising weedy energy crop. Annals of Applied Biology 157, 191-202 (2010). 
Mauzerall, D. L. \& Wang, X. Protecting agricultural crops from the effects of tropospheric ozone exposure: Reconciling Science and Standard Setting in the United States, Europe, and Asia. Annual Review of Energy and the Environment 26, 237-268 (2001).

McNaughton, S. J. \& Tarrants, J. L. Grass leaf silicification: Natural selection for an inducible defense against herbivores. PNAS 80, 790-791 (1983).

Monson, R. K. \& Fall, R. Isoprene Emission from Aspen Leaves Influence of Environment and Relation to Photosynthesis and Photorespiration. Plant Physiol. 90, 267-274 (1989).

Monson, R. K., Jones, R. T., Rosenstiel, T. N. \& Schnitzler, J.-P. Why only some plants emit isoprene. Plant, Cell \& Environment 36, 503-516 (2013).

Moore, G. W., Watts, D. A. \& Goolsby, J. A. Ecophysiological responses of giant reed (Arundo donax) to herbivory. Invasive Plant Science and Management 3, 521529 (2010).

Nassi o Di Nasso, N., et al. Giant reed (Arundo donax L.) as energy crop in Central Italy: a review. Italian Journal of Agronomy 8, e3 (2013).

Nassi o Di Nasso, N., Roncucci, N., Triana, F., Tozzini, C. \& Bonari, E. Productivity of giant reed (Arundo donax L.) and miscanthus (Miscanthus x giganteus Greef et Deuter) as energy crops: growth analysis. Italian Journal of Agronomy 6, e22 (2011).

Nippert, J. B., Fay, P. A. \& Knapp, A. K. Photosynthetic traits in C3 and C4 grassland species in mesocosm and field environments. Environmental and Experimental Botany 60, 412-420 (2007).

Pankow, J. F. et al. Volatilizable Biogenic Organic Compounds (VBOCs) with two dimensional Gas Chromatography-Time of Flight Mass Spectrometry (GC $\mathrm{x}$ GC-TOFMS): sampling methods, VBOC complexity, and chromatographic retention data. Atmospheric Measurement Techniques 5, 345-361 (2012).

Papazoglou, E. G., Karantounias, G. A., Vemmos, S. N. \& Bouranis, D. L. Photosynthesis and growth responses of giant reed ( $<\mathrm{i}>$ Arundo donax $</ \mathrm{i}>\mathrm{L}$.) to the heavy metals Cd and Ni. Environment international 31, 243-249 (2005).

Papiez, M. R. et al. The impacts of reactive terpene emissions from plants on air quality in Las Vegas, Nevada. Atmospheric Environment 43, 4109-4123 (2009).

Peñuelas, J., Llusià, J., Asensio, D. \& Munné-Bosch, S. Linking isoprene with plant thermotolerance, antioxidants and monoterpene emissions. Plant, Cell \& Environment 28, 278-286 (2005). 
Perdue, R. E. Arundo donax-Source of musical reeds and industrial cellulose. Econ Bot 12, 368-404 (1958).

Porter, W. C., Barsanti, K. C., Baughman, E. C. \& Rosenstiel, T. N. Considering the Air Quality Impacts of Bioenergy Crop Production: A Case Study Involving Arundo donax. Environ. Sci. Technol. 46, 9777-9784 (2012).

Porter, W. C. Dissertation defense PowerPoint presentation, personal communication (2013).

Rasulov, B., Copolovici, L., Laisk, A. \& Niinemets, Ü. Postillumination isoprene emission: in vivo measurements of dimethylallyldiphosphate pool size and isoprene synthase kinetics in aspen leaves. Plant Physiology 149, 1609-1618 (2009).

Rosenstiel, T. N., Ebbets, A. L., Khatri, W. C., Fall, R. \& Monson, R. K. Induction of Poplar Leaf Nitrate Reductase: A Test of Extrachloroplastic Control of Isoprene Emission Rate. Plant Biology 6, 12-21 (2004).

Rosenstiel, T. N., Potosnak, M. J., Griffin, K. L., Fall, R. \& Monson, R. K. Increased CO2 uncouples growth from isoprene emission in an agriforest ecosystem. Nature 421, 256-259 (2003).

Ryan, A. C. et al. Isoprene emission protects photosynthesis but reduces plant productivity during drought in transgenic tobacco (Nicotiana tabacum) plants. New Phytologist 201, 205-216 (2014).

Schepers, J. S., Francis, D. D., Vigil, M. \& Below, F. E. Comparison of corn leaf nitrogen concentration and chlorophyll meter readings. Communications in Soil Science and Plant Analysis 23, 2173-2187 (1992).

Searchinger, T., et al. Use of U.S. Croplands for Biofuels Increases Greenhouse Gases Through Emissions from Land-Use Change. Science, 319, 1238-1240. (2008)

Sharkey, T. D. \& Yeh, S. Isoprene Emission from Plants. Annual Review of Plant Physiology and Plant Molecular Biology 52, 407-436 (2001).

Sharkey, T. D., Singsaas, E. L., Vanderveer, P. J. \& Geron, C. Field measurements of isoprene emission from trees in response to temperature and light. Tree Physiol 16, 649-654 (1996).

Sharkey, T. D., Wiberley, A. E. \& Donohue, A. R. Isoprene emission from plants: why and how. Annals of Botany 101, 5-18 (2008).

Sharkey, T. D. Is it useful to ask why plants emit isoprene? Plant, Cell \& Environment 36, 517-520 (2013). 
Shipley, B. Net assimilation rate, specific leaf area and leaf mass ratio: which is most closely correlated with relative growth rate? A meta-analysis. Functional Ecology 20, 565-574 (2006).

Sillman, S. \& He, D. Some theoretical results concerning O3-NOx-VOC chemistry and NOx-VOC indicators. Journal of Geophysical Research: Atmospheres 107, ACH 26-1-ACH 26-15 (2002).

Siwko, M. E. et al. Does isoprene protect plant membranes from thermal shock? A molecular dynamics study. Biochimica et Biophysica Acta (BBA)Biomembranes 1768, 198-206 (2007).

Tischner, R. Nitrate uptake and reduction in higher and lower plants. Plant, Cell \& Environment 23, 1005-1024 (2000).

Velikova, V. \& Loreto, F. On the relationship between isoprene emission and thermotolerance in Phragmites australis leaves exposed to high temperatures and during the recovery from a heat stress. Plant, Cell \& Environment 28, 318-327 (2005).

Velikova, V., Edreva, A. \& Loreto, F. Endogenous isoprene protects Phragmites australis leaves against singlet oxygen. Physiologia Plantarum 122, 219-225 (2004).

Velikova, V., Loreto, F., Tsonev, T., Brilli, F. \& Edreva, A. Isoprene prevents the negative consequences of high temperature stress in Platanus orientalis leaves. Functional Plant Biology 33, 931-940 (2006).

Velikova, V. et al. Increased Thermostability of Thylakoid Membranes in IsopreneEmitting Leaves Probed with Three Biophysical Techniques. Plant Physiol. 157, 905-916 (2011).

Velikova, V., Sharkey, T. D. \& Loreto, F. Stabilization of thylakoid membranes in isoprene-emitting plants reduces formation of reactive oxygen species. Plant signaling \& behavior 7, (2012).

Velikova, V. et al. The Genetic Manipulation of Isoprene Emissions in Poplar Plants Remodels the Chloroplast Proteome. J. Proteome Res. (2014).

Vickers, C. E., Gershenzon, J., Lerdau, M. T. \& Loreto, F. A unified mechanism of action for volatile isoprenoids in plant abiotic stress. Nat Chem Biol 5, 283291 (2009).

Vickers, C. E. et al. Isoprene synthesis protects transgenic tobacco plants from oxidative stress. Plant, Cell \& Environment 32, 520-531 (2009). 
Vierling, E. The roles of heat shock proteins in plants. Annual review of plant biology 42, 579-620 (1991).

Wagner, W. P., Nemecek-Marshall, M. \& Fall, R. Three Distinct Phases of Isoprene Formation during Growth and Sporulation of Bacillus subtilis. J. Bacteriol. 181, 4700-4703 (1999).

Waschmann, R. S., Watrud, L. S., Reece, L. R. \& Shiroyama, T. Sunlit mesocosms designed for pollen confinement and risk assessment of transgenic crops. Aerobiologia 26, 311-325 (2010).

Watrud, L. S. et al. Changes in constructed Brassica communities treated with glyphosate drift. Ecological Applications 21, 525-538 (2011).

Watts, D. A. \& Moore, G. W. Water-Use Dynamics of an Invasive Reed, Arundo donax, from Leaf to Stand. Wetlands 31, 725-734 (2011).

Wiberley, A. E., Linskey, A. R., Falbel, T. G. \& Sharkey, T. D. Development of the capacity for isoprene emission in kudzu. Plant, Cell \& Environment 28, 898905 (2005).

Wise, M., et al. Implications of Limiting $\mathrm{CO}_{2}$ Concentrations for Land Use and Energy. Science, 324, 1183-1186 (2009). 
Appendix: Supplemental Data

Table 1. Fertilizers added to each individual plant by treatment group

\begin{tabular}{|r|r|r|r|r|r|r|r|r|r|r|}
\hline Treatment & AMS & urea & ESN (g) & $\begin{array}{r}120 \text { day } \\
\text { Duration (g) }\end{array}$ & $\begin{array}{r}\text { 180 day } \\
\text { Dur. (g) }\end{array}$ & $\mathbf{P}$ & Kcl & K2S 04 & Gypsum & $\begin{array}{r}\text { Total, all } \\
\text { fertilizers (g) }\end{array}$ \\
\hline Control & 0 & $\mathrm{x}$ & 0 & 0 & 0 & $\mathrm{x}$ & $\mathrm{x}$ & $\mathrm{x}$ & $\mathrm{x}$ & 0 \\
\hline Low N & 15.8 & $\mathrm{x}$ & 7.6 & 7.6 & 7.6 & $\mathrm{x}$ & $\mathrm{x}$ & $\mathrm{x}$ & $\mathrm{x}$ & 38.5 \\
\hline Mid N & 31.6 & $\mathrm{x}$ & 15.1 & 15.1 & 15.1 & $\mathrm{x}$ & $\mathrm{x}$ & $\mathrm{x}$ & $\mathrm{x}$ & 76.9 \\
\hline $\mathrm{Hi} \mathrm{N}$ & 47.5 & $\mathrm{x}$ & 22.7 & 22.7 & 22.7 & $\mathrm{x}$ & $\mathrm{x}$ & $\mathrm{x}$ & $\mathrm{x}$ & 115.4 \\
\hline Urea & $\mathrm{x}$ & 7.2 & 7.6 & 7.6 & 7.6 & $\mathrm{x}$ & $\mathrm{x}$ & $\mathrm{x}$ & $\mathrm{x}$ & 29.9 \\
\hline $\mathrm{N}, \mathrm{P}, \mathrm{KCl}, \mathrm{S}$ & 15.8 & $\mathrm{x}$ & 7.6 & 7.6 & 7.6 & 12.8 & 32.1 & $\mathrm{x}$ & 57.8 & 141.2 \\
\hline $\mathrm{N} \mathrm{k2so4}$ & 15.8 & $\mathrm{x}$ & 7.6 & 7.6 & 7.6 & $\mathrm{x}$ & $\mathrm{x}$ & 39.9 & $\mathrm{x}$ & 78.3 \\
\hline $\mathrm{N} \mathrm{Kcl}$ & 15.8 & $\mathrm{x}$ & 7.6 & 7.6 & 7.6 & $\mathrm{x}$ & 32.1 & $\mathrm{x}$ & $\mathrm{x}$ & 70.6 \\
\hline $\mathrm{KCL}+\mathrm{K} 2 \mathrm{so} 4$ & 15.8 & $\mathrm{x}$ & 7.6 & 7.6 & 7.6 & $\mathrm{x}$ & 16.1 & 19.9 & $\mathrm{x}$ & 74.5 \\
\hline
\end{tabular}

Table 2. Ibs acre ${ }^{-1}$ fertilizer usage for each treatment

\begin{tabular}{|l|l|l|l|l|l|}
\hline Treatment & Ibs./acre N & Ibs./acre P & Ibs./acre Kcl & lbs./acre K2So4 & Gypsum \\
\hline Control & 0 & $\mathrm{x}$ & $\mathrm{x}$ & $\mathrm{x}$ & $\mathrm{x}$ \\
\hline Low N & 200 & $\mathrm{x}$ & $\mathrm{x}$ & $\mathrm{x}$ & $\mathrm{x}$ \\
\hline Mid N & 400 & $\mathrm{x}$ & $\mathrm{x}$ & $\mathrm{x}$ & $\mathrm{x}$ \\
\hline $\mathrm{Hi} \mathrm{N}$ & 600 & $\mathrm{x}$ & $\mathrm{x}$ & $\mathrm{x}$ & $\mathrm{x}$ \\
\hline Urea & 200 & $\mathrm{x}$ & $\mathrm{x}$ & $\mathrm{x}$ & $\mathrm{x}$ \\
\hline $\mathrm{N}, \mathrm{P}, \mathrm{KCl}, \mathrm{S}$ & 200 & 100 & 300 & $\mathrm{x}$ & 200 \\
\hline $\mathrm{N} \mathrm{k2so4}$ & 200 & $\mathrm{x}$ & $\mathrm{x}$ & 300 & $\mathrm{x}$ \\
\hline $\mathrm{N} \mathrm{Kcl}$ & 200 & $\mathrm{x}$ & 300 & $\mathrm{x}$ & $\mathrm{x}$ \\
\hline $\begin{array}{l}\mathrm{N} \mathrm{KCL}+ \\
\mathrm{K} 2 \mathrm{so4}\end{array}$ & 200 & $\mathrm{x}$ & 150 & 150 & $\mathrm{x}$ \\
\hline
\end{tabular}


Table 3. Mean values and standard deviations for physiological attributes of Arundo donax-mean values are listed in black text and standard deviation from mean are in red.

\begin{tabular}{|c|c|c|c|c|c|c|}
\hline Treatment & $\begin{array}{c}\text { Photosynthesis } \\
\text { Rate } \\
\mu \mathrm{mol} \mathrm{CO}_{2} \\
\mathrm{~m}^{-2} \sec ^{-1}\end{array}$ & $\begin{array}{c}\text { Chlorophyll } \\
\text { Level } \\
\mu \mathrm{mol} \text { Chl } \\
\mathrm{m}^{-2}\end{array}$ & $\begin{array}{c}\text { Stomatal } \\
\text { Conductance } \\
\text { mol } \mathrm{H}_{2} \mathrm{O} \\
\mathrm{m}^{-2} \mathrm{sec}^{-1}\end{array}$ & $\begin{array}{l}\text { Water use } \\
\text { efficiency } \\
\mu \mathrm{mol} \mathrm{CO} \mathrm{C}_{2} \\
\mathrm{molH}_{2} \mathrm{O}^{-1}\end{array}$ & $\begin{array}{c}\text { Specific leaf } \\
\text { mass (DW) } \\
\mathrm{g} \mathrm{m}^{-2}\end{array}$ & $\begin{array}{c}\text { Isoprene } \\
\text { emission } \\
\text { rate } \\
\mathrm{nmol}^{-2} \mathrm{sep}^{-1} \\
\mathrm{~m}^{-1} \mathrm{se}^{2}\end{array}$ \\
\hline \multirow[b]{2}{*}{$\begin{array}{c}\text { Control } \\
2012 \\
\end{array}$} & 17.33 & 385.45 & .414 & 4.35 & 227.00 & 16.96 \\
\hline & 4.36 & 98.48 & .119 & 1.10 & 15.43 & 11.37 \\
\hline \multirow[b]{2}{*}{$\begin{array}{c}\text { Low N } \\
2012\end{array}$} & 20.07 & 508.81 & .335 & 6.08 & 222.92 & 38.72 \\
\hline & 4.32 & 105.57 & .121 & 1.48 & 20.22 & 13.91 \\
\hline \multirow{2}{*}{$\begin{array}{l}\text { Mid N } \\
2012\end{array}$} & 20.77 & 619.86 & .290 & 7.26 & 230.40 & 42.55 \\
\hline & 4.42 & 98.45 & .090 & 1.97 & 19.96 & 27.01 \\
\hline \multirow[b]{2}{*}{$\begin{array}{l}\text { High N } \\
2012\end{array}$} & 21.00 & 647.35 & .270 & 7.59 & 227.00 & 54.50 \\
\hline & 4.25 & 86.26 & .095 & 4.10 & 22.02 & 26.79 \\
\hline \multirow[b]{2}{*}{$\begin{array}{c}\text { Control } \\
2013\end{array}$} & 22.04 & 458.57 & .743 & 3.10 & 202.107 & 241.14 \\
\hline & 5.29 & 63.31 & .358 & .71 & 23.53 & 141.07 \\
\hline \multirow{2}{*}{$\begin{array}{l}\text { Low N } \\
2013\end{array}$} & 23.89 & 512.92 & .662 & 3.76 & 206.26 & 139.19 \\
\hline & 3.17 & 72.62 & .260 & 1.28 & 18.83 & 92.82 \\
\hline \multirow[b]{2}{*}{$\begin{array}{c}\text { High N } \\
2013\end{array}$} & 23.55 & 625.21 & .632 & 4.26 & 211.72 & 159.04 \\
\hline & 8.96 & 77.48 & .375 & 1.01 & 29.91 & 156.65 \\
\hline \multirow[b]{2}{*}{$\begin{array}{l}\text { Urea } \\
2013\end{array}$} & 21.18 & 497.87 & .560 & 3.71 & 200.40 & 133.59 \\
\hline & 4.20 & 70.37 & .251 & 1.23 & 11.99 & 113.95 \\
\hline \multirow{2}{*}{$\begin{array}{l}\mathrm{N}-\mathrm{KCl} \\
2013\end{array}$} & 23.20 & 582.43 & .590 & 4.09 & 192.16 & 135.37 \\
\hline & 6.89 & 82.30 & .348 & 1.18 & 20.10 & 90.51 \\
\hline \multirow{2}{*}{$\begin{array}{c}\mathrm{N}-\mathrm{K}_{2} \mathrm{SO}_{4} \\
2013\end{array}$} & 24.99 & 599.22 & .761 & 3.65 & 191.36 & 136.36 \\
\hline & 3.16 & 88.34 & .319 & 1.25 & 22.50 & 84.99 \\
\hline \multirow[b]{2}{*}{$\begin{array}{c}\mathrm{N}-\mathrm{KCl}-\mathrm{K}_{2} \mathrm{SO}_{4} \\
2013\end{array}$} & 22.14 & 531.20 & .615 & 4.13 & 197.60 & 135.38 \\
\hline & 4.80 & 385.45 & .316 & 2.54 & 11.40 & 89.31 \\
\hline \multirow[b]{2}{*}{$\begin{array}{c}\mathrm{N}-\mathrm{KCl}- \\
\mathrm{CaSO}_{4}-\mathrm{P} \\
2013\end{array}$} & 21.10 & 98.48 & .509 & 4.30 & 215.61 & 111.03 \\
\hline & 7.32 & 508.81 & .348 & 1.43 & 20.66 & 80.87 \\
\hline
\end{tabular}

